\title{
Synthesis of Antitumor Fluorinated Pyrimidine Nucleosides
}

\author{
Patrizia Ferraboschi, Samuele Ciceri, and Paride Grisenti
}

\section{QUERY SHEET}

This page lists questions we have about your paper. The numbers displayed at left can be found in the text of the paper for reference. In addition, please review your paper as a whole for correctness.

There are no Editor Queries in this paper.

TABLE OF CONTENTS LISTING

The table of contents for the journal will list your paper exactly as it appears below:

Synthesis of Antitumor Fluorinated Pyrimidine Nucleosides

Patrizia Ferraboschi, Samuele Ciceri, and Paride Grisenti 


\title{
Synthesis of Antitumor Fluorinated Pyrimidine Nucleosides
}

\author{
Patrizia Ferraboschi, Samuele Ciceri, and Paride Grisenti \\ Dipartimento di Biotecnologie Mediche e Medicina Traslazionale, Università \\ degli Studi di Milano, Via Saldini 50, 20141 Milano, Italy
}

\section{Introduction}

Nucleosides, due to their biological role as constituents of nucleic acids, are main targets in the development of analogues aimed at antimetabolite-based therapy. Modified nucleosides can disrupt biological processes causing the death of cancer or virally-infected cells.

Fluorinated analogues of biologically active compounds are often characterized by a dramatic change in their activity, compared with the parent molecules. Fluorine, the most electronegative element, is isosteric with a hydroxy group, the C-F bond length $(1.35 \AA)$ being similar to the $\mathrm{C}-\mathrm{O}$ bond length $(1.43 \AA$ A). In addition, it is the second smallest atom and it can mimic hydrogen in a modified structure; its van der Waals radius $(1.47 \AA)$ is intermedi-

15 ate between that of hydrogen $(1.20 \AA)$ and that of oxygen $(1.52 \AA)$. The strength of the C-F bond exceeds that of $\mathrm{C}-\mathrm{H}$ bond and for this reason organofluorine compounds are often biologically and chemically more stable than their corresponding natural compounds.

In the case of nucleosides and their analogues, fluorine atoms can be introduced either in the nucleobase or in the sugar moiety. An example of the first type modification

20 is capecitabine $^{1}$ ( $\mathrm{N}^{4}$-pentyloxycarbonyl-5'-deoxy-5-fluorocytidine), a 5-fluoropyrimidine nucleoside approved as a drug against colorectal, gastric and breast tumors; gemcitabine ${ }^{2}$ ( $2^{\prime}$-deoxy-2',2'-difluorocytidine) is an example of a nucleoside fluoro-modified in the sugar moiety, approved as a drug against solid tumors.

The aim of this review is to discuss the synthesis of antitumor pyrimidine nucleosides

25 containing fluorine atoms in either the nucleobase or the sugar moiety. Because of the ongoing need of new antitumor chemotherapies, over the years many fluorinated pyrimidine nucleosides have been prepared in order to assay their activity. The synthesis of these compounds has thus been driven largely by results on their biological potential. Nonetheless, it is important for experimentalists to be aware of the full range of methods

30 used, whether or not the compounds synthesized have actually demonstrated antitumor activity. It is our hope, then, that researchers investigating fluoropyrimidines for purposes other than their anticancer properties will also find this article useful.

Received June 1, 2016; in final form November 15, 2016.

Address correspondence to Patrizia Ferraboschi, Dipartimento di Biotecnologie Mediche e Medicina Traslazionale, Università degli Studi di Milano, Via Saldini 50, 20141 Milano, Italy. E-mail:patrizia.ferraboschi@unimi.it

This work is dedicated to Dr Giuseppe Celasco deceased on May 10, 2016. 


\section{Fluoropyrimidines}

\section{5-Fluorouracil}

35 Interest in the fluoropyrimidines stemmed from studies of the metabolism of uracil in rat hepatoma cells. The observation that these cells utilize uracil more avidly than normal rat intestinal mucosa prompted the preparation of fluorinated pyrimidines in order to improve disruption of tumor DNA biosynthesis. ${ }^{3}$

In 1957 5-fluorouracil (5-FU) $\mathbf{1}$ was synthesized by Heidelberger et al. ${ }^{4}$ with the aim of

40 blocking metabolism in malignant cells. The replacement of a hydrogen atom at C-5 by the fluorine atom modifies the interaction with the active sites of enzymes involved in metabolism.

This antimetabolite, although toxic, is still one of the most widely used agents against solid tumors. Its action is due to two different mechanisms: ${ }^{5}$ after penetration into the cell, 5-FU $\mathbf{1}$ is transformed into the 5-fluorouridine triphosphate that mimics UTP, is recognized by RNA

45 polymerase and consequently incorporated into RNA. The most significant action, however, is due to the 5-FU conversion into 5-fluoro-2'-deoxyuridine (FdUMP) 2, a known inhibitor of thymidylate synthetase (TS), a key enzyme in the DNA synthesis. ${ }^{6,7}$ TS, in the presence of methylene tetrahydrofolate and deoxyuridine monophosphate (dUMP) 3 forms a ternary complex that catalyzes the substitution of 5-H uracil with a methyl group, affording thymine. If FdUMP

$50 \mathbf{2}$ is present, the above ternary complex is not able to carry out this reaction, due to the presence of fluorine in the 5-position: the formation of TMP 4 (2'-deoxythymidine $5^{\prime}$-monophosphate), the only nucleotide precursor specific to DNA, is, therefore, blocked (Scheme 1), decreasing the availability of TTP $\left(2^{\prime}\right.$-deoxythymidine $5^{\prime}$-triphosphate) for DNA synthesis.

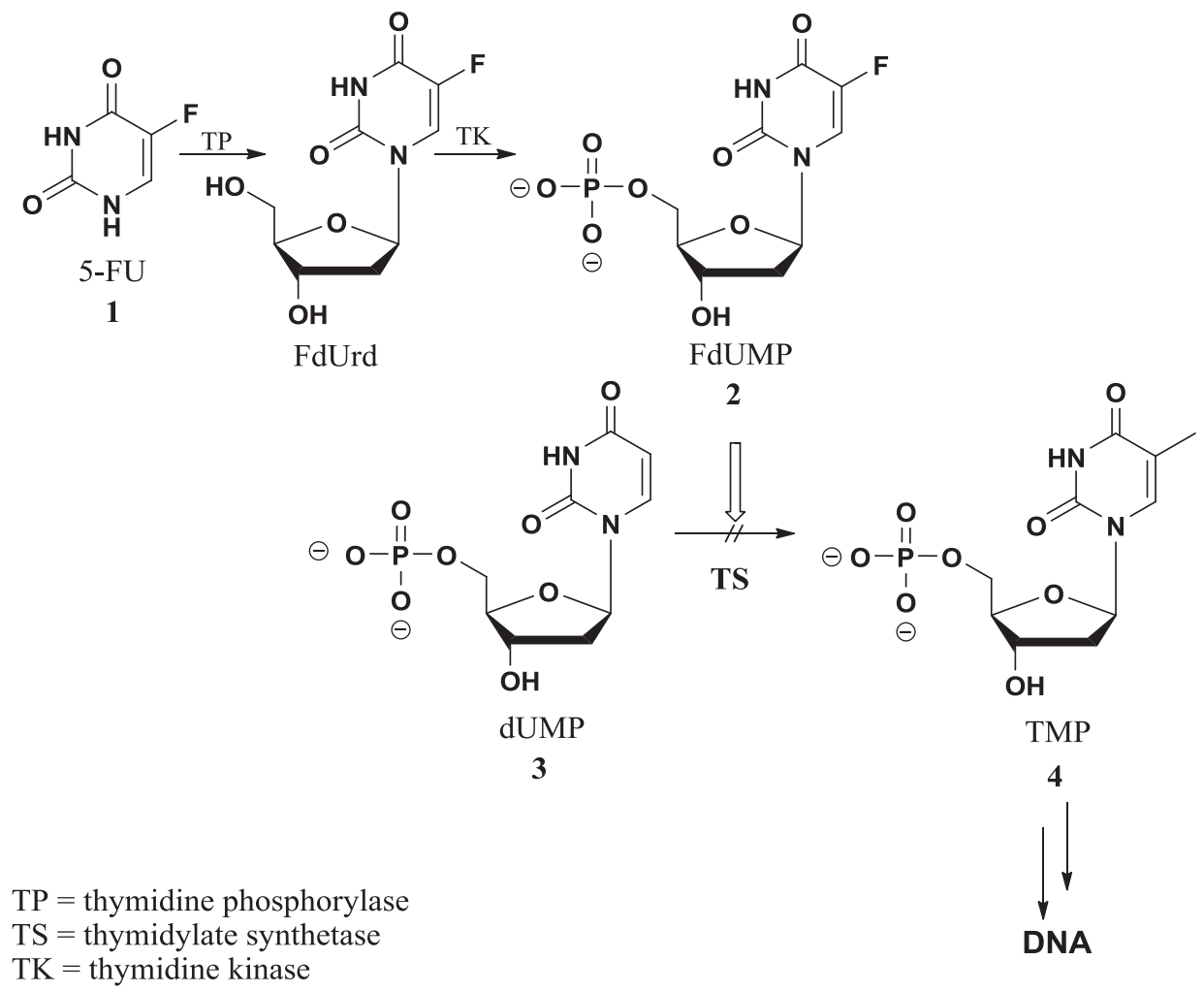

Scheme 1 
Later two additional mechanisms were proposed for 5-FU 1 antitumor activity: the 55 incorporation of 5-FU into DNA and the alteration of the membrane function of 5-FU 1 treated cells. Recent studies indicate that the TS-direct mechanism predominates when $\mathbf{1}$ is administered at low doses for a prolonged time, whereas the RNA-mediated process is more active following a bolus administration. ${ }^{8-10}$

Synthesis of 5-FU 1, by construction of the pyrimidine ring, was first realized by Hei60 delberger et al. in $1957^{4,11,12}$ by reaction of a thiourea derivative 5 with the enolate of ethyl $\alpha$-fluoro, $\alpha$-formyl acetate $\mathbf{6}$ which, in turn, was obtained from methyl formate and ethyl fluoroacetate (Scheme 2). Depending on the chosen $\alpha$-fluoro- $\beta$-ketoester the method is also applicable to the synthesis of other 5-fluoropyrimidines.<smiles>CCOC(=O)CF</smiles>

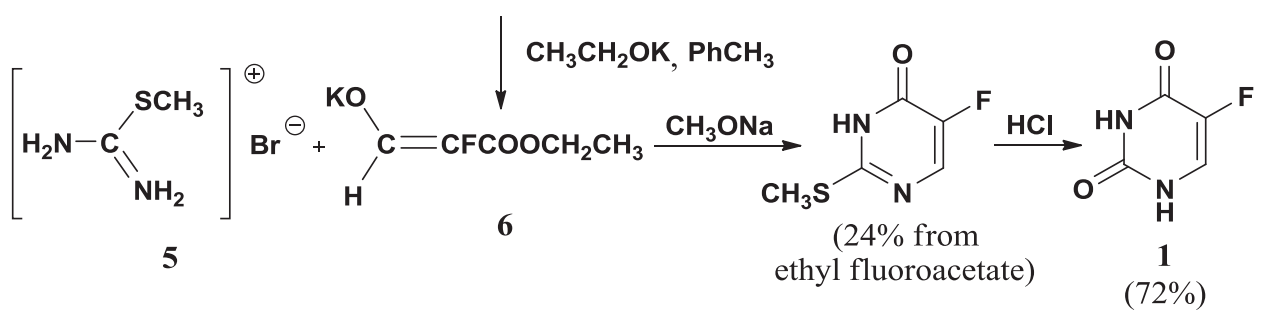

Scheme 2

An alternative method for the total synthesis is the direct fluorination of the pyrimi65 dine ring of compound 7 by means of trifluoromethyl hypofluorite $\left(\mathrm{CF}_{3} \mathrm{OF}\right)^{13}$ proposed by Robins in 1971. In the case of $\mathrm{CF}_{3} \mathrm{OF}$ in methanol/fluorotrichloromethane an intermediate was formed that, after treatment with triethylamine, afforded 5-FU 1 in $84 \%$ yield. $^{13}$ If the reaction was carried out with $\mathrm{CF}_{3} \mathrm{OF}$ in trifluoroacetic acid $\mathbf{1}$ was directly isolated in $85 \%$ yield. ${ }^{14}$ The method proposed by Robins ${ }^{13}$ is suitable also for the direct introduction 70 of fluorine on preformed nucleosides, for example compound $\mathbf{8}$ (Scheme 3).<smiles></smiles><smiles>O=C1C=C(C(=O)O[Na])C(=O)NC1=O</smiles>

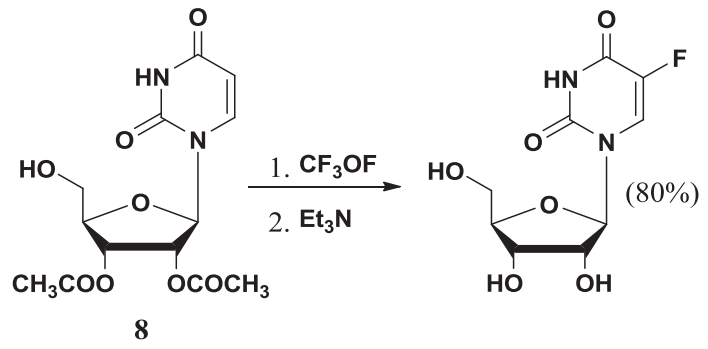

Scheme 3 
The mechanism of the reaction with $\mathrm{CF}_{3} \mathrm{OF}$ in methanol followed by treatment with triethylamine was later investigated by Robins et al. ${ }^{15}$ who assigned the structure of ( \pm )-cis-5-fluoro-6-methoxy-5,6-dihydrouracil to intermediate 9 that, by treatment with triethylamine, afforded 5-FU 1 (Scheme 4).

76

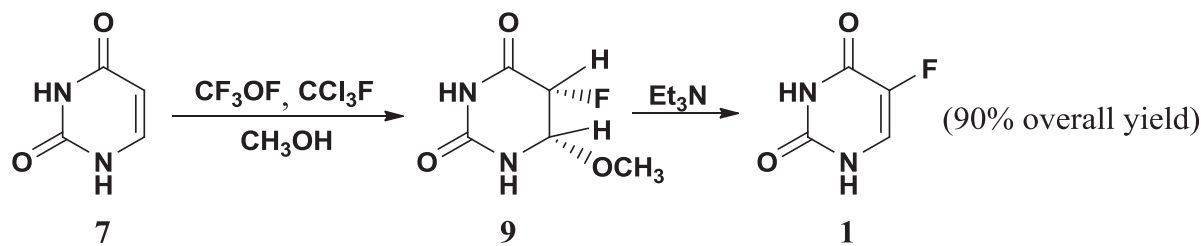

Scheme 4

85

The use of fluorine as fluorinating agent ${ }^{16,17}$ requires efficient dissipation of the heat of reaction, in order to avoid the destruction of the carbon skeleton of pyrimidine. This result can be achieved by bubbling a mixture of fluorine and an inert gas through a cold liquid,

90 or removing the heat of reaction by carrying out the reaction in the presence of a metal packing or, finally, by addition of very large amount of an inert diluent gas. This last procedure is the most followed and usually fluorine is diluted with an equal amount of nitrogen and then passed through the reaction mixture. 5-FU 1 was obtained in $92.4 \%$ yield $^{16}$ and sublimation at $190^{\circ} \mathrm{C}$ and $1 \mathrm{~mm} \mathrm{Hg}$ provided a highly pure product. ${ }^{17}$

95 Xenon difluoride can be used for direct fluorination of the pyrimidine ring but it is difficult to handle due to its high reactivity; in 1980 Kagan et al. realized the direct fluorination of uracil 7 employing $\mathrm{C}_{19} \mathrm{XeF}_{6}$, which is much more stable than free xenon hexafluoride. ${ }^{18}$

Uracil 7 was the starting material of the above described direct fluorination methods. ${ }^{13-18}$ In a method patented in $1979,{ }^{19}$ cytosine $\mathbf{1 0}$ was fluorinated by means of fluorine fluorosulfo100 nate $\left(\mathrm{FOSO}_{2} \mathrm{~F}\right)$ diluted with nitrogen (60\%) affording 5-FU 1 (87.7\% yield) (Scheme 5).

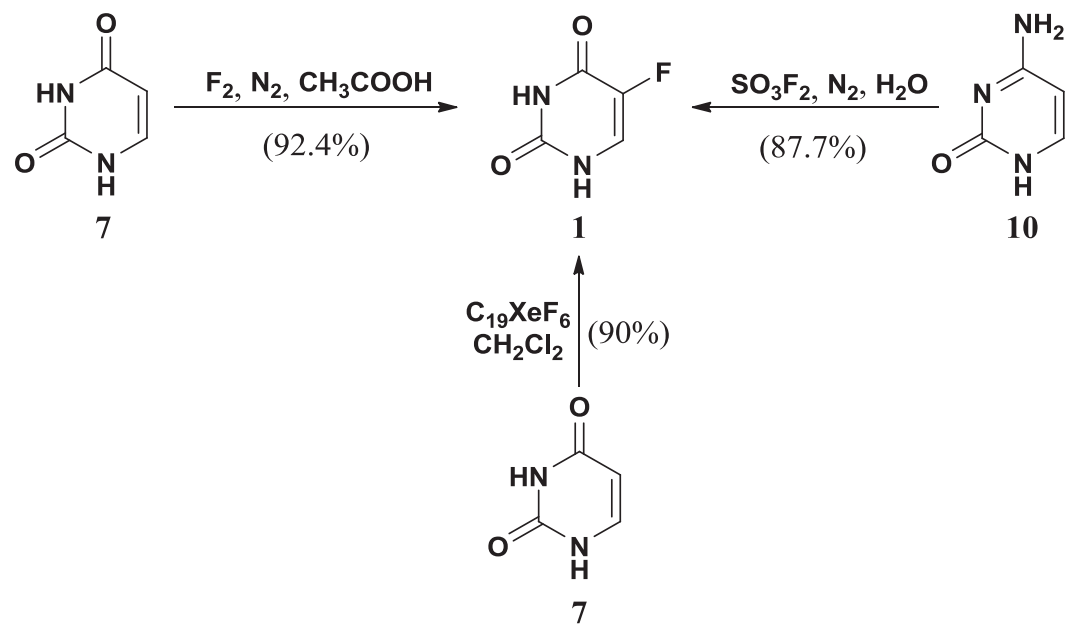

Scheme 5 
Orotic acid ${ }^{20} 11$ was, instead, the starting material for a synthesis of 5-FU by a combination of a fluorination and a decarboxylation (Scheme 6). In the course of the reaction an intermediate was formed that can be converted into 5-fluoro orotic acid $\mathbf{1 2}$ (in boiling water) which was, in turn, transformed into 5-FU by heating at $240^{\circ} \mathrm{C}$.<smiles>O=C(O)c1cc(=O)[nH]c(=O)[nH]1</smiles>

Orotic acid 11<smiles>O=C1NC(=O)C(F)C(C(=O)O)N1</smiles>

$(80 \%)$

12<smiles>O=c1[nH]cc(F)c(=O)[nH]1</smiles>

$(64 \%)$

1

Scheme 6

105 Starting from the methyl ester of uracil 5-carboxylic acid $\mathbf{1 3}$ the synthesis of 5-FU $\mathbf{1}$ was realized in one-pot, in excellent yield $(92 \%)$, by addition of a reducing agent (sodium bisulfite) aimed to exclude the formation of peroxides by reaction of water with fluorine (Scheme 7). ${ }^{21,22}$<smiles>CC(=O)c1c[nH]c(=O)[nH]c1=O</smiles>

13

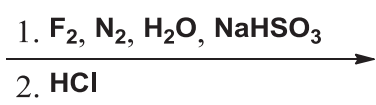

2. $\mathrm{HCl}$<smiles>O=c1[nH]cc(F)c(=O)[nH]1</smiles>

1

$(92 \%)$

Scheme 7

A different approach to the synthesis of $\mathbf{1}$ provided the substitution of the halo atoms of the 2,4,5-trichloropyrimidine or 2,4-dichloro,5-bromopyrimidine $\mathbf{1 4}$ by means of potassium fluo-

110 ride at $400^{\circ} \mathrm{C}$ to afford the corresponding 2,4,5-trifluoropyrimidine 15 ; its treatment with sodium hydroxide in water at $80^{\circ} \mathrm{C}$ gave the desired 5-FU $1 .^{23}$ The starting 2,4,5-trihalopyrimidine 14 was obtained from uracil 7 by reaction with chlorine, or bromine, followed by treatment of the 5-halouracil 16 with phosphoryl chloride (76 or 82\%, respectively) (Scheme 8).<smiles></smiles>

gemcitabine hydrochloride

$151 \cdot \mathrm{HCl}$

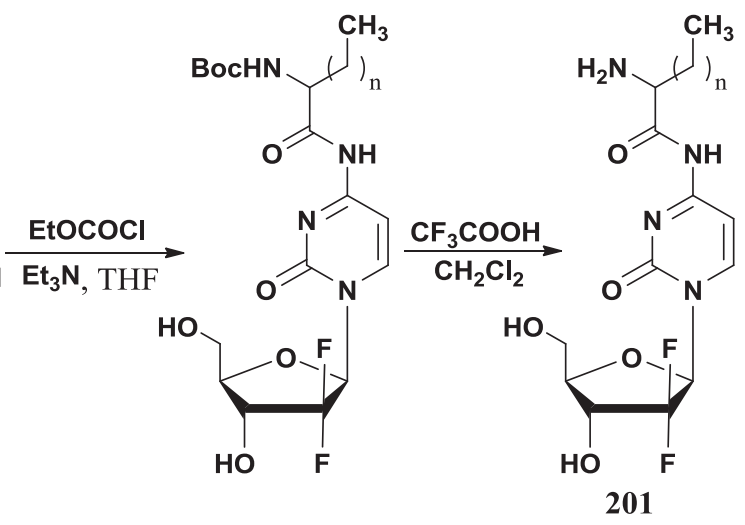

$(69 \%$ overall yield)

Scheme 8 
Some years later a similar approach ${ }^{24}$ starting from tetrafluoropyrimi115 dine $^{25}$ 17, was described by Baasner et al. 4,6-Dichloro-2,5-difluoropyrimidine 18 was obtained in $64 \%$ yield from tetrafluoropyrimidine 17 by reaction with gaseous hydrogen chloride. Chlorine in the 6-position was selectively removed by hydrogenation in the presence of palladium on carbon in ethyl acetate and triethylamine (70.5\% yield). The resulting 4-chloro-2,5-difluoro-

120 pyrimidine 19 was hydrolyzed with sodium hydroxide in water affording 5-FU 1 in $93 \%$ yield.

Direct fluorination of uracil continued to be of interest. In 1981 a method based on the use of fluorine/nitrogen in acetic acid was proposed: the intermediate 6-acetoxy-5-fluoro-5,6-dihydrouracil $\mathbf{2 0}$, obtained in $70 \%$ yield, was converted into the desired 5-FU 1 125 by acetic acid elimination. ${ }^{26}$ (Scheme 9 ).<smiles>CC(=O)OC1NC(=O)NC(=O)C1F</smiles>

Scheme 9

In a similar approach the use of fluorine diluted with helium in aqueous phosphoric acid ${ }^{27}$ (Scheme 9) afforded 5-FU 1 in $84.5 \%$. The advantages of this method are the low cost of phosphoric acid, the capability of its solution to work as an adsorbent of the by-product hydrogen fluoride and to precipitate the final product as 130 crystals.

Another fluorinating agent, acetyl hypofluorite, (generated in situ from fluorine and acetic acid) was studied, in comparison with fluorine in acetic acid, from a mechanistic point of view. ${ }^{28}$ The two geometric isomers of 5-fluoro-6-acetoxyuracil 20 were isolated as reaction intermediates; their configuration cannot 135 be assigned by ${ }^{1} \mathrm{H}$ and ${ }^{19} \mathrm{~F}$ NMR spectra since the coupling constants of cis and trans compounds are too similar. Only one of the isomers, by addition of acetate ion, was transformed into 5-FU 1, acetate being a strong enough base to facilitate acetic acid elimination. The cis and trans configurations were assigned considering that in the cis isomer the $\mathrm{H}$ atom and the acetate group are in trans position, 140 which is the favored one for the elimination of acetic acid. In presence of triethylamine both isomers afforded 5-FU 1 (Scheme 10). 


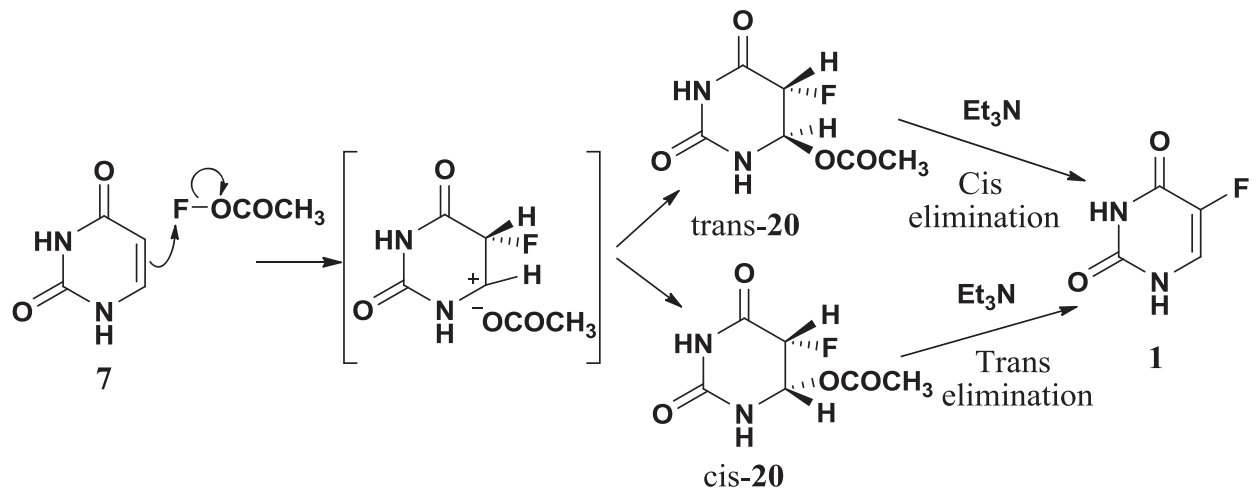

Scheme 10

Visser et $a .^{29-30}$ also studied the mechanism and the stereochemistry of uracil 7 fluorination 145 with fluorine or acetyl hypofluorite, proposing that addition at the 5-6 double bond occurs through radical anion 21; formed 5-fluoro-6-acetoxy derivative $\mathbf{2 0}$ evolves into the final product through an intermediate that in the presence of a base affords final 5-FU $\mathbf{1}^{29}$ (Scheme 11).

The influence of the N-1 substituent on the stability of 5-fluoro-6-acetoxy intermediate $^{31}$ and conversion by reaction with alcohols were also studied. ${ }^{30}$

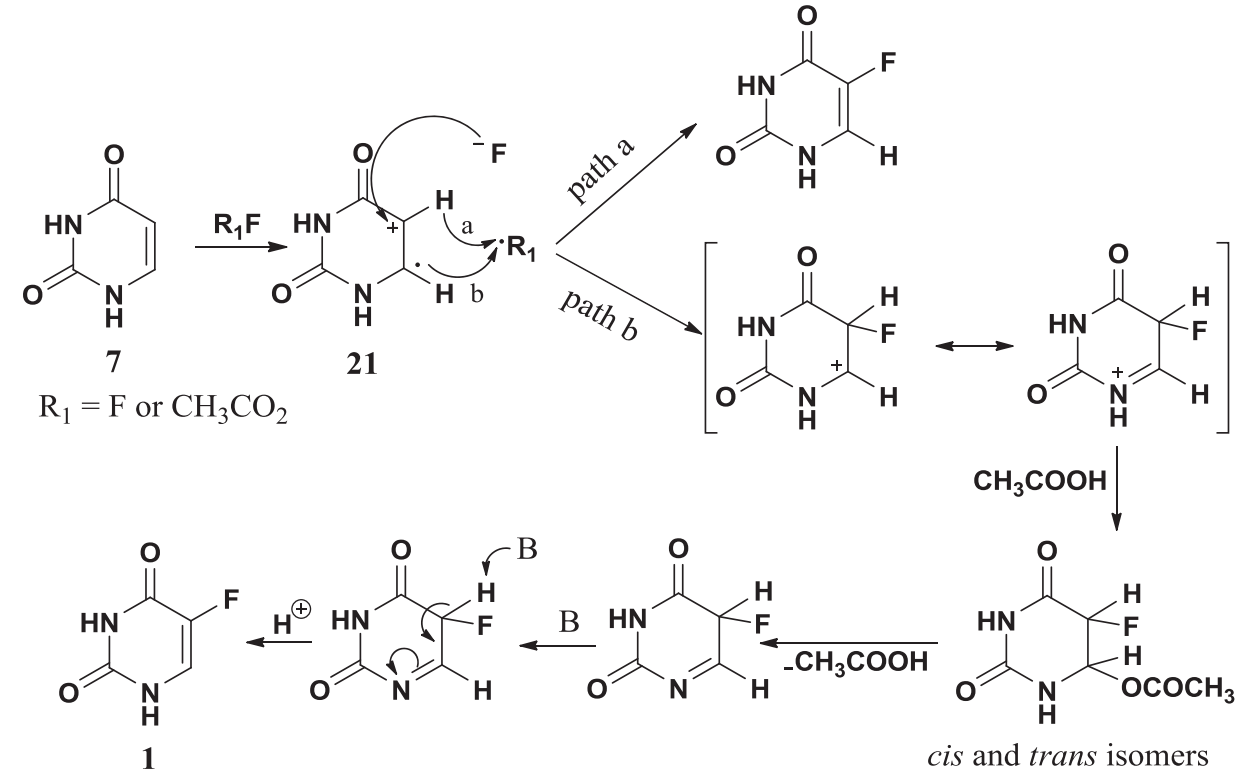

20

Scheme 11

150 A commercially available, stable, easy to handle fluorinating agent, SELECTFLUOR, was proposed in 1995 for the synthesis of fluorohydrin 22 that, by sublimation, provided 5-FU $1(82 \%)^{32}$ (Scheme 12). 
<smiles>O=C1NC(=O)C(F)C(O)NC1=O</smiles>

\section{Scheme 12}

Some approaches avoiding the direct fluorination are reported in the literature. For example, starting from $s$-triazine $\mathbf{2 3}$, it is possible to prepare 5-FU $\mathbf{1}$ ( $88 \%$ yield) by reac155 tion of fluoroacetamide and lithium diisopropylamide (Scheme 13). ${ }^{33}$<smiles>Cn1cnc(=O)n(C)c1=O</smiles>

23<smiles>O=c1[nH]cc(F)c(=O)[nH]1</smiles>

$(88 \%)$

Scheme 13

Diethyl fluoromalonate (prepared from trifluoroacrylic acid) was easily converted to 5-fluoro-6-chlorouracil $\mathbf{2 5}$ by reaction with urea to afford 5-fluorobarbituric acid $\mathbf{2 4}$ (97\% yield) followed by reaction with phosphoryl chloride in dimethylaniline (46\% yield). The 6-chlorine atom of $\mathbf{2 5}$ was removed by hydrogenolysis (Pd/C) affording 5-FU 1 in $73-$ $91 \%$ yield, depending on the reaction conditions (Scheme 14). ${ }^{34}$

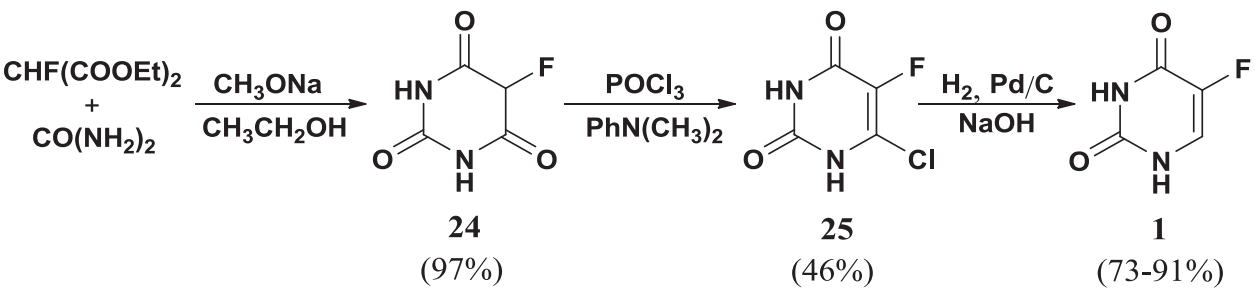

\section{Scheme 14}

The methyl ester of 2-fluoro-3-methoxy acrylic acid $\mathbf{2 6}$ can be used as a synthon of the fluorinated uracil ring: by reaction with $\mathrm{O}$-(trimethylsilyl)urea intermediate $\mathbf{2 7}$ was formed that by cyclization with sodium hydroxide afforded 5-FU 1 (67\% yield) (Scheme 15). ${ }^{35}$

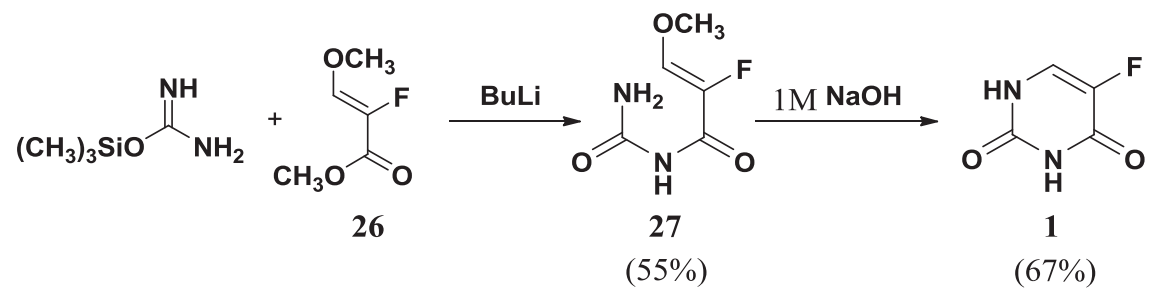


Recently, ${ }^{36} 5$-FU 1 was prepared by deamination of 5 -fluorocytosine 28 by means of 165 a new 5-methylcytosine deaminase: expression of deaminase in E. coli caused an efficient transformation of non-toxic 5-fluorocytosine $\mathbf{2 8}$ into 5-FU 1 that abolished or severely inhibited growth of cells. The goal of this study was, of course, to transfect cancer cells with the deaminase (Scheme 16).

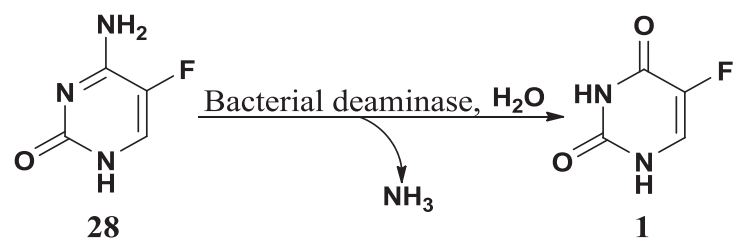

Scheme 16

5-FU 1, since its introduction more than 50 years ago, has become a component of 170 therapy for gastrointestinal, head and neck and breast cancers. The activity of 5-FU is limited by its rapid degradation into 5,6-dihydro-5-fluorouracil (5- $\left.\mathrm{FUH}_{2}\right) 29$ under the action of dihydropyrimidine dehydrogenase (DPD), an enzyme NADPH-dependent (Scheme 17). ${ }^{5}$ It has been demonstrated that this enzyme deactivates more than $85 \%$ of the injected 5-FU 1.

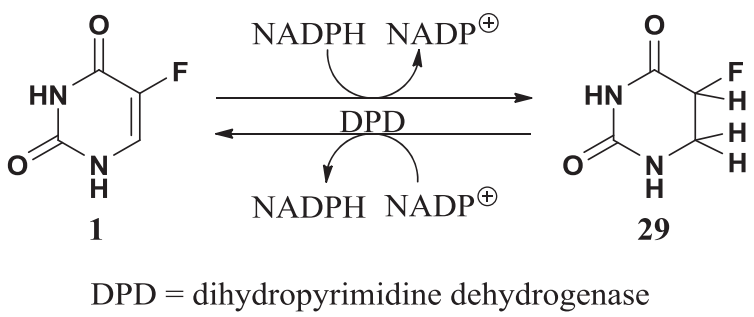

Scheme 17

175 At the beginning 5-FU 1 was administered by intravenous bolus but its low biological $t_{1 / 2}$ makes continuous infusion more convenient. The use of oral 5-FU 1 was abandoned some decades ago because of its irregular absorption, due to intra- and inter-individual differences depending on the variable activity of dihydropyrimidine dehydrogenase. In addition to the inconvenience of i.v. administration, the efficiency

180 of 5 -FU 1 is limited by its toxicity due to phosphorylation in the digestive tract and to the lack of selectivity toward tumors. The development of 5-FU $\mathbf{1}$ derivatives was the target of many studies. The toxicity of 5-FU $\mathbf{1}$ can be reduced by derivatives which are stable to enzymatic degradation, by derivatives that inhibit DPD or by prodrugs of $\mathbf{1}$ that liberate the active principle in tumor cells. A prodrug is defined

185 as a pharmacologically inactive compound that is converted into an active agent by metabolic transformations. The prodrugs of 5-FU $\mathbf{1}$ are characterized by a pyrimidine ring bearing a fluorine atom in the 5 position. The main benefit is oral administration, with the improvement in quality of life of the patient. 
In the present review we now describe some derivatives in which 5-FU $\mathbf{1}$ is conjugated to drug carriers or molecules endowed with antitumor activity.

\section{5-Fluorouracil Derivatives}

In $1985 \mathrm{~N}^{1}$-(3-aminopropyl)-5-fluoro uracil 30 was synthesized from 5-FU 1 by treatment with hexamethyldisilazane and trimethylchlorosilane followed by reaction with $\mathrm{N}$-(3-bromopropyl)-phthalimide. Deprotection afforded the desired product in $54 \%$ yield. The

195 amino derivative was considered a suitable precursor of $\mathrm{N}^{1}$-(2-formylethyl)-5-fluorouracil 31, which may be converted to 5-FU following an enzymatic reaction. Indeed, in presence of amine oxidase the amine was transformed into 5-FU 1 and acrolein, in the course of $24 \mathrm{~h}$ incubation. The slow enzymatic conversion, however, indicated that 5-FU-derivative 30 might not be efficiently metabolized in vivo (Scheme 18). ${ }^{37}$

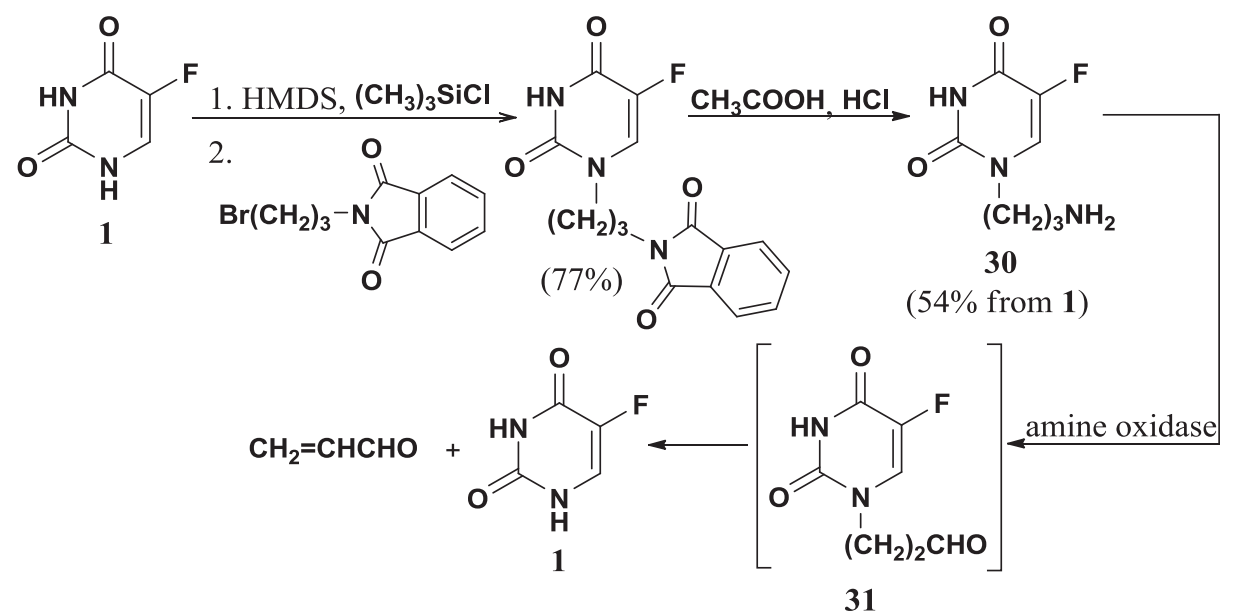

\section{Scheme 18}

200 A mutual prodrug consists of two synergistic drugs joined together. The two molecules may be connected directly or by means of a linker: in 1997 work $^{38} 5$-FU 1 was linked to cytarabine 32, an antitumor agent used mainly in the treatment of acute leukemia and lymphomas, affording compound 33. Cytarabine (ara-C) $\mathbf{3 2}$ is attached to the double drug through a hydrolyzable amide bond, while 5-FU is attached via an acyloxy205 methylene group, easily removable. Two spacers with different length (two or four methylene groups) were used and the synthesis is outlined in Scheme 19. The synthesis afforded the product with yield ranging from moderate to excellent; and, after the introduction of 5-FU 1, mild conditions and selective reagents, due to the formation of the labile N-O ketal derivative, were required. The benzenesulfenyl chloride, by-product of 210 the preparation of chloromethylester 34, was removed by trapping it with cyclohexene1,2-dicarboxylic acid, instead of the usual cyclohexene, in order to remove the addition product by an aqueous washing. This avoided separation by distillation of products having similar boiling points. Final compound $\mathbf{3 3}$ with $\mathrm{n}=4$ was stabler than the corresponding compound with $\mathrm{n}=2$, over a wide range of $\mathrm{pH}$, and for this reason it was estimated to 215 be more suitable for biological testing. 
<smiles>CCCCC(=O)OCn1cc(F)c(=O)[nH]c1=O</smiles>

$\mathrm{EDCl} \cdot \mathrm{HCl}=1$-(3-(dimethylamino)propyl)-3-ethylcarbodiimide hydrochloride ara-C $=$ cytarabine

\section{Scheme 19}

More recently ${ }^{39}$ another mutual prodrug of 5-FU 1 was developed with diazeniumdiolates, which are known to be controlled sources of NO. NO can inhibit metastasis, enhance cancer cells apoptosis and assist macrophages to kill tumor cells. Two different conjugates, with methylene or acyloxymethylene as spacers, were synthesized starting

220 from sodium 1-(pyrrolidin-1-yl)diazen-1-ium-1,2-diolate (PYRRO/NO) 35 in turn prepared according to a procedure already reported. ${ }^{40}$ The key intermediate of the two syntheses was the $\mathrm{O}^{2}$-chloromethyl 1-(pyrrolidin-1-yl)diazen-1-ium-1,2-diolate (chloromethyl PYRRO/NO) 36 that by direct reaction with 5-FU $\mathbf{1}$ or through its succinic acid derivative 37 afforded the desired products 38 together with the $\mathrm{N}^{1}, \mathrm{~N}^{5}$-bisalkylation prod225 ucts 39 (Scheme 20). The two mono-alkylated conjugates were evaluated in hydrolysis by monitoring the NO release. Both prodrugs showed greater activity than 5-FU, but the 


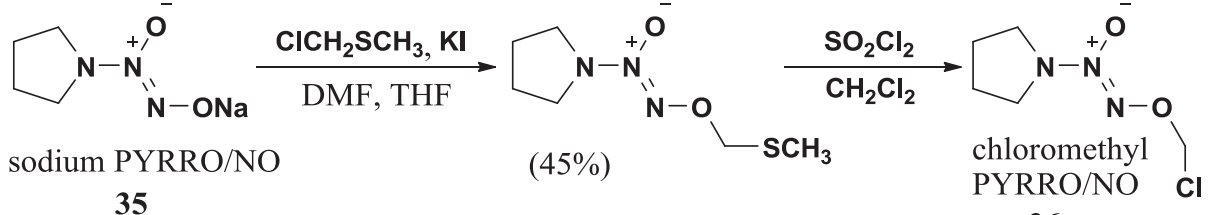

35<smiles>O=c1c(F)cn(CO/N=[N+](/O)N2CCCC2)c(=O)n1CO/N=[N+](\O)N1CCCC1</smiles>

$(12 \%)$<smiles>O=c1[nH]c(=O)n(CO/N=[N+](/O)N2CCCC2)cc1F</smiles>

$(21 \%)$

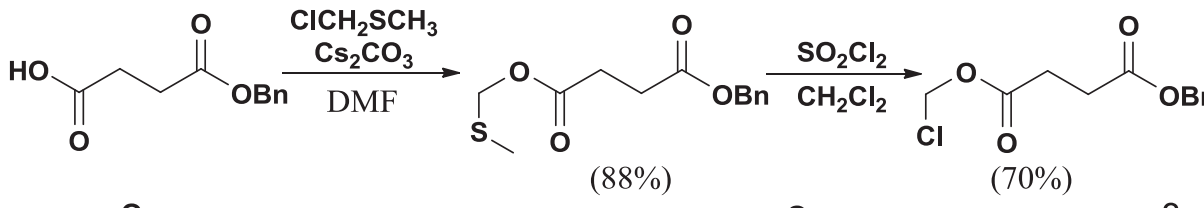<smiles>O=C(O)CCC(=O)OCn1cc(F)c(=O)[nH]c1=O</smiles><smiles>CCCCC(=O)OCn1cc(F)c(=O)[nH]c1=O</smiles><smiles>CC(C)(F)F</smiles>

$(54 \%)$

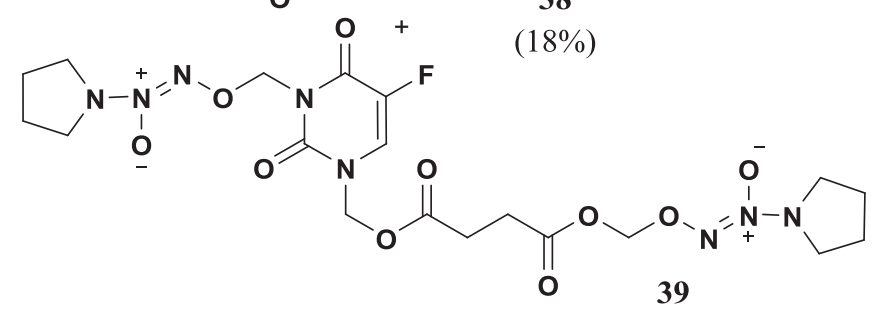

$(12 \%)$

Scheme 20

compound with methylene as spacer was very stable in aqueous solution and no substantial NO was detected. On the contrary the other prodrug with a longer spacer released NO both at $\mathrm{pH} 8$ and in the presence of esterase. 
230 In order to enhance the delivery characteristics of 5-FU $\mathbf{1}$ a series of $\mathrm{N}$-acyl and $\mathrm{N}$-alkoxycarbonyl derivatives were prepared and their antitumor activity evaluated. ${ }^{41,42}$

According to a 1980 article $^{41}$, the most promising antitumor agent, even when administered orally, was the $\mathrm{N}^{1}$-acetyl- $\mathrm{N}^{3}$-ortho-toluyl-5-fluorouracil 40. The paper

235 described the different acylated products that can be obtained depending on the chosen acylating agent, solvent and reaction temperature. $\mathrm{N}^{1}$-Acetyl- $\mathrm{N}^{3}$-orthotoluyl-5-FU 40 was prepared starting from $\mathrm{N}^{1}$-acetyl derivative $\mathbf{4 1}$ by reaction with ortho-toluyl chloride in dioxane and triethylamine. The $\mathrm{N}^{3}$-ortho-toluyl derivative of 5-FU, 42, was isolated in mice serum when $\mathrm{N}^{1}$-acetyl- $\mathrm{N}^{3}$-ortho-toluyl-5-FU $\mathbf{4 0}$

240 was orally administered. In order to obtain this $\mathrm{N}^{3}$-monosubstituted compound 42 the best conditions used ortho-toluyl chloride in pyridine at room temperature (Scheme 21).

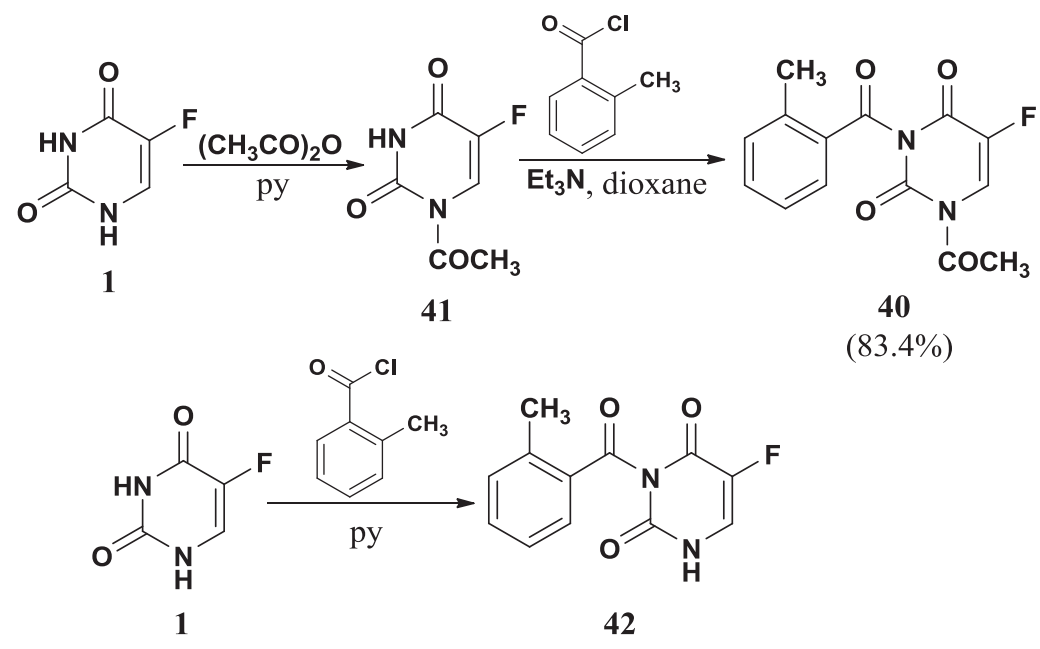

$(84.5 \%)$

Scheme 21

Further, the $\mathrm{N}^{1}$-alkoxycarbonyl derivatives ${ }^{42}$ prepared from 5 -FU $\mathbf{1}$ by reaction with the appropriate chloroformates in pyridine were hydrolyzed in serum affording 245 the 5-FU 1.

$\beta$-Lactam based prodrugs, in particular cephalosporin-based prodrugs, have been reported in the past and in $2009^{43}$ this approach was also applied to $5-\mathrm{FU}$ 1. The 5-FU-cephalosporin conjugate was synthesized starting from the $\mathrm{N}^{1}$-BOC-5-FU 43 and the suitably functionalized cephem 44 (Scheme 22),

250 affording a compound stable in aqueous media; conjugate 45 in the presence of $\beta$-lactamase was completely cleaved to 5-FU $\mathbf{1}$ and the hydrolyzed cephalosporin, demonstrating its strategic potential against a range of human carcinoma cells.

The observation that the phthalide fragment was widely used in the creation 255 of transport forms of antibiotics prompted the introduction of this moiety in the 


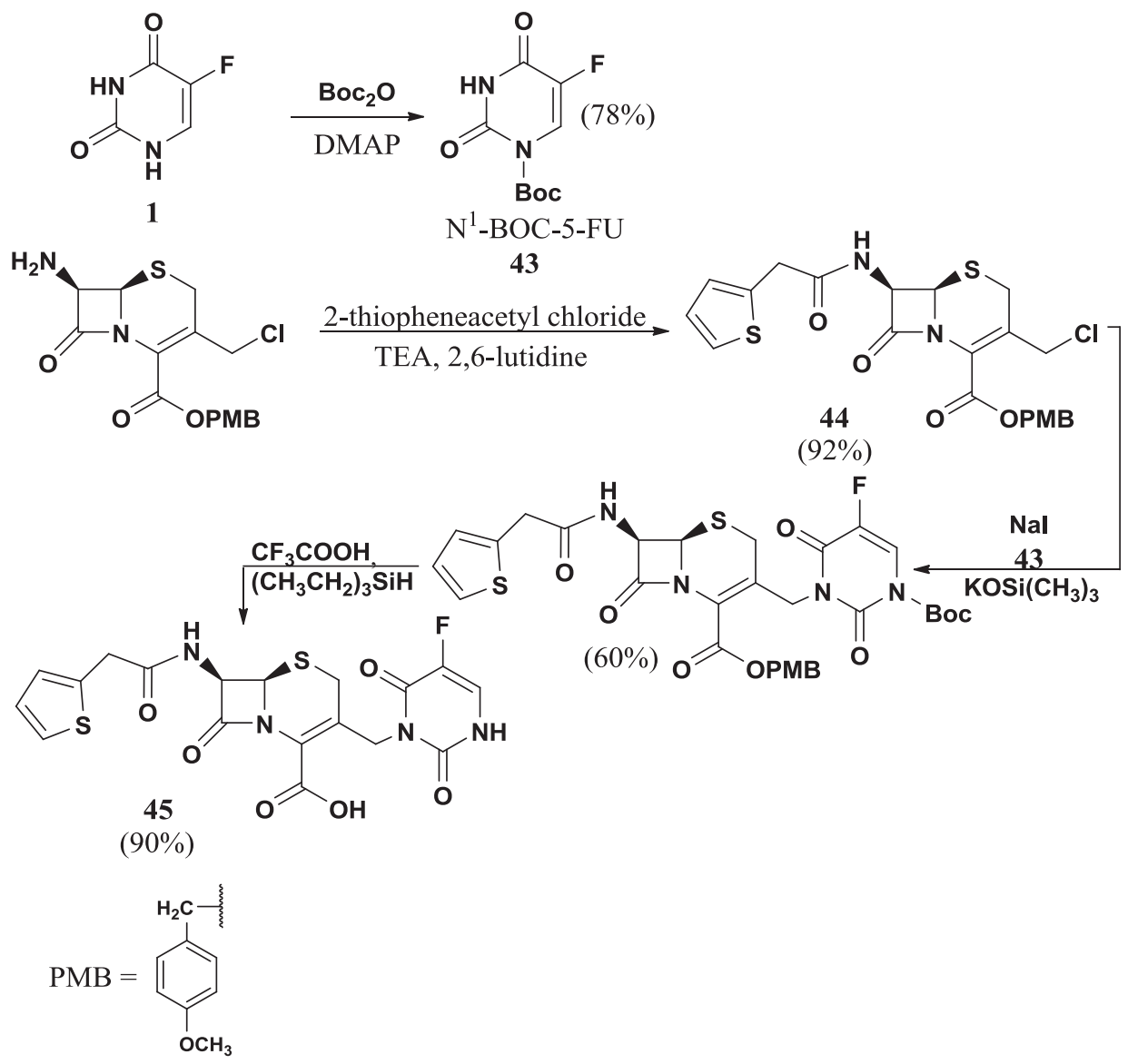

Scheme 22

5-FU 1 molecule. ${ }^{44,45}$ 1-(3-Phthalidyl)-5-fluorouracils were synthesized starting from the $\mathrm{N}^{3}$-benzoyl-5-FU $\mathbf{4 6}^{44}$ or from the bis(trimethylsilyl) derivative of 5FU $\mathbf{4 7}^{45}$ (Scheme 23). In the first case $\mathrm{N}^{3}$-benzoyl-5-FU $\mathbf{4 6}^{44}$ was reacted with 3-bromophthalide in presence of sodium hydride affording phthalide derivative 26048 in $59 \%$ yield. Subsequent acidic hydrolysis gave desired product 49 in $54 \%$ yield. The phthalide derivative was effectively biotransformed into 5-FU $\mathbf{1}$ in mice serum. Starting from 2,4-bis(trimethylsylil)-5-fluorouracil $47^{45}$ phthalide derivative 49 was obtained in $94 \%$ yield by reaction with 3 -bromo phthalide at $100^{\circ} \mathrm{C}$.

265 Some 5-FU prodrugs with a removable attachment were also proposed. For example porphyran 50, a polysaccharide from the red algae Porphyra haitanensis, was employed as a drug carrier, allowing the fixation at 5-FU 1 at the 6-position through an acetyl spacer group of polysaccharide derivative $\mathbf{5 1}$ (Scheme 24). ${ }^{46}$ The release of 5-FU $\mathbf{1}$ from conjugate 52 was studied in $0.01 \mathrm{M} \mathrm{NaOH}$ solution, in $0.1 \mathrm{M} \mathrm{HCl}$ solution and in phosphate buffer. The amount of released 5-FU 1 was significantly different, and only in basic media did the prodrug release quickly the 5-FU 1 . In vivo studies are not reported. 


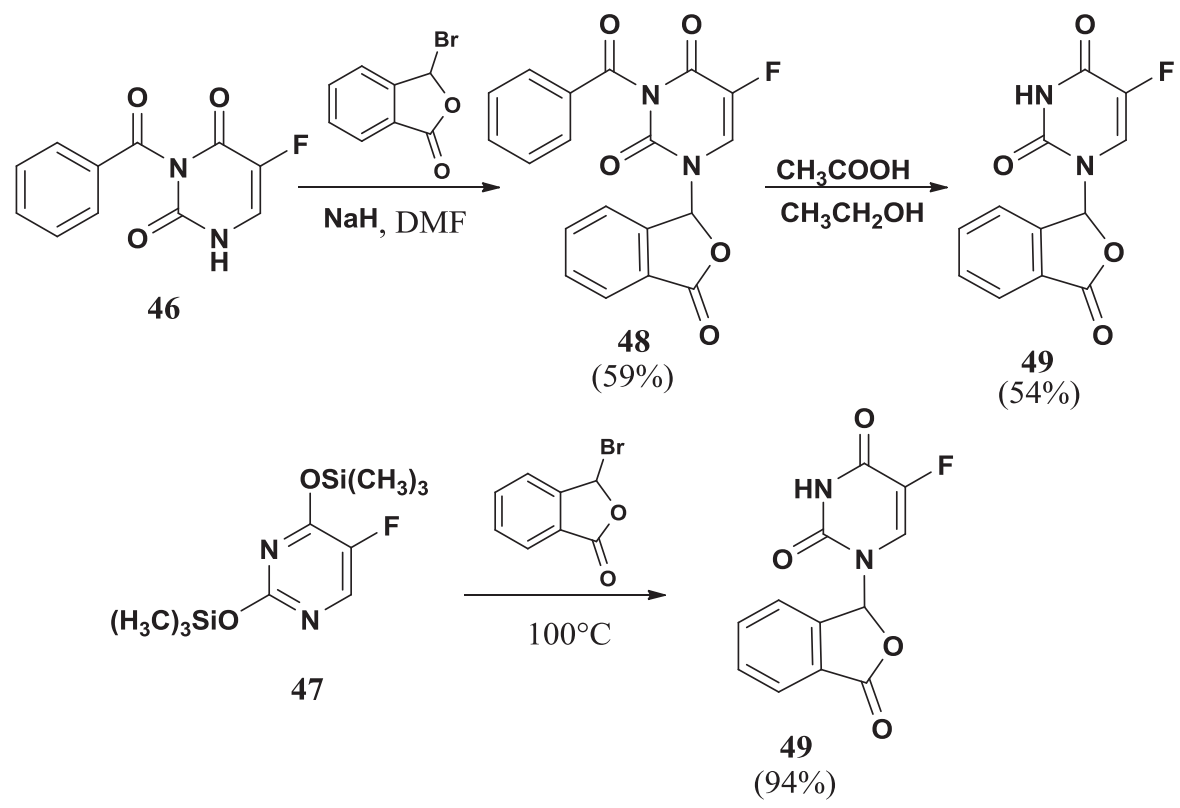

Scheme 23

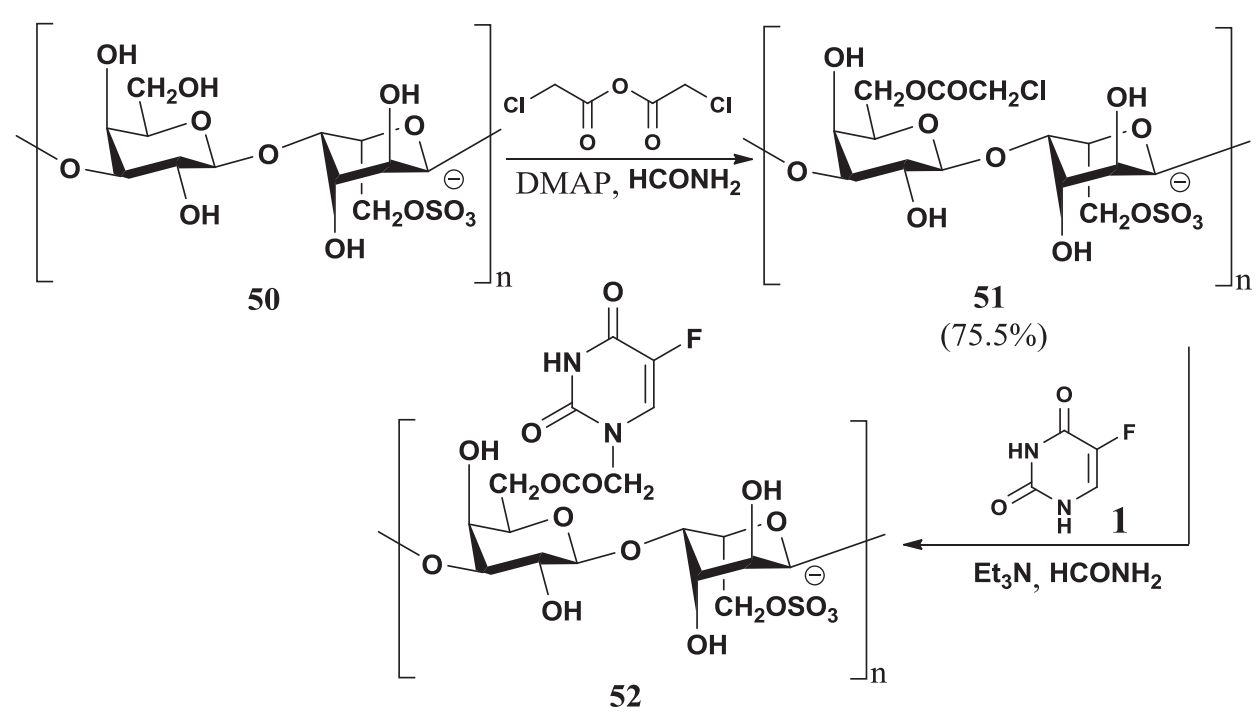

Scheme 24

In order to decrease the toxicity of 5-FU 1,2,5-triacetyl- $\beta$-D-glucofuranurono-6,3lactone 53 was reacted with 2,4-bis(trimethylsylil)-5-fluorouracil 47 , according to a reported method. ${ }^{47}$ The obtained molecule combines the active principle 5-FU 1 and the 275 nontoxic glucuronic acid, which participates in the detoxification of xenobiotics in the organism by forming the glucuronides (Scheme 25). ${ }^{48}$ Biological studies showed that 
<smiles>COc1nc(O[14CH3])nc([18F])c1F</smiles>

Scheme 25

5-FU derivative $\mathbf{5 4}$ has a very low toxicity and a relatively high antitumor activity. At $\mathrm{pH}$ 1.4 only the lactone ring undergoes splitting while at $\mathrm{pH} 7.4$ the lactone ring and the $\mathrm{N}$-glycosidic bond are split with formation of 5-FU $\mathbf{1}$.

280 The concept of "radioinduced drug" proposed for cancer therapy is also noteworthy: 5-FU derivatives variously substituted at the 1-position were prepared and the release of the antitumor drug was observed upon $\gamma$-irradiation. ${ }^{49} 5$-FU dimer $\mathbf{5 5}^{50}$ and 5-fluoro-1-(2'-oxocycloalkyl)uracil $\mathbf{5 6}^{51}$ released 5-FU $\mathbf{1}$ by radiation activation under hypoxic conditions (Scheme 26).<smiles>O=c1[nH]cc(F)c(=O)[nH]1</smiles>

1 electrolytic oxidation

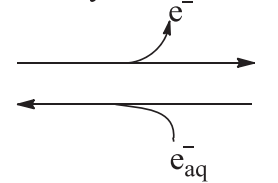

radiolytic reduction<smiles>O=C1NC(=O)C(F)(n2cc(F)c(=O)[nH]c2=O)C(O)N1</smiles>

55<smiles>CC(C)C1CCCC1</smiles>

56

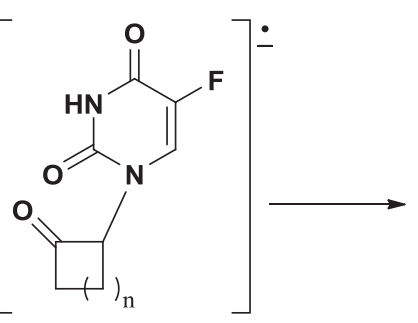

57

$\mathrm{n}=0-4,9$

Scheme 26

5-FU 1 can also be released from gold nanoparticles by photoirradiation. ${ }^{52}$ In this 285 case 1 was conjugated to gold nanoparticles through a photoresponsive ortho-nitrobenzyl linkage. 
Photoirradiation was also responsible for the recently reported ${ }^{53}$ release of 5-FU from oligonucleotide tetramer $\mathbf{5 8}$ (Scheme 27). The key reaction was the elimination of a nucleobase by photoinduced $\mathrm{Cl}^{\prime}$ hydrogen abstraction, in turn caused by the radical (compound 59) photo-generated at $C 5$ of the adjacent 5-halouracil. This approach seems to be promising, since the 5-FU could be released by photoirradiation only in the irradiated area of the body.

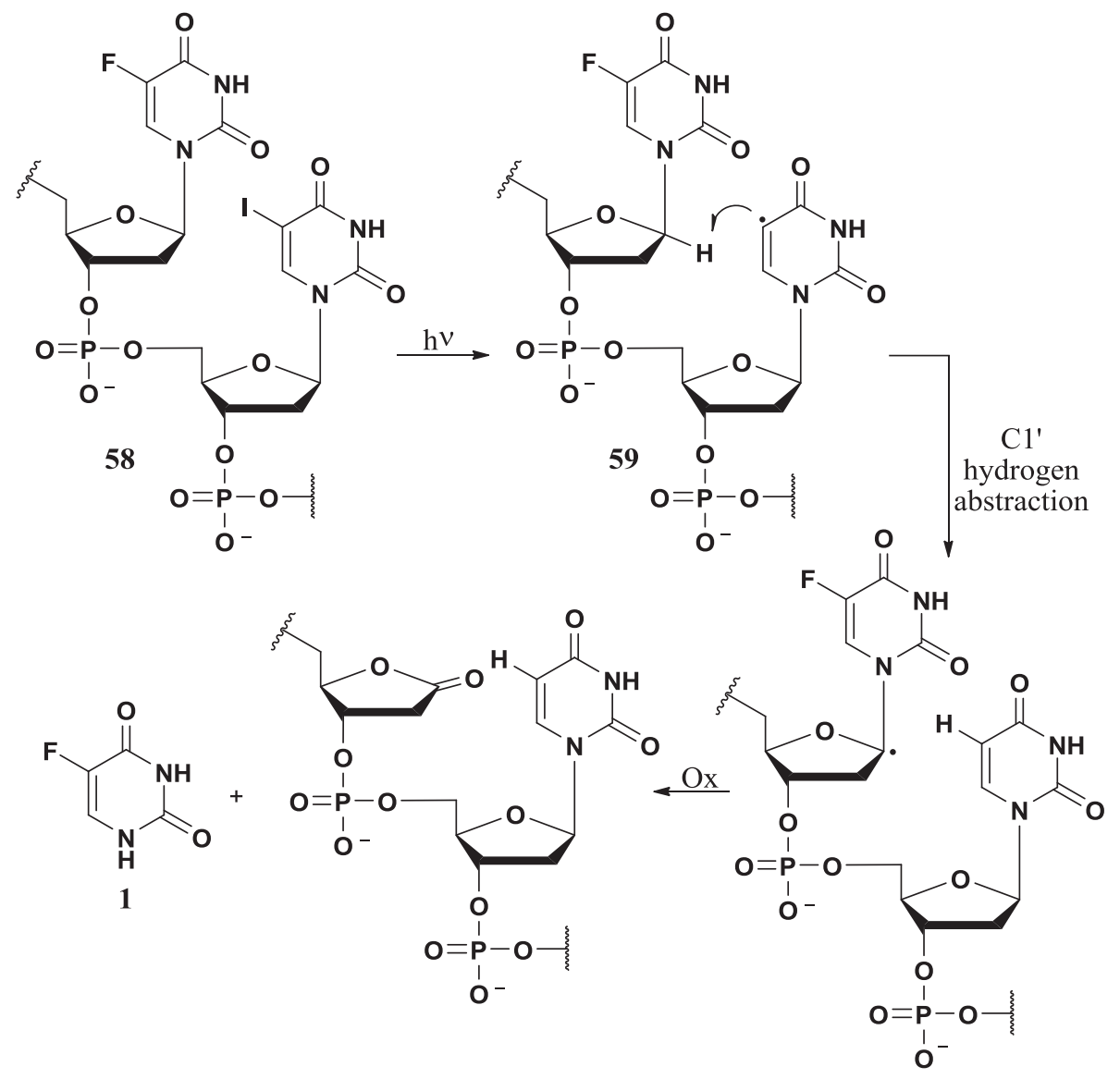

Scheme 27

Even if they are certainly promising, the 5-FU derivatives described herein have not yet found application in clinical trials, although some of them are under investigation, and studies to assess their possible therapeutic use are still in progress.

\section{II. Fluoropyrimidine Nucleosides}

Among the 5-FU derivatives developed for oral administration, 5-fluoropyrimidine nucleosides deserve an outstanding position as proven by a 2000 review $^{5}$ about the 5 -FU prodrugs considered from the clinical point of view. Protracted oral administration should be the ideal route of administration of 5-FU, being preferred by the patients and by pharmacoeconomic considerations. The low oral bioavailability of 5-FU 1 has been overcome by the new generation of oral fluoropyrimidine nucleosides. ${ }^{54-56}$ The main 5-FU prodrugs are depicted in Scheme 28. 


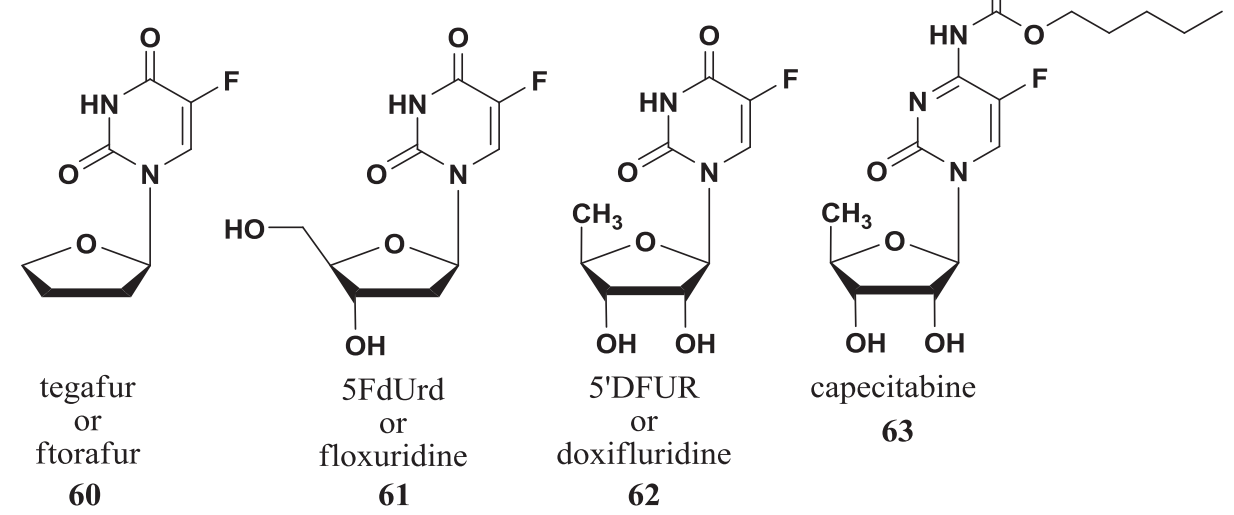

Scheme 28

\section{Tegafur (Ftorafur)}

Tegafur 60, also known as ftorafur (1-(tetrahydro-furanyl)-5-fluorouracil) is the first designed 5-FU prodrug. It has a high chemotherapeutic activity (twice that of 5-FU) and 305 low toxicity (5-6 times less than 5-FU) and it is used for the treatment of breast and gastrointestinal tract cancer. Typically, it is used in combinations with other drugs to further improve its bioavailability. ${ }^{54-57}$ For instance, the combination of uracil 7 and tegafur 60 (4:1), namely UFT, allows for higher levels of circulating 5-FU, by saturating the dihydropyrimidine dehydrogenase with its natural substrate uracil 7.

310 Tegafur was synthesized for the first time in $1969^{58}$ through the condensation of the bis(trimethylsilyl) derivative of 5-FU 47 and 2-chlorotetrahydrofuran 64 (Scheme 29) or by condensation of 5-fluorouracil-mercury and 2-chlorotetrahydrofuran $\mathbf{6 4}$ in dimethylformamide and toluene $(75 \%)$.

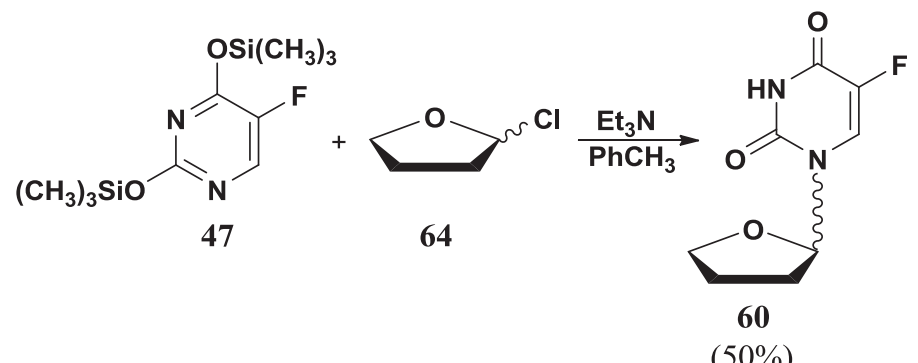

Scheme 29

2-Chlorotetrahydrofuran 64 was also used by other authors ${ }^{59-61}$, and its preparation 315 was the object of studies ${ }^{60}$ that included determination of the best molar ratios ${ }^{61}$ between the reagents in order to minimize the formation of the 1,3-bis(tetrahydro-2'-furyl)-5-fluorouracil that is the main by-product due to the double condensation reaction. 
Tegafur $\mathbf{6 0}$ is administered as a racemic mixture, due to no significant differences in the effects of the stereoisomers, as confirmed by the tests carried out with the separated 320 enantiomers in $1977 .{ }^{62}$ The separation of enantiomers was achieved by formation of diastereoisomers with brucine (Scheme 30). The racemic mixture of tegafur was, in this case, prepared in $91 \%$ yield, by reaction of 2-acetoxy tetrahydrofuran $\mathbf{6 5}$ with the silylderivative of 5-FU 47, using sodium iodide as catalyst.<smiles>COc1ncc(F)c(O[GaH])n1</smiles>

Scheme 30

The same 2-acetoxytetrahydrofuran $\mathbf{6 5}$ was also used with typical Friedel-Craft cata325 lysts $^{63}$ or without catalyst at $120^{\circ} \mathrm{C}$ in dimethylformamide (Scheme 31); higher temperatures lead to the degradation either of tegafur $\mathbf{6 0}$ or of 2-acetoxytetrahydrofuran $\mathbf{6 5} .^{64}$

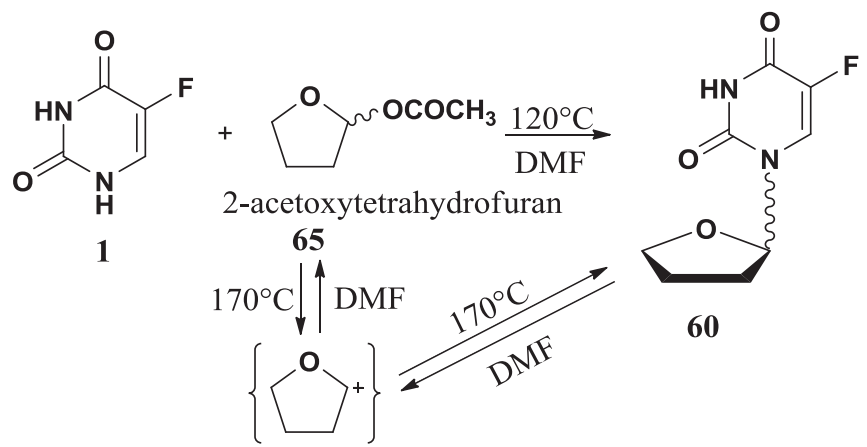

tetrahydrofuryl cation

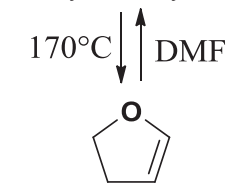

2,3-dihydrofurane

66

Scheme 31

A different catalyst, cesium chloride, was used in the condensation between disilylated 5-FU 47 and 2-acetoxytetrahydrofuran 65, in acetonitrile affording tegafur $\mathbf{6 0}$ in $87 \%$ yield (Scheme 32). ${ }^{65}$ 
<smiles></smiles>

65

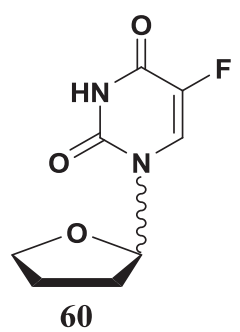

$(87 \%)$

Scheme 32

330 The most popular tetrahydrofuran derivative in the synthesis of tegafur $\mathbf{6 0}$ was, however, the 2,3-dihydrofuran 66. In a French patent, an excess of this compound was reacted with 5-FU 1 in aprotic polar solvents affording tegafur $\mathbf{6 0}^{\mathbf{6 6}}$ (Scheme 33) with yield depending on the chosen solvent.<smiles>O=c1[nH]cc(F)c(=O)[nH]1</smiles>

66<smiles>O=c1[nH]c(=O)n(CC2CCCO2)cc1F</smiles>

60
SOLVENT (yield) $\beta$-picoline $(61 \%)$ DMA $(55 \%)$ HMPTA $\quad(51 \%)$ pyridine $(39.4 \%)$

Scheme 33

In similar conditions but in the presence of an acidic catalyst (for example triethyl335 amine hydrochloride, and tetrabutoxytitanium) 59-89\% yields were observed. ${ }^{67}$ The same reaction was realized in the presence of phosphorus pentachloride in hexamethylphosphoramide affording tegafur $\mathbf{6 0}$ in $88 \%$ yield; poor yields were observed changing the solvent (DMF or DMA) and a decreased regioselectivity was obtained using phosphorus trichloride instead of phosphorus pentachloride. ${ }^{68}$

340 Two patents of two different Japanese companies described the synthesis of tegafur 60 from 5-FU 1 and 2,3-dihydrofuran 66 in the presence of trimethylsilyl chloride and triethylamine in dimethylformamide ${ }^{69}$ or in the presence of dimethyldichlorosilane and triethylamine in acetonitrile. ${ }^{70}$ The optimization of the molar ratio between 5-FU $\mathbf{1}$ and 2,3-dihydrofuran $\mathbf{6 6}$ and the use of calcium chloride as catalyst, under pressure, afforded 345 very high yields $(85-92 \%)$ of tegafur $\mathbf{6 0} .^{71}$

A one-pot synthesis ${ }^{72}$ was realized starting from 2,3-dihydrofuran 66 that was treated with water in the presence of an acidic catalyst $\left(\mathrm{H}_{3} \mathrm{PO}_{4}, \mathrm{H}_{2} \mathrm{SO}_{4}\right.$, alkylsulfonic acids) at a $\mathrm{pH}$ value below 2.5; after removal of the excess of unreacted material the obtained mixture was treated with the silyl derivative of 5-FU 47 and Friedel-Craft catalyst $\left(\mathrm{SnCl}_{4}\right.$, $\mathrm{BF}_{3}, \mathrm{TiCl}_{4}, \mathrm{NaI}$ ) (Scheme 34). 


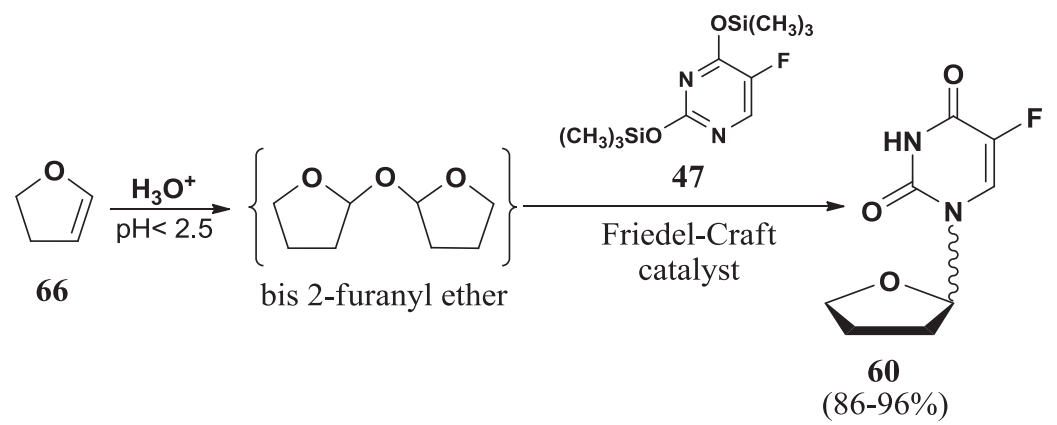

Scheme 34

Depending on the ratio between 2,3-dihydrofuran 66 and 5-FU 1, in pyridine, in a sealed tube, tegafur 60 or 1,3-bis(tetrahydrofuryl)-5-fluorouracil $\mathbf{6 7}$ were obtained (Scheme 35). ${ }^{73}$ Interestingly, the heating of the bis-substituted 5FU 67 at $135^{\circ} \mathrm{C}$ for $12 \mathrm{~h}$, at reduced pressure, afforded tegafur in $76 \%$ yield.

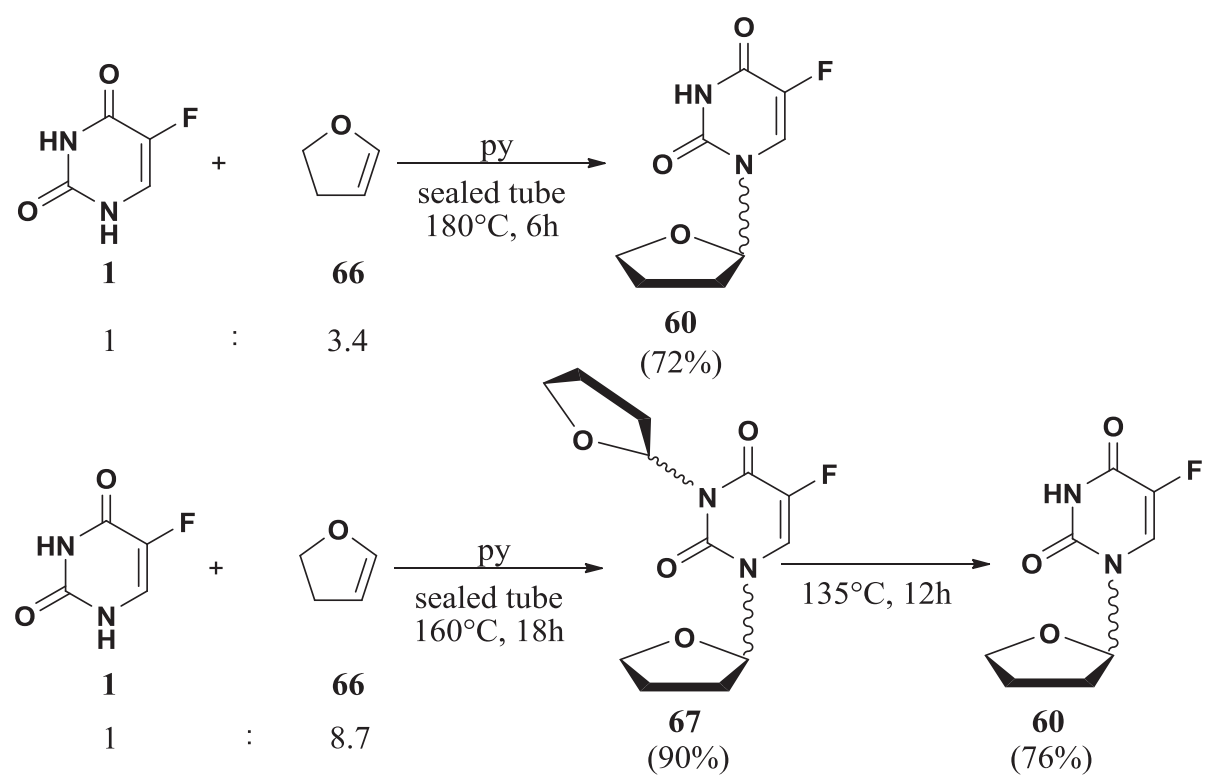

Scheme 35

Some different starting materials were also proposed, alternative to the 5-FU or to the tetrahydrofuran derivatives. For example, the 5-fluoro-6-hydroxy-5,6-dihydrouracil $\mathbf{6 8}^{74}$ provided, by reaction with hexamethyldisilazane or hexamethyldisilazane and trimethylsilyl chloride, bis(trimethylsilyl)-5-fluorouracil 47 (80-82\%), which by further reaction with 2-chlorotetrahydrofuran 64, in THF, afforded tegafur 60 (51\% yield) (Scheme 36). 


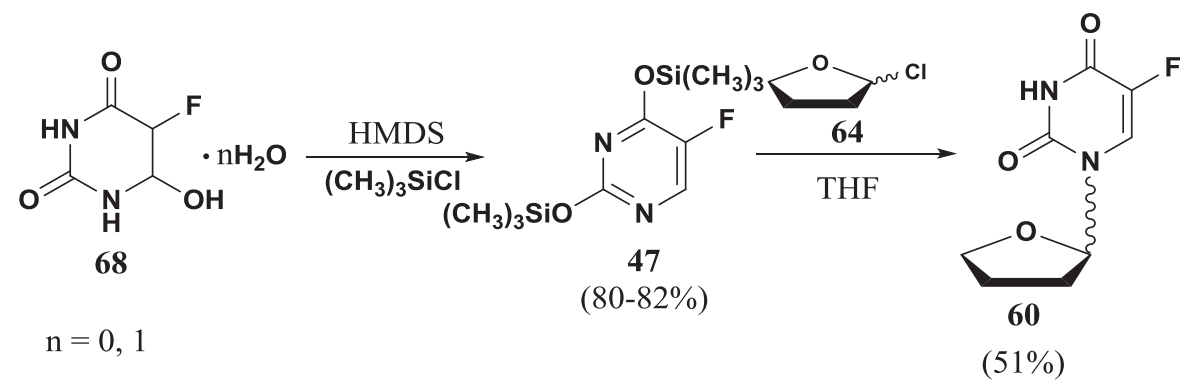

Scheme 36

A series of 2-alkoxyderivatives was used, the best results being achieved with the 2-tert-butoxytetrahydrofuran 69 (67\% yield) ${ }^{75}$ The small amount of disubstituted by-product 67 was quantitatively converted into tegafur by treatment with acetic acid (Scheme 37).

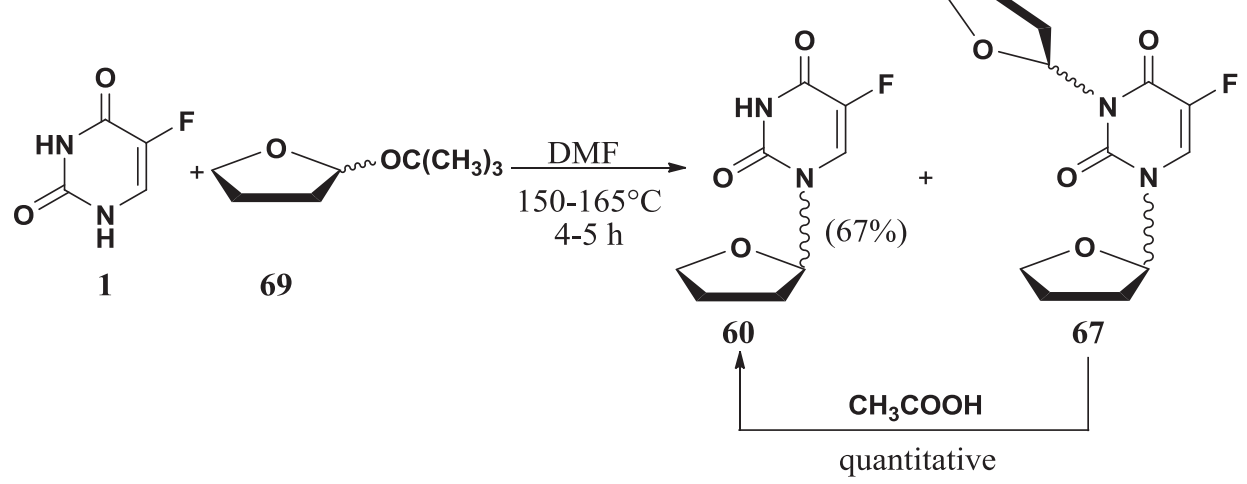

Scheme 37

365 In a different approach, a preformed nucleoside, $\beta$-5-fluoro- $2^{\prime}$-deoxy-uridine 61, was used as starting material and submitted to the reaction with black platinum in water and sodium hydrogen carbonate; the recovered $5^{\prime}$-carboxyderivative $\mathbf{7 0}$ was transformed into the corresponding methyl ester $\mathbf{7 1}$ and the $3^{\prime}$-hydroxy group was derivatized as mesylate 72. Simultaneous elimination of $3^{\prime}$-O-mesylate and $5^{\prime}-\mathrm{COOCH}_{3}$ afforded the dihydro370 furan ring (compound 73); catalytic hydrogenation gave the $\left(2^{\prime} R\right)$ isomer of tegafur $\mathbf{6 0}$ (Scheme 38). ${ }^{76}$ Starting from the $\alpha$-preformed nucleoside the $\left(2^{\prime} S\right)$ enantiomer of tegafur $\mathbf{6 0}$ was obtained. 


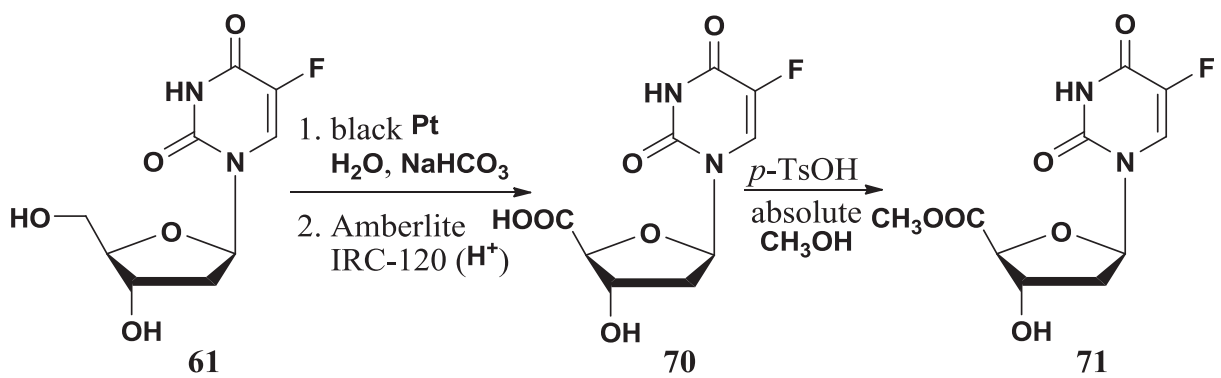

(84\% from 61)

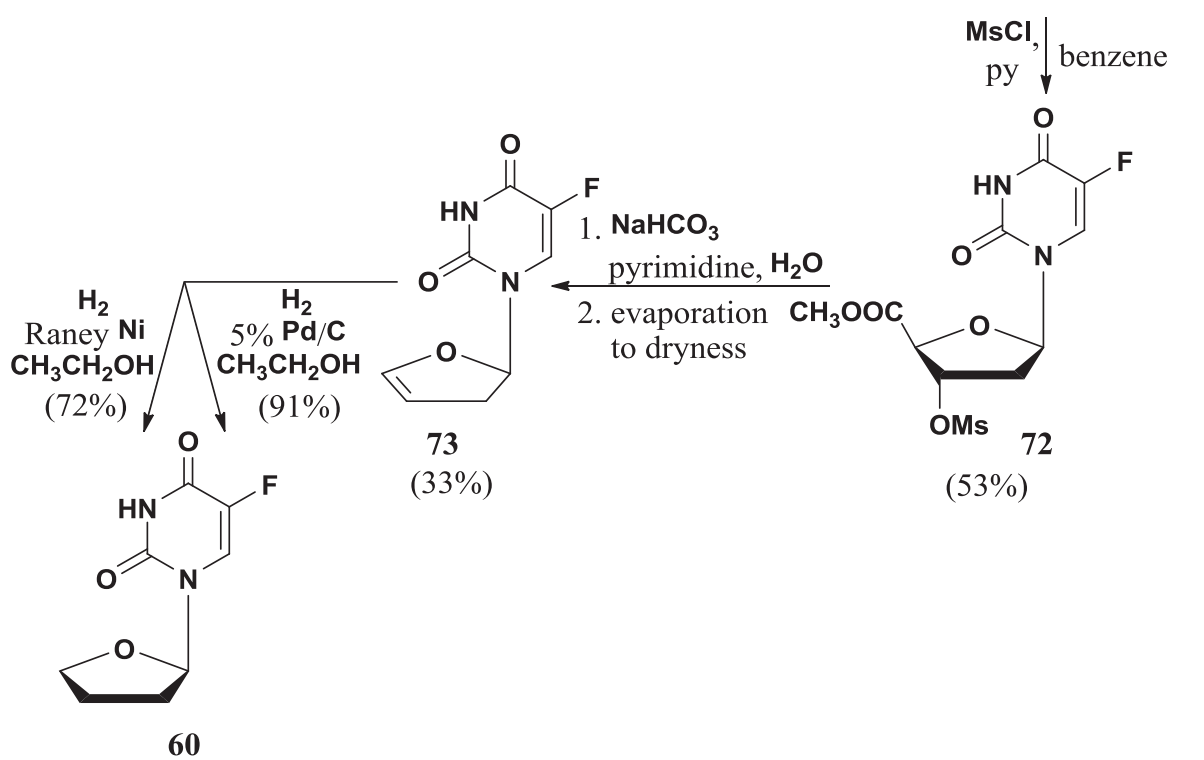

Scheme 38

The dimethylacetal of 4-hydroxybutanal-4-O-trimethylsilylether $\mathbf{7 4}$ was used as precursor of the tetrahydrofuran ring: ${ }^{.7}$ the acetal was treated with bis(trimethylsilyl)-5-fluo375 rouracil 47, in acetonitrile, in the presence of stannic chloride. Tegafur 60 was recovered in $84 \%$ yield (Scheme 39 ).

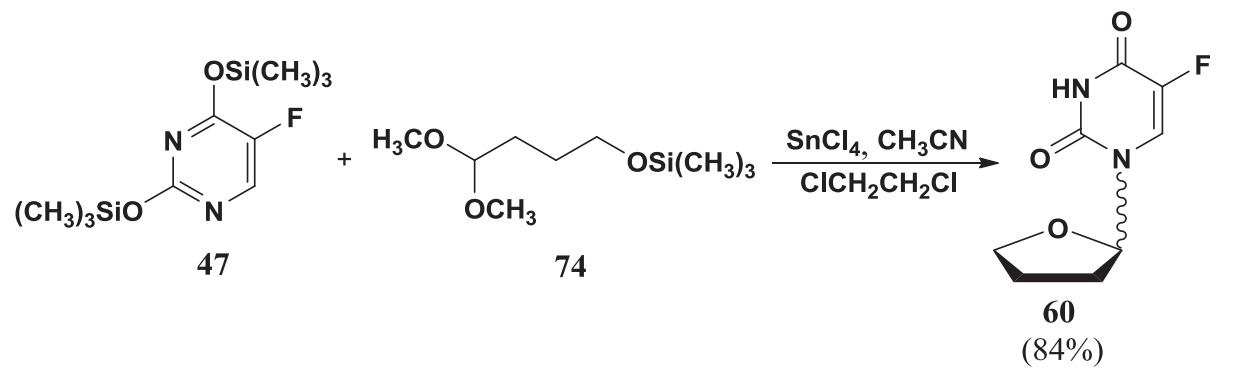

Scheme 39

bis(Trialkylstannyl)-5-fluoro uracil $\mathbf{7 5}^{\mathbf{7 8}}$ was used, instead of the usual silyl derivative, in the reaction with a series of 2-substituted tetrahydrofurans, in the presence of 
different acid catalysts. The formation of desired tegafur $\mathbf{6 0}$ (70-95\%) was obtained when 380 a 1:1 molar ratio was utilized of 5-FU derivative/2-substituted tetrahydrofuran. In the case of a molar ratio 1:2 the $\mathrm{N}^{1}, \mathrm{~N}^{3}$-disubstituted product was isolated. As previously reported ${ }^{75} \mathrm{~N}^{1}, \mathrm{~N}^{3}$-disubstituted product 67 was converted into tegafur $\mathbf{6 0}$ by acidic treatment (Scheme 40).

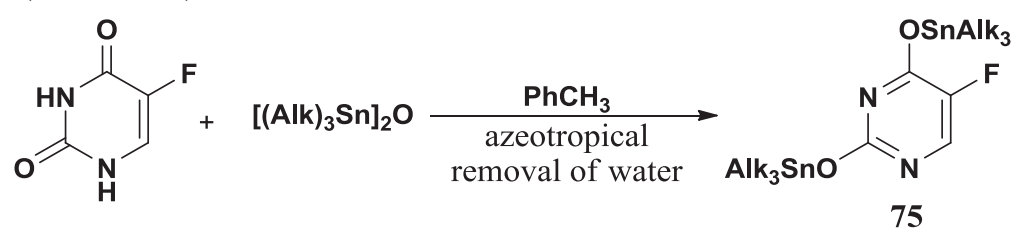

Alk = n-butyl, n-propyl<smiles>[X]C1CCCO1</smiles>

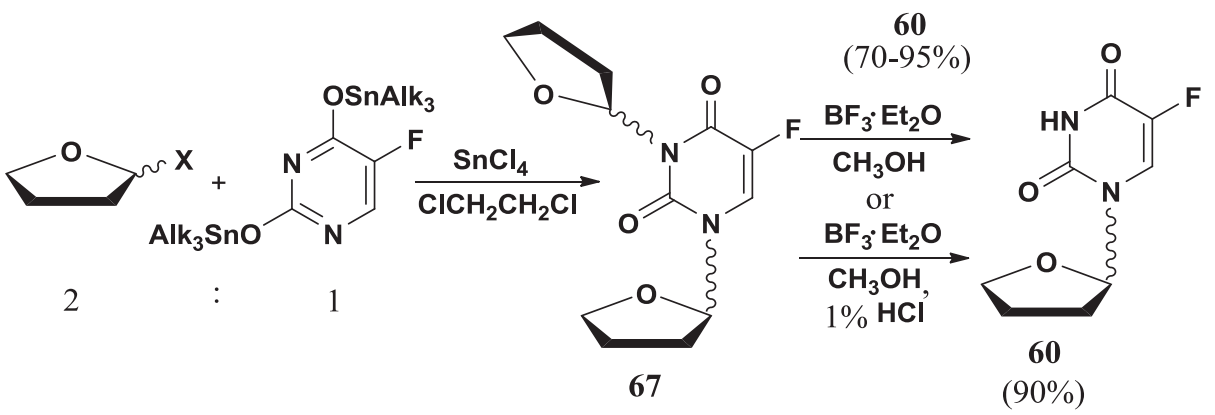

Scheme 40

As in the case of 5-FU 1 synthesis the direct fluorination of the preformed nucleoside 385 was described. Trifluoromethyl hypofluorite in dichloromethane ${ }^{79}$ gave the fluorination of 1-(tetrahydrofuranyl) uracil 76 in $60 \%$ yield (Scheme 41).<smiles>COc1ccnc(O[13CH3])n1</smiles>

\section{Scheme 41}

Using fluorine as fluorinating agent, the reaction with 1-(2'-tetrahydrofuryl)-5-methoxycarbonyluracil 77 gave different intermediates depending on the chosen solvent. ${ }^{21,22}$ In water 5-fluoro-6-hydroxy intermediate $\mathbf{7 8}$ was obtained, while in acetic acid 5-fluoro-6-acetoxy derivative $\mathbf{7 9}$ was formed. Both intermediates led to desired tegafur $\mathbf{6 0}$ in $84 \%$ and $62 \%$ yield, respectively (Scheme 42) by hydrolysis of the methyl ester and elimination reaction. 


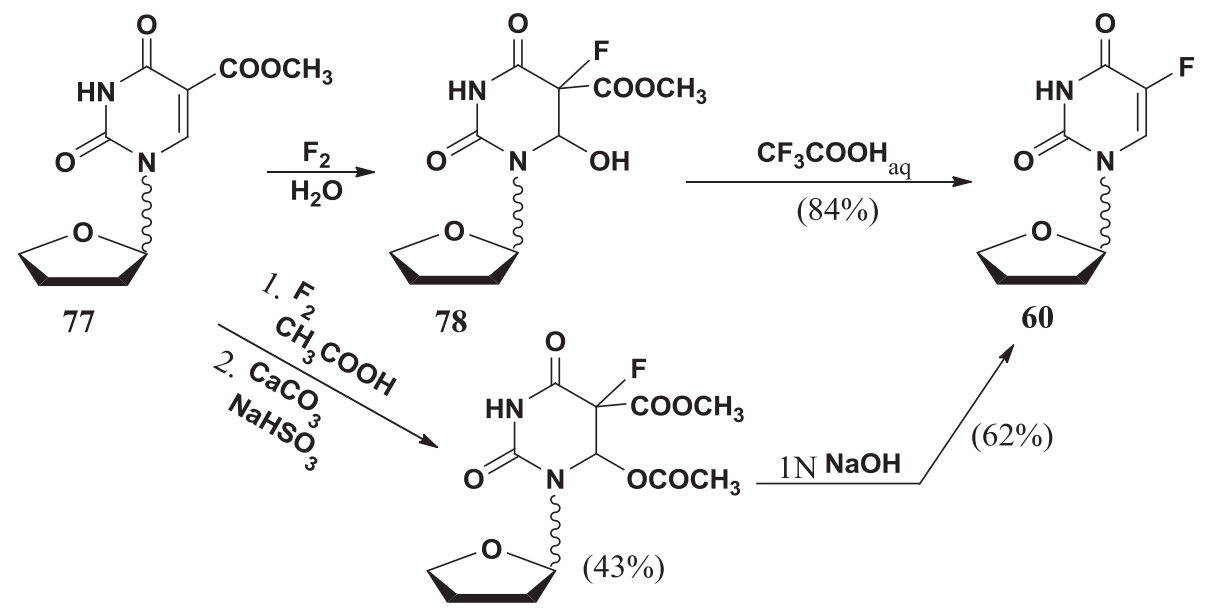

79

\section{Scheme 42}

More recent works about tegafur are especially focused on the improvement of its oral absorption and biological half-life and to lowering its toxicity. With this aim in mind, a lighttriggered porphyrin tegafur prodrug was developed. ${ }^{80}$ Porphyrins are photosensitizers used in

395 photodynamic therapy and they tend to accumulate in neoplastic tissue to higher concentrations than in adjacent normal tissue. The porphyrin prodrug was composed of three parts: a

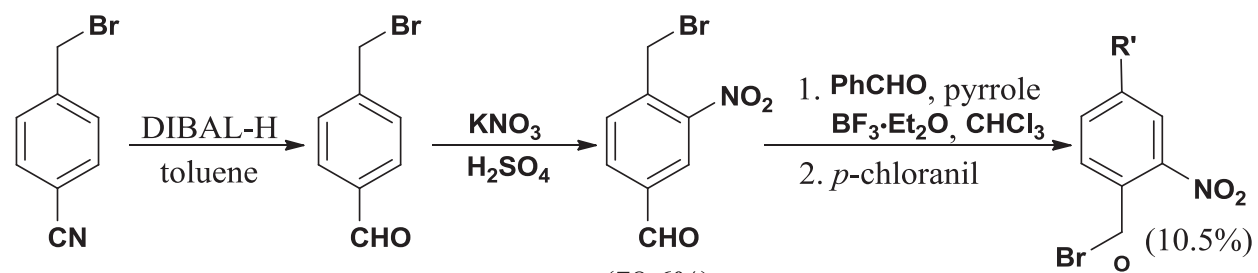

$(78.6 \%)$

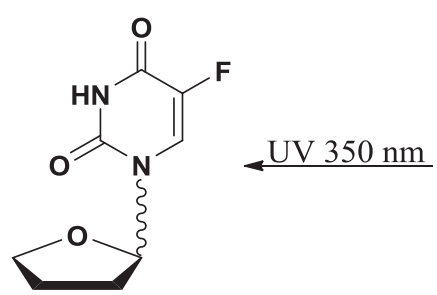

$(70 \%)$

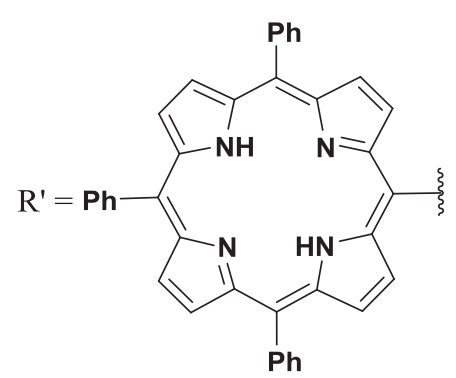

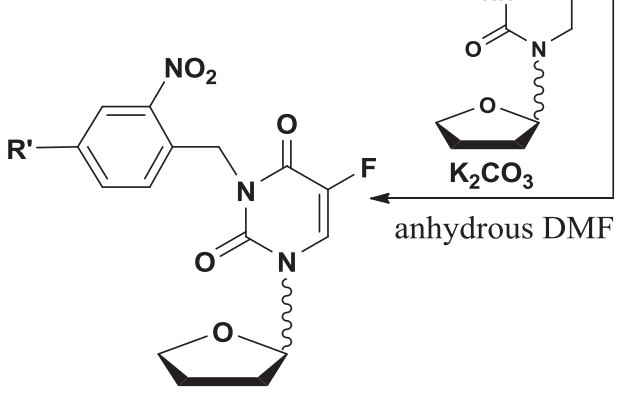


porphyrin, a photocleavable ortho-nitro benzyl moiety, as a light-triggered group, and tegafur. In vitro tests demonstrated that this prodrug is less toxic than its parent drug and that it can release cytotoxic tegafur $\mathbf{6 0}$ upon photoactivation with long wavelength UV light (350 $400 \mathrm{~nm}$ ). The synthesis of porphyrinic prodrug $\mathbf{8 0}$ is depicted in Scheme 43.

\section{Floxuridine}

Floxuridine 61 (5-fluoro-2'-deoxyuridine, FdUrd) (See Scheme 28) is the deoxyribose metabolite of 5-FU and the precursor of 5-fluorouridine monophosphate 2 (FdUMP) that inhibits thymidilate synthetase (TS) (See Scheme 1). FdUrd 61 can be also converted into

405 5-FU 1 in the liver by thymidine phosphorylase (TP). It was approved in therapy by the FDA in 1970 and has been extensively used for the clinical treatment of carcinoma of the ovary, breast and gastrointestinal tract. Due to the higher toxicity, costs and equal efficacy compared to 5-FU 1 the use of FdUrd $\mathbf{6 1}$ is restricted to the treatment of liver metastases caused by colorectal cancer. ${ }^{81}$ It was first synthesized at Hoffman-La Roche through the 410 reaction (Scheme 44$)^{82,83}$ of a mercury derivative of 5-FU 81 with a protected 2-deoxyD-ribosyl chloride $\mathbf{8 2}$ (68-70\% yield) followed by separation of $\alpha$ and $\beta$-anomers by crystallization (42.5\% of $\beta$-isomer) and removal of protecting groups (90\%).

The same company obtained FdUrd $\mathbf{6 1}$ and its phosphates through a biocatalytic approach (cells of Streptococcus faecalis). ${ }^{84}$

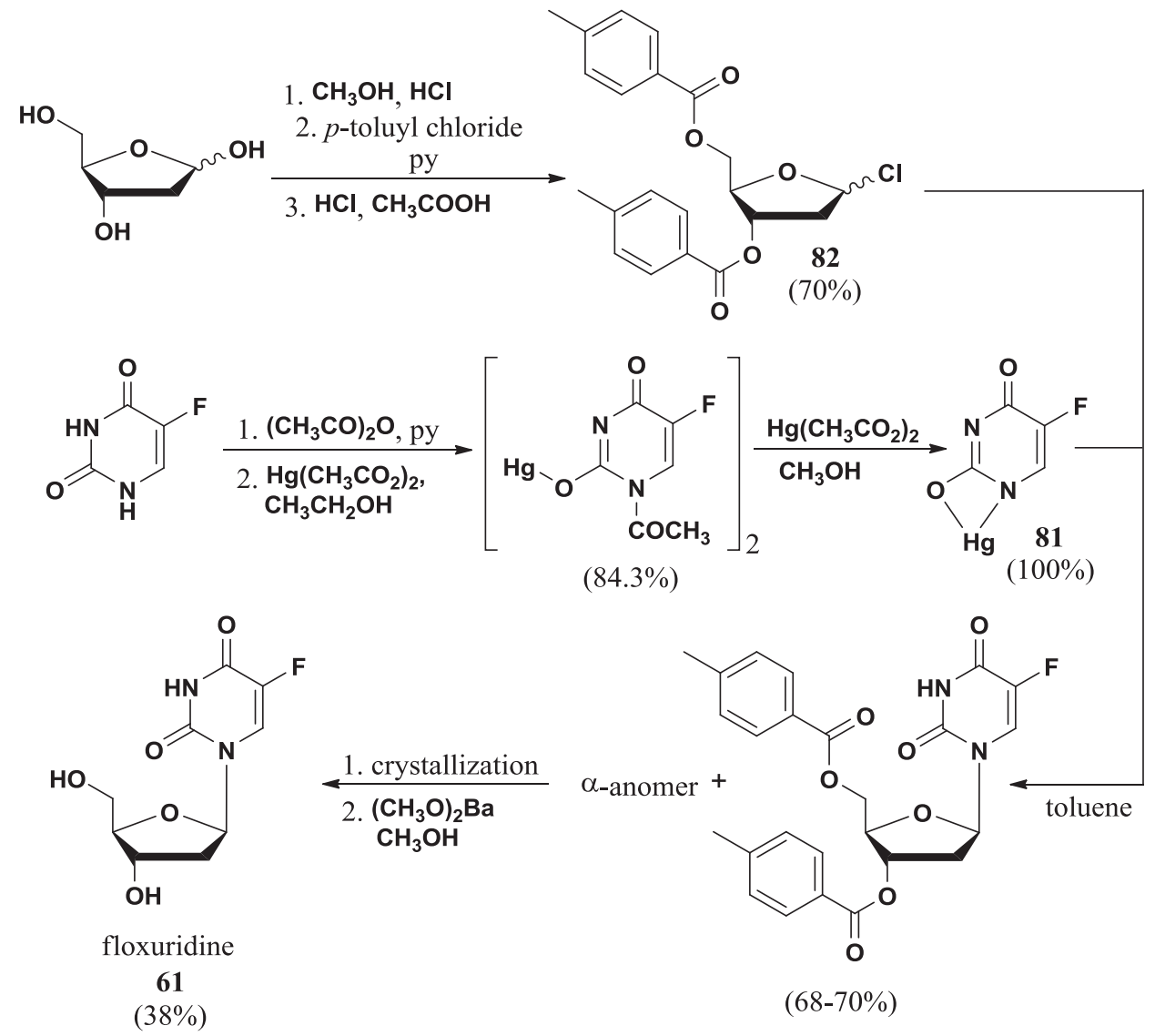

Scheme 44 
415 A subsequent approach provided the formation of $2^{\prime}$-deoxyribose starting from a preformed $\beta$-nucleoside, namely 5 -fluorouridine $\mathbf{8 3}$. This purpose was achieved by means of the removal of $2^{\prime}$-chlorine $\mathbf{8 5}^{\mathbf{8 5}}$ or $2^{\prime}$-bromine $\mathbf{8 6}^{86}$ in turn obtained by the ring opening of a $\mathrm{O}^{2,2}$ '-anhydrouridine $\mathbf{8 4}$ (Scheme 45). Use of tributyltin hydride allowed removal of the $2^{\prime}$-halogen selectively.

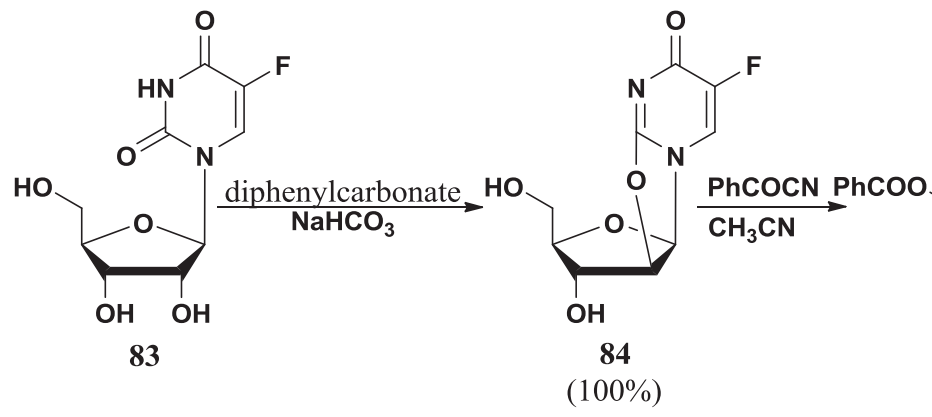

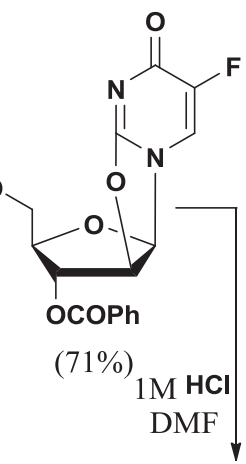<smiles>CO[C@H]1C[C@H](O)[C@@H](CO)O[C@H]1n1cc(F)c(=O)[nH]c1=O</smiles>

$(26 \%)$

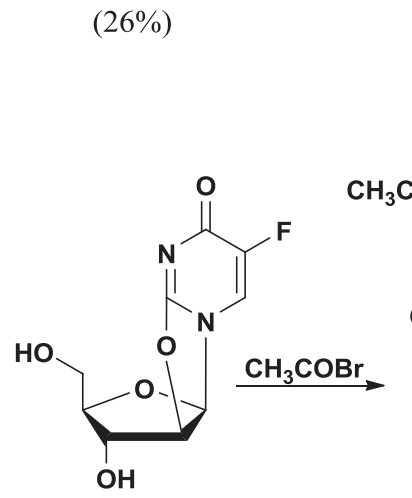

84<smiles>O=c1[nH]cc(F)c(=O)[nH]1</smiles>

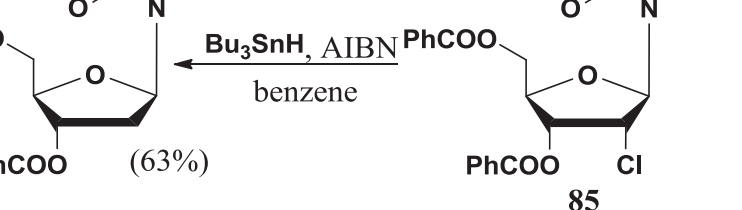

85<smiles>O=c1[nH]cc(F)c(=O)[nH]1</smiles>
$\mathrm{CH}_{3} \mathrm{COO}$ 1. separation $\mathrm{Bu}_{3} \mathrm{SnH}, \mathrm{AIBN}$<smiles></smiles>

(47.5\% from 83$)$<smiles></smiles>

(72\%)

Scheme 45 
420 Applying a method developed in $1974^{87}$ for the synthesis of $2^{\prime}$-deoxyuridine from uridine, floxuridine $\mathbf{6 1}$ was obtained in $50 \%$ yield from 5-fluorouridine 83. The 2'hydroxy group was substituted by a bromine atom that was removed by hydrogenation (Scheme 46). ${ }^{88}$ A mechanism of the substitution reaction was proposed.

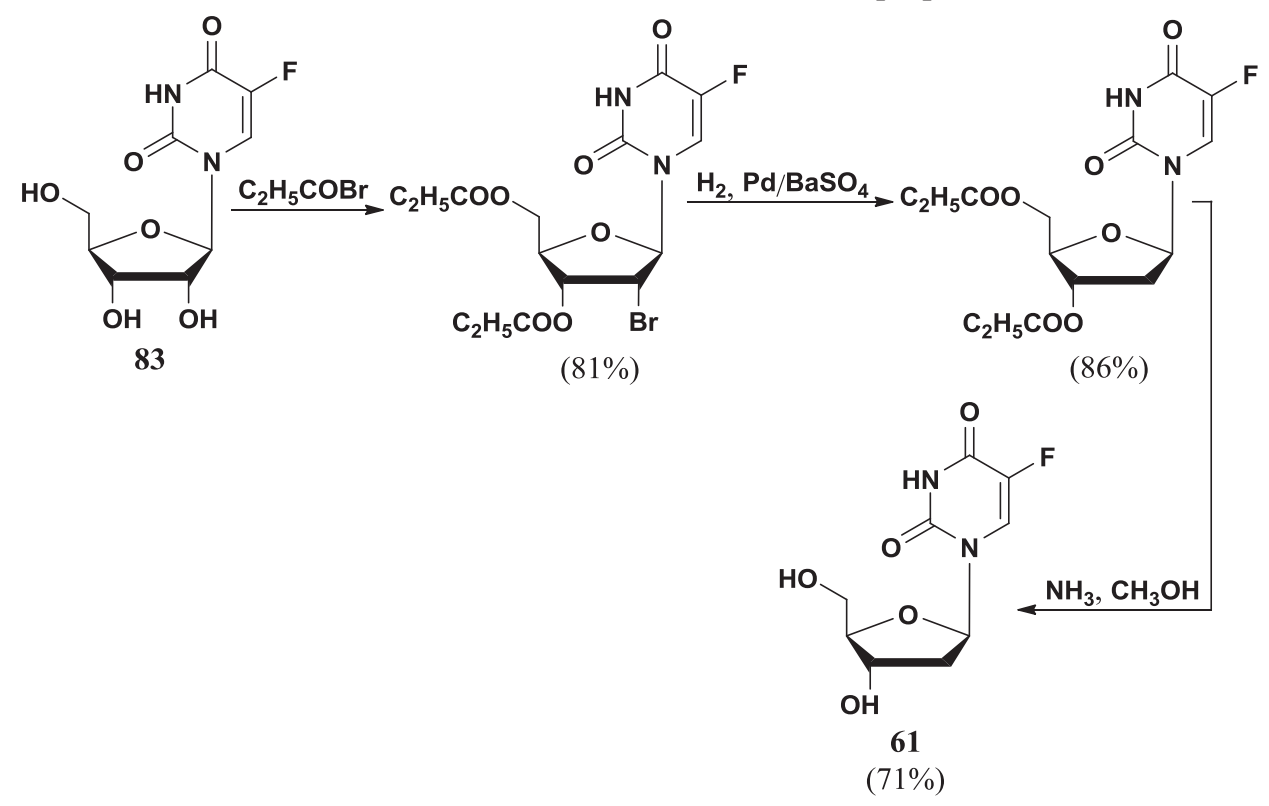

Scheme 46

Similar to 5-FU $\mathbf{1}$ and tegafur $\mathbf{6 0}$, the direct fluorination of the peracetylated pre425 formed 2'-deoxy nucleoside was realized using, as fluorinating agent, trifluoromethyl hypophosphite. ${ }^{13,15}$ Perbenzoate $2^{\prime}$-deoxyuridine $\mathbf{8 7}$ was fluorinated with fluorine in acetic acid (60-90\% yield). The benzoyl esters were removed from compound $\mathbf{8 8}$ by methanolysis affording floxuridine 61 (60-90\% yield) ${ }^{89}$ (Scheme 47).

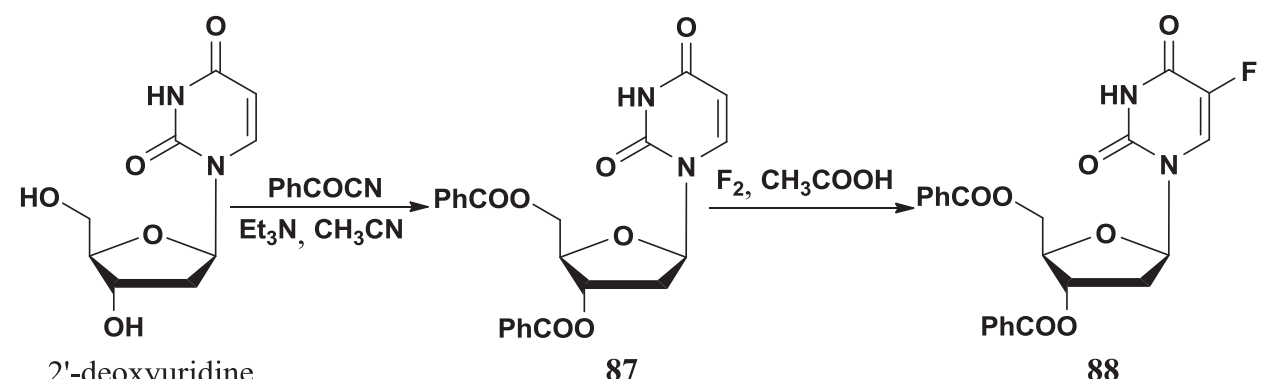

2'-deoxyuridine

87

(yield not given)
88

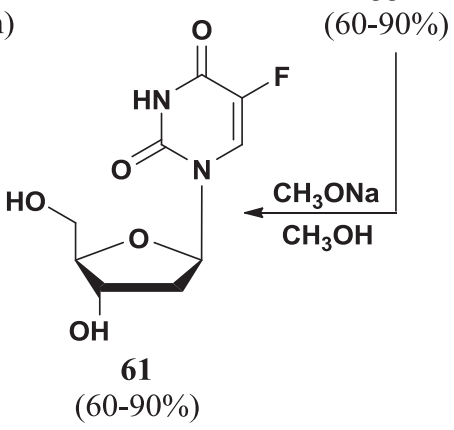


In a different approach, a study, carried out with the aid of ${ }^{1} \mathrm{H}$ NMR, allowed workers 430 to establish which parameters influence the stereoselectivity of the reaction between the bis-silyl derivative of 5-FU 47 and 3,5-bis(O-para-chlorobenzoyl)-2-deoxy- $\alpha$-D-ribofuranosyl chloride 89. In the presence of para-nitrophenol the $\beta$-anomer of $\mathbf{9 0}$ was obtained stereoselectively in high yields. In the presence of pyridine and para-nitrophenol, the $\alpha$-anomer of 90 was formed stereoselectively (Scheme 48). ${ }^{90}$

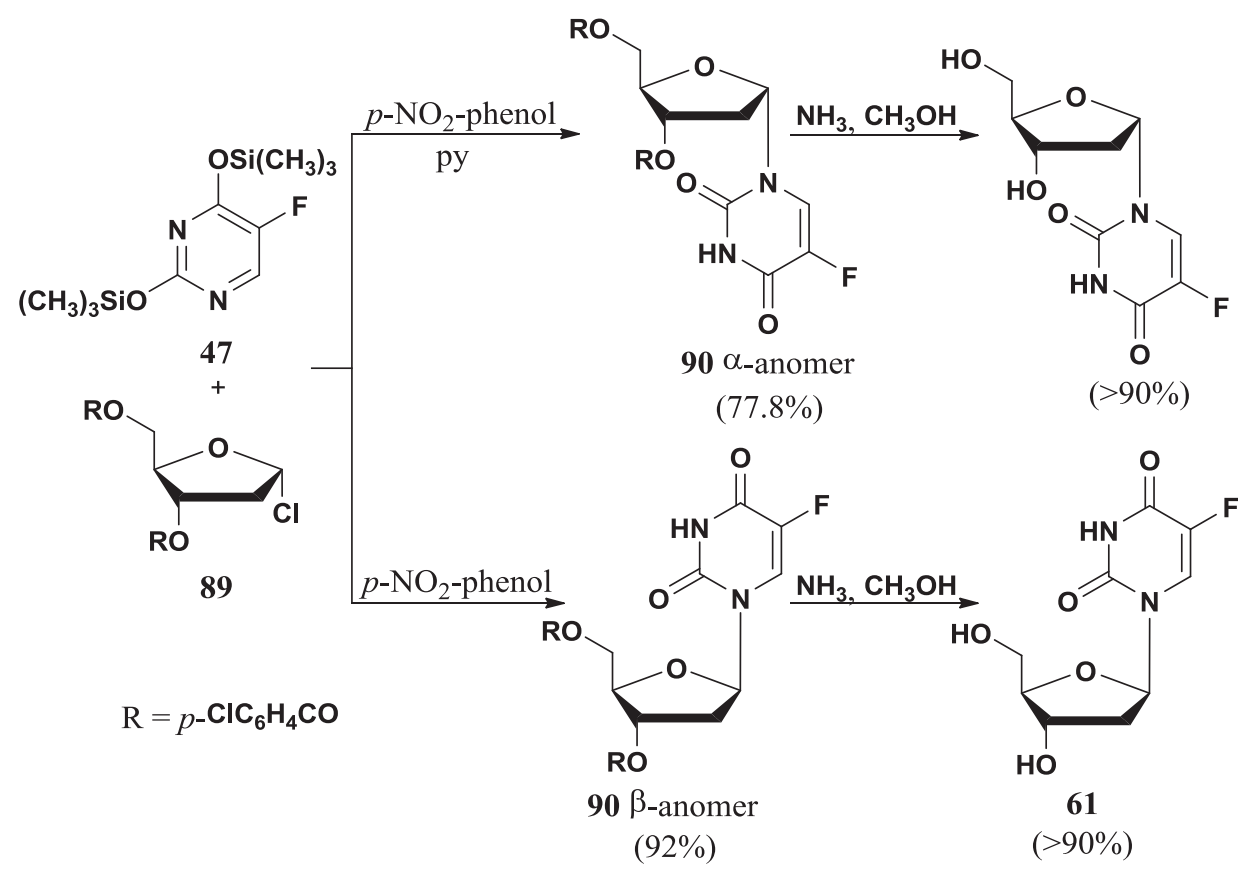

Scheme 48

435 A biocatalytic approach to floxuridine $\mathbf{6 1}$ includes the use either of purified enzymes or of microorganisms in toto. The regioselective behavior of hydrolytic enzymes towards the esters of floxuridine was already observed in 1989. A lipase from Pseudomonas fuorescens was able to regioselectively remove the $3^{\prime}$-acyl group from the $3^{\prime}, 5^{\prime}$-diester of floxuridine 91. The selective removal of the $5^{\prime}$-acyl group was achieved by means of sub440 tilisin, the protease from Bacillus subtilis (Scheme 49). ${ }^{91}$

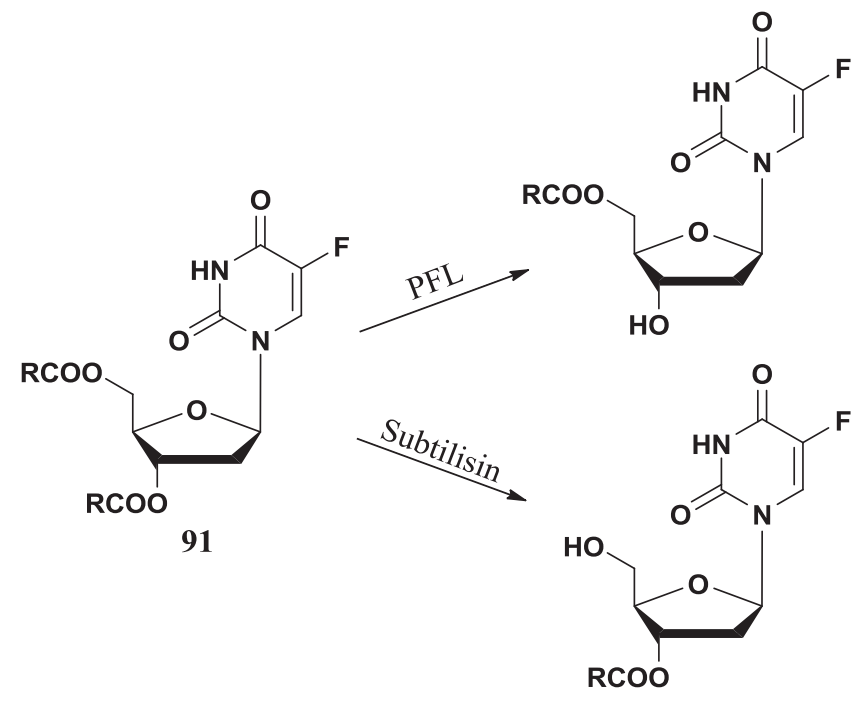


A synthesis of floxuridine $\mathbf{6 1}$ starting from 2-deoxyribose $\mathbf{9 2}$ was performed in 2008 through a chemo-enzymatic approach: CAL B, the lipase from Candida antarctica, was first used to selectively introduce an acetyl group at the 5-position of the carbohydrate (compound 93) and, in the next step of the synthesis, to selectively remove the same acyl

445 group, under alcoholysis conditions (compound 94). Intermediate 5-phosphate 95 was used as starting material for the glycosylation reaction catalyzed by a combination of phosphopentomutase (PPM) and thymidine phosphorylase (TP). PPM catalyzed the transfer of the phosphate group from the 5-position to the 1-position of the furanose, providing the substrate of TP. Floxuridine $\mathbf{6 1}$ was obtained in $60 \%$ yield from 2-deoxy-D-ribose-5450 phosphate 95 (Scheme 50). ${ }^{92}$

HO

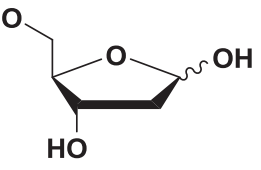

2'-deoxyribose

92

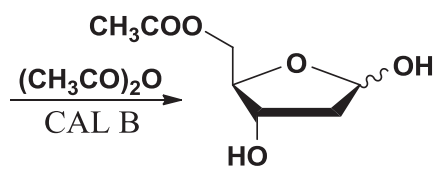

93

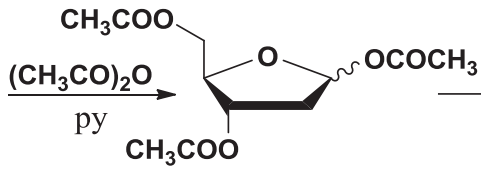

(82\% from 2-deoxyribose)

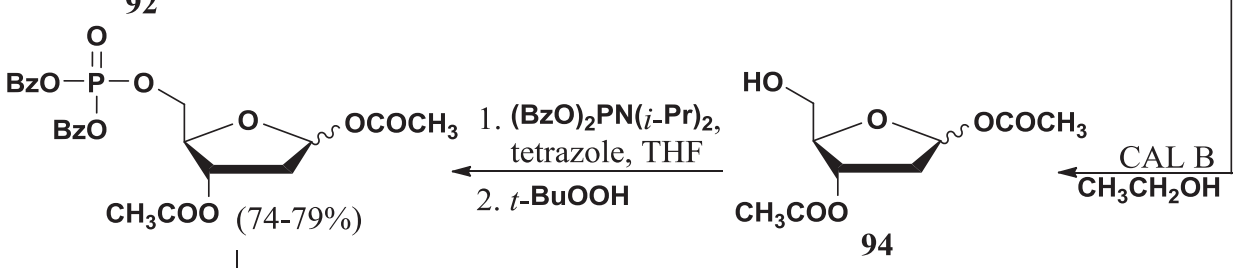

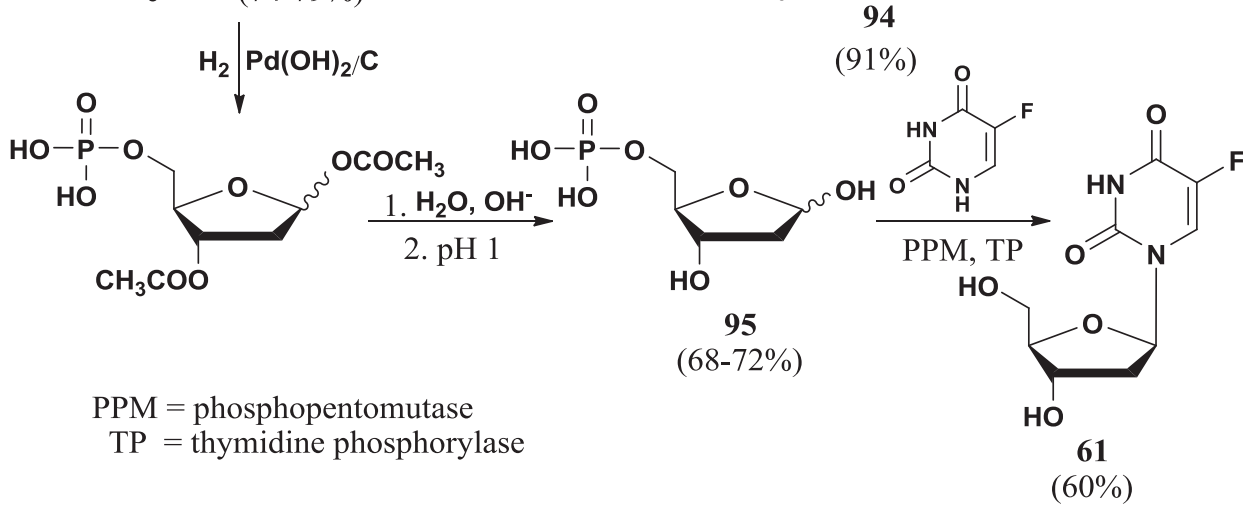

Scheme 50

The use of TP as biocatalyst of the nucleobase exchange reaction, aimed to convert thymidine 96 to floxuridine $\mathbf{6 1}$ (transglycosilation), was also reported. In one case immobilized TP was used (62\% yield) ${ }^{93}$ by using commercially available $\mathrm{TP}^{94}$ a $86 \%$ yield was observed (Scheme 51).

Immobilized bacterial cells from E. coli ${ }^{95}$ or from Lactobacillus animalis ${ }^{96,97}$ were reported to catalyze the transglycosilation reaction of thymidine 96 to floxuridine 61 with $62 \%$ and $95 \%$ yield, respectively.

Similarly to 5-FU 1, floxuridine $\mathbf{6 1}$ has a short plasma half-life and causes gastrointestinal toxicity. Some esters of floxuridine with long chain aliphatic acids show higher therapeutic indices than floxuridine ${ }^{98}$ and for this reason the susceptibility of a series of 
<smiles>Cc1cn(C2C[C@H](O)[C@@H](CO)O2)c(=O)[nH]c1=O</smiles><smiles>Cc1c[nH]c(=O)[nH]c1=O</smiles>

61

$(62 \%$, imm. TP)

$(86 \%$, comm. TP $)$

Scheme 51

$3^{\prime}, 5^{\prime}$-diesters or $3^{\prime}$-and $5^{\prime}$-monoesters to porcine liver esterase was investigated. The obtained results suggested that the higher antitumor activity of longer alkyl chain diesters of floxuridine was partly due to their slow rate of hydrolysis by non-specific esterase.

Many efforts have been made to develop a variety of prodrugs undergoing hydrolysis to release floxuridine 61: for example, conjugates with a cyclic peptide with an ester linker $^{99}$ or a peptide with a 3-aminoxypropionate-based linker. ${ }^{100}$ This last prodrug 97 shows a linker that cyclizes readily under physiological conditions and in the interstitial tissues of solid tumors (Scheme 52).

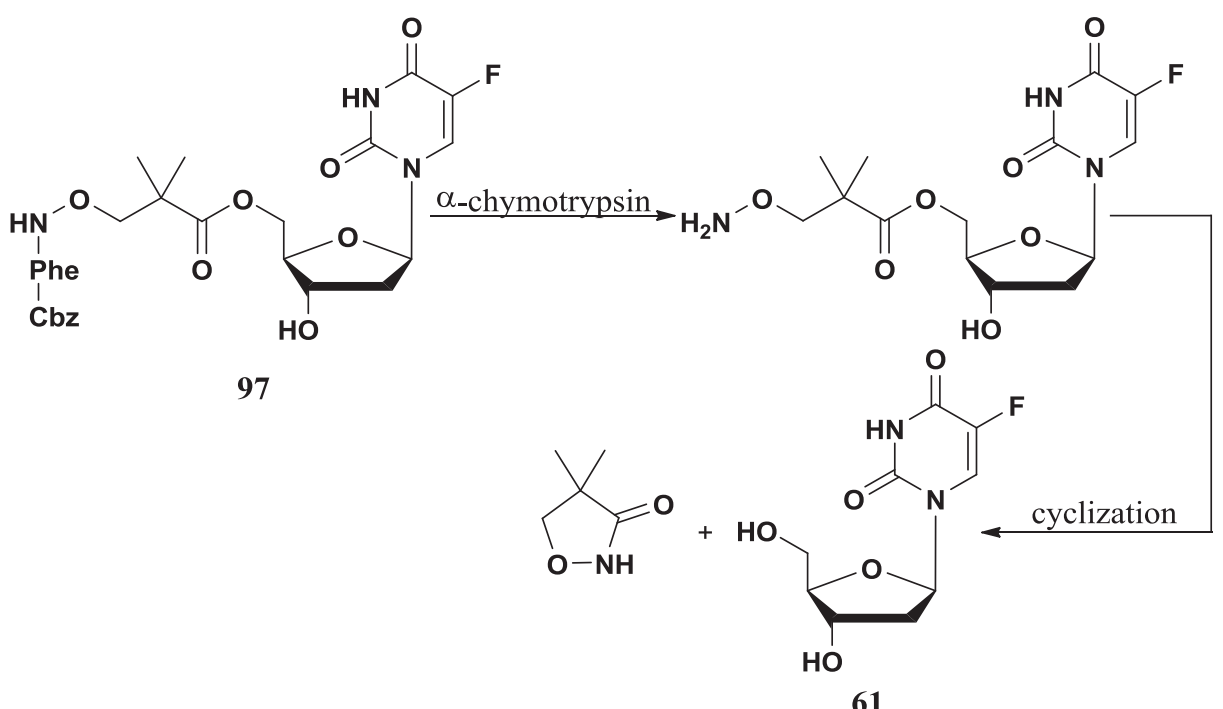

Scheme 52 
470 Floxuridine binding to antibodies in order to drive the cytotoxic activity ${ }^{101,102}$ was also studied; and further photolabile carbonate prodrug 98 was synthesized that, by photolysis, rapidly released floxuridine $\mathbf{6 1}$ (Scheme 53). ${ }^{103}$

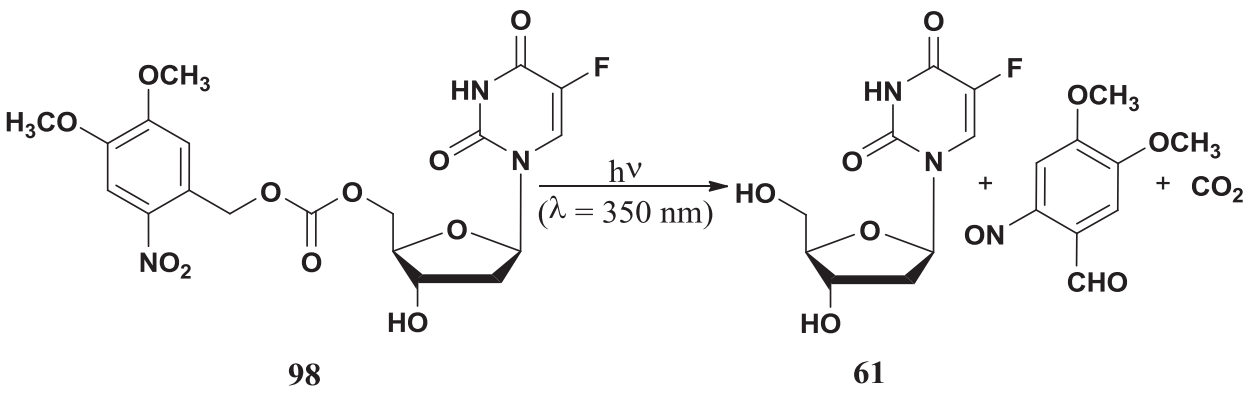

Scheme 53

It is known (see Scheme 1) that floxuridine $\mathbf{6 1}$ is activated by phosphorylation, catalyzed by thymidine kinase (TK), to 5-fluorodeoxyuridine monophosphate (FdUMP) 2, the TS-inhibitor.

475 In TK-deficient tumors floxuridine lost its cytostatic potential. Direct administration of phosphorylated floxuridine has little therapeutic advantage since the charged monophosphate, under physiological conditions, shows poor, if any, penetration across the cell membrane. The administration of lipophilic phosphoramidate 99 can circumvent these problems (Scheme 54). ${ }^{104}$

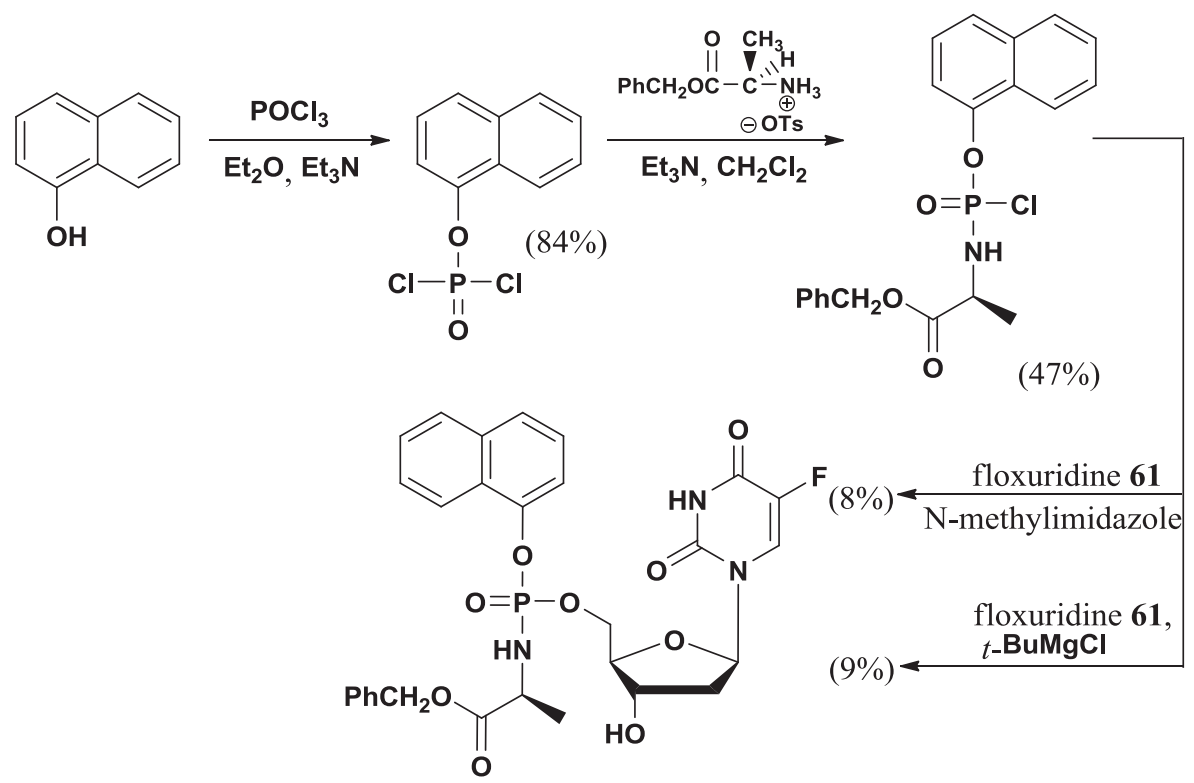

99

Scheme 54

According to a recent patent, a floxuridine prodrug was prepared and a biorthogonal cleav480 age (under biocompatible conditions) was suggested (Scheme 55). ${ }^{105}$ The target of the study was the development of a prodrug releasing the active drug by means of a reaction susceptible to occur in a biological environment without interfering with the normal functions of its 


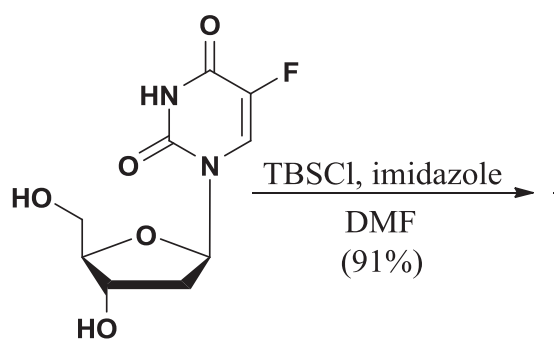

61

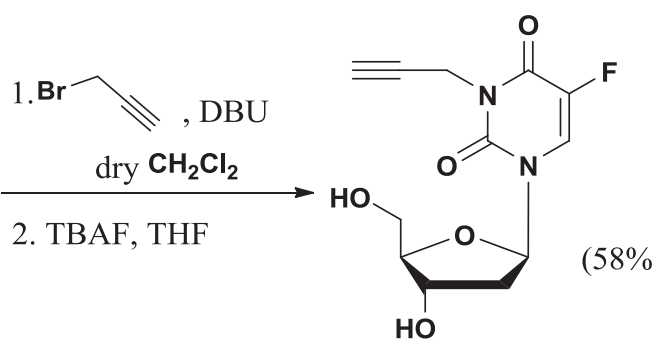

pro-floxuridine

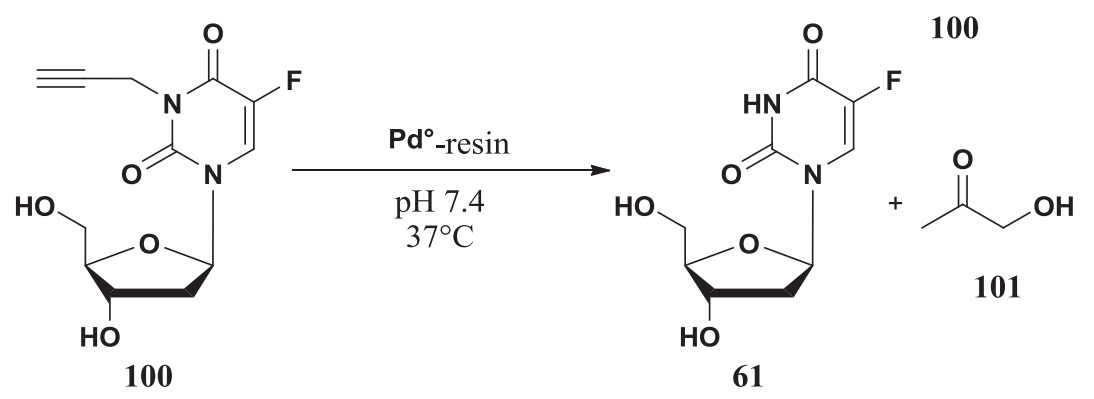

\section{Scheme 55}

component. Thus, 3-propargyl-5-fluoruridine $\mathbf{1 0 0}$ was synthesized and the free active drug was generated using biocompatible palladium catalyst, at $37^{\circ} \mathrm{C}$ and $\mathrm{pH} 7.4$; also the by-product 1hydroxyacetone $\mathbf{1 0 1}$ is biocompatible. Palladium implants, can, therefore, deprotect the prodrug at the disease site, reducing the general systemic concentration of the free drug.

\section{Doxifluridine}

Doxifluridine (5'-deoxy-5-fluorouridine, $5^{\prime}$-DFUR) 62 is a prodrug that requires thymidine phosphorylase (TP) for its one-step conversion to 5-FU 1 . Since TP expression is high in the gastrointestinal tract, doxifluridine therapy resulted in dose-limiting toxicity, such as diarrhea. It is orally administered for the treatment of breast, stomach, colon cancer and nasopharyngeal carcinoma.

A large number of $5^{\prime}$-deoxy nucleosides have been synthesized taking into account that several biologically active nucleosides require the presence of a $5^{\prime}$-hydroxy group for activation, usually by phosphorylation. Removal of this function provides interesting compounds for biochemical and biological studies. 5'-Deoxy compounds are potentially interesting medicinal agents, since such molecules cannot be phosphorylated and incorporated into nucleic acids and thus offer the possibility of reduced toxicity and increased specificity. The $5^{\prime}$-deoxy carbohydrates can be synthesized before the formation of the N-

500 glycosidic bond with the 5-fluoropyrimidine or, alternatively, a preformed nucleoside can be used as starting material for the $5^{\prime}$-modification.

In a 1982 patent, ${ }^{106}$ the 5 -deoxy carbohydrate was prepared, starting from suitably protected D-ribose 102, through 5-bromo derivative 103 (Scheme 56). Removal of the 5bromine atom was achieved by means of a catalytic hydrogenation affording compound

505104 (90\% yield). Deoxy peracetylated sugar 105 was used in the glycosylation reaction affording diacetate of doxifluridine $\mathbf{1 0 6}$ that was deprotected by means of sodium methylate $\left(97 \%\right.$ yield). The same authors, by this method, prepared also the $5^{\prime}$-monodeutero and the $5^{\prime}, 5^{\prime}$-dideutero derivatives and the $\alpha$-anomer of doxifluridine. ${ }^{107}$ 


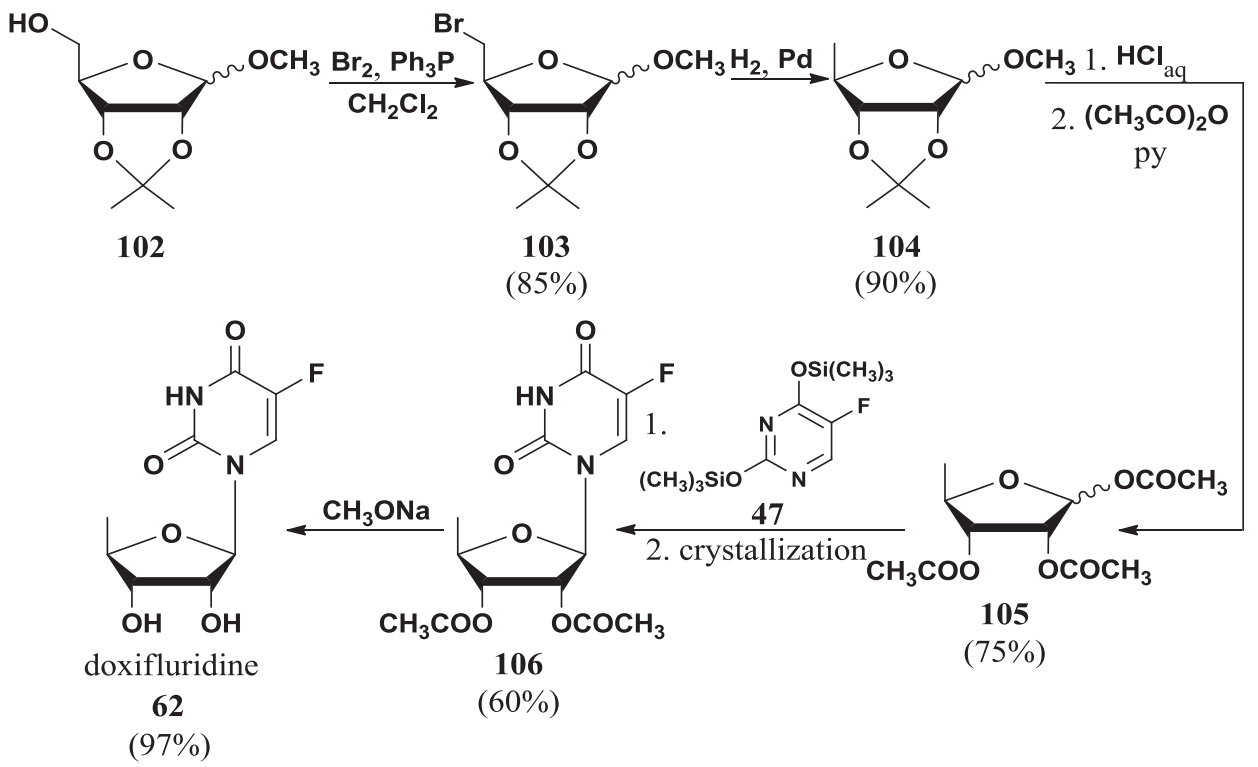

Scheme 56

A modification of the coupling method between the 5'-deoxysugar and the 5-fluoro 510 pyrimidine allowed workers to increase the yields and the purity of the final product, at a temperature below $0{ }^{\circ} \mathrm{C} .^{108}$

In a 1978 article $^{109}$ the $5^{\prime}$-deoxy group was obtained starting from 5-fluorouridine $\mathbf{8 3}$ (Scheme 57), through the simultaneous protection of $2^{\prime}$ - and $3^{\prime}$-hydroxy groups as a cyclic

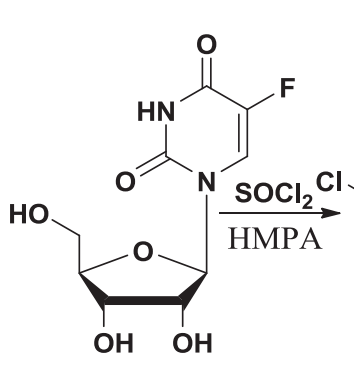

83<smiles>CCCCl</smiles>

107

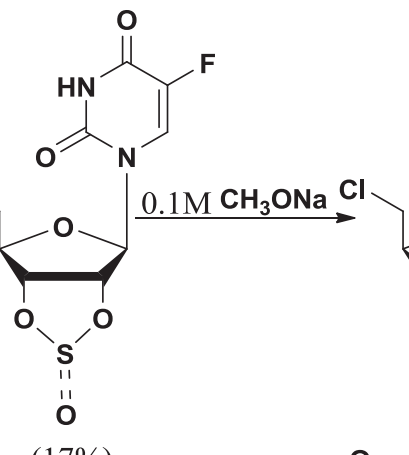<smiles></smiles>

$(86 \%)$

$(17 \%)$

(37\%)

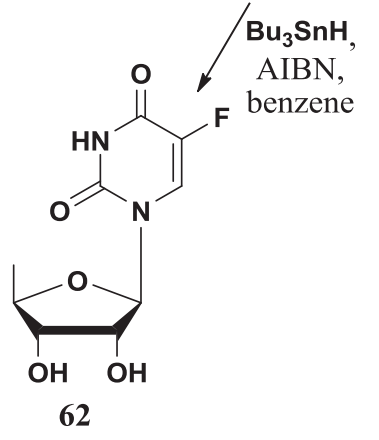

$(57 \%)$

Scheme 57 
sulphinyl derivative, and the substitution of $5^{\prime}$-hydroxy group with a chlorine atom (com515 pounds 107), by means of thionyl chloride. The chlorine atom was then removed by reaction with tributyltin hydride.

Protection of the $2^{\prime}$ - and $3^{\prime}$-hydroxy groups of 5-fluorouridine as the isopropylidene derivative $\mathbf{1 0 8}$, followed by iodination ${ }^{110}$ afforded suitable $5^{\prime}$-iodo intermediate 109 in order to obtain the 5'-deoxy 5-fluoronucleoside $\mathbf{6 2}$ (Scheme 58).

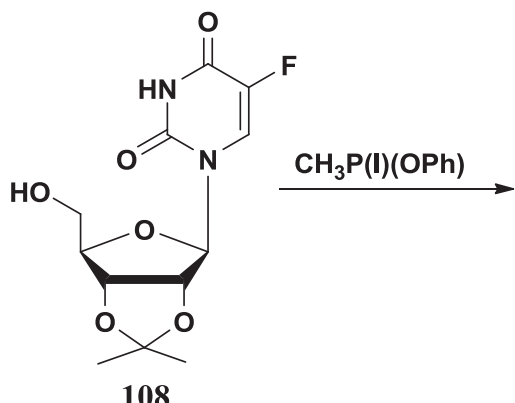

108

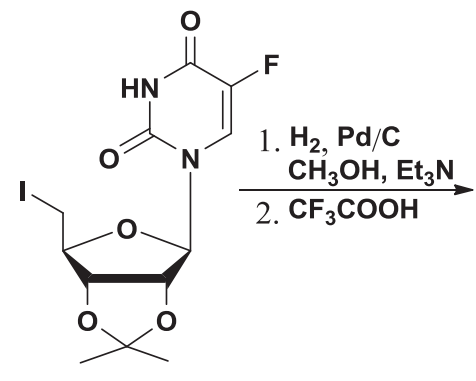

109

$(85 \%)$<smiles>O=c1[nH]c(=O)n([C@@H]2O[C@H](C(O)O)[C@@H](O)[C@H]2O)cc1F</smiles>

$(79 \%)$

Scheme 58

520 The same $5^{\prime}$-iodo derivative, compound 109, as later reported in an Italian patent, ${ }^{111}$ was transformed into the $5^{\prime}$-deoxy nucleoside by removal of the acetonide, followed by reaction with tributyltin hydride in toluene (Scheme 59).

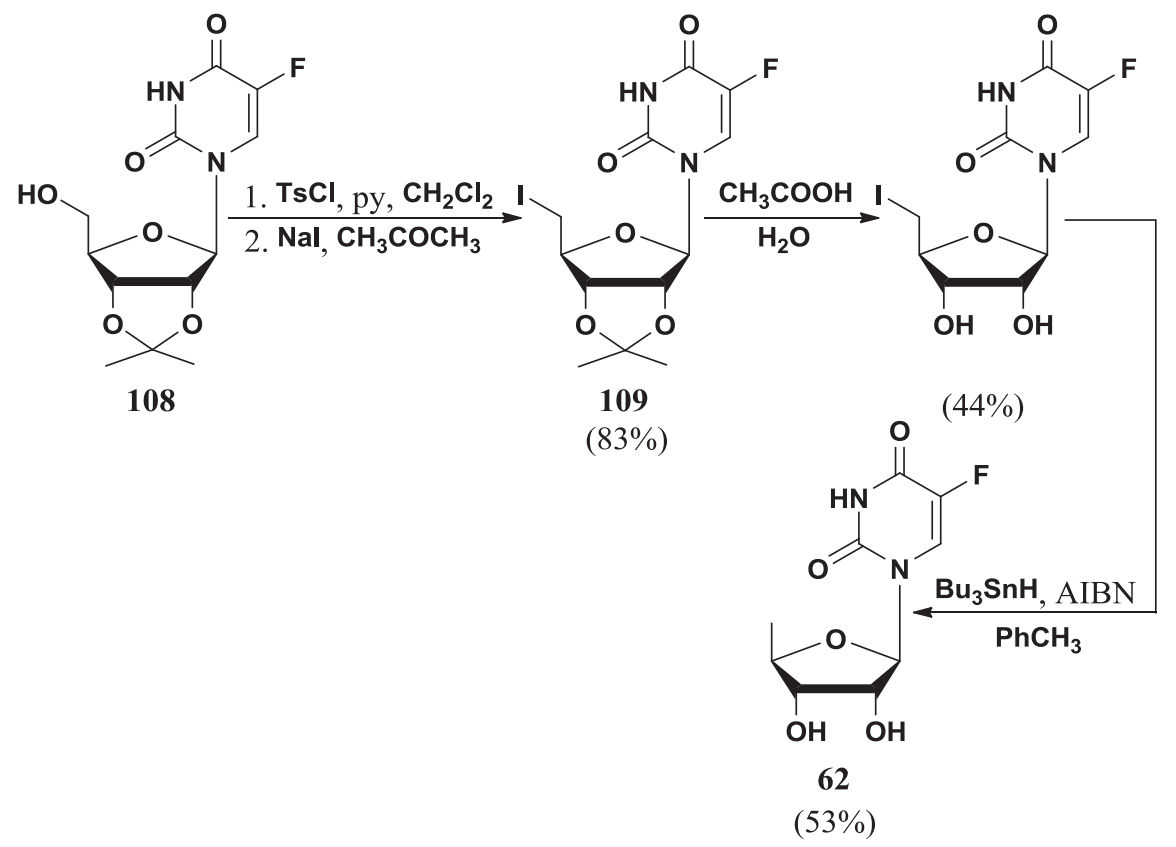

Scheme 59 
Another Italian team in $2009^{112}$ described a chemo-enzymatic approach to the synthesis of doxifluridine through the regioselective enzymatic hydrolysis of triacetyluridine

525110 followed by a phosphorylase-catalyzed transglycosylation (Scheme 60). The regioselective hydrolysis of $5^{\prime}$-acetate was achieved by means of lipase from Pseudomonas fluorescens in $\mathrm{pH} 7$ buffer; the $5^{\prime}$-hydroxy group of compound 111 was transformed into $5^{\prime}$ bromo derivative $\mathbf{1 1 2}$ in two steps. Reduction of $5^{\prime}$-bromonucleoside (tributyltin hydride) and removal of protecting groups afforded $5^{\prime}$-deoxy uridine 113, a suitable substrate for a 530 phosphorylase-catalyzed substitution of the nucleobase.

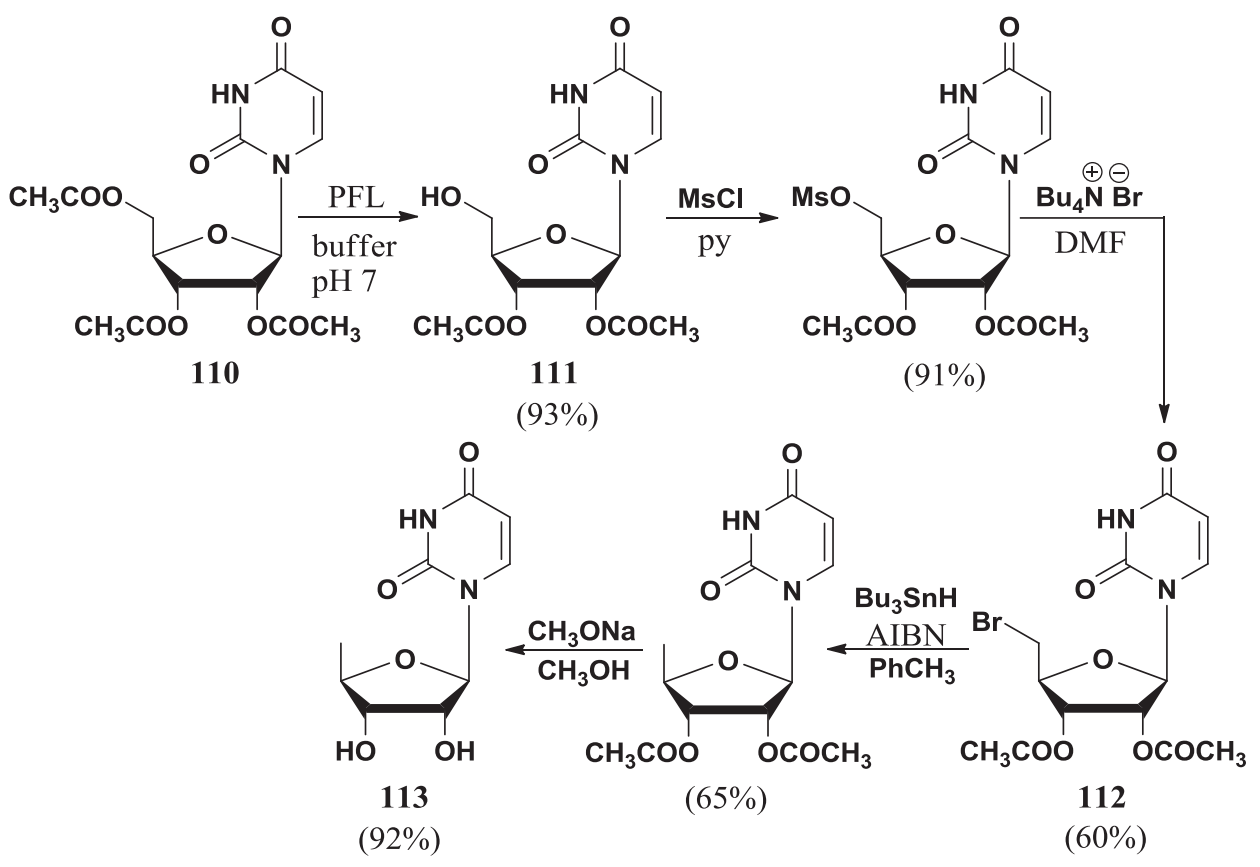<smiles>CC(O)[C@H](O)[C@H]1O[C@@H](C)[C@@H](O)[C@H]1O</smiles>

113

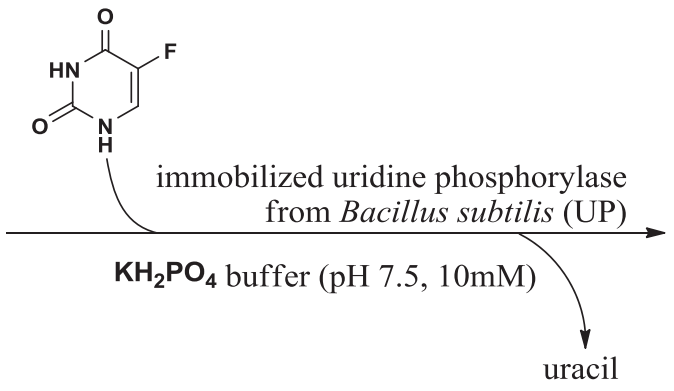

Scheme 60

\section{Capecitabine}

Capecitabine ( $\mathrm{N}^{4}$-pentyloxycarbonyl-5'-deoxy-5-fluorocytidine, Xeloda $\left.{ }^{\circledR}\right)$ 63, an oral prodrug of 5-FU, was designed to circumvent the gastrointestinal toxicity of doxifluridine $\mathbf{6 2}$ and to generate 5-FU preferentially at the tumor site. ${ }^{113-116}$ The activation of capecita535 bine $\mathbf{6 3}$ by transformation into 5-FU required three distinct enzyme-catalyzed steps. After 
oral administration capecitabine passes the intestine unaltered; in the liver the carbamoyl moiety is removed by carboxylesterase; the second step is the conversion to $5^{\prime}$-deoxy-5fluorouridine 62 by cytidine deaminase, an ubiquitous enzyme, ${ }^{117}$ responsible for the deamination of nucleosidic analogs, localized in the liver and in various tumor types.

540 Finally, 5'-deoxy-5-fluorouridine $\mathbf{6 2}$ can be converted to 5-FU in the tumors by thymidine phosphorylase, ${ }^{118}$ an enzyme that leads to the preferential generation of 5-FU in tumors as a result of its overexpression in malignant tissue (Scheme 61).

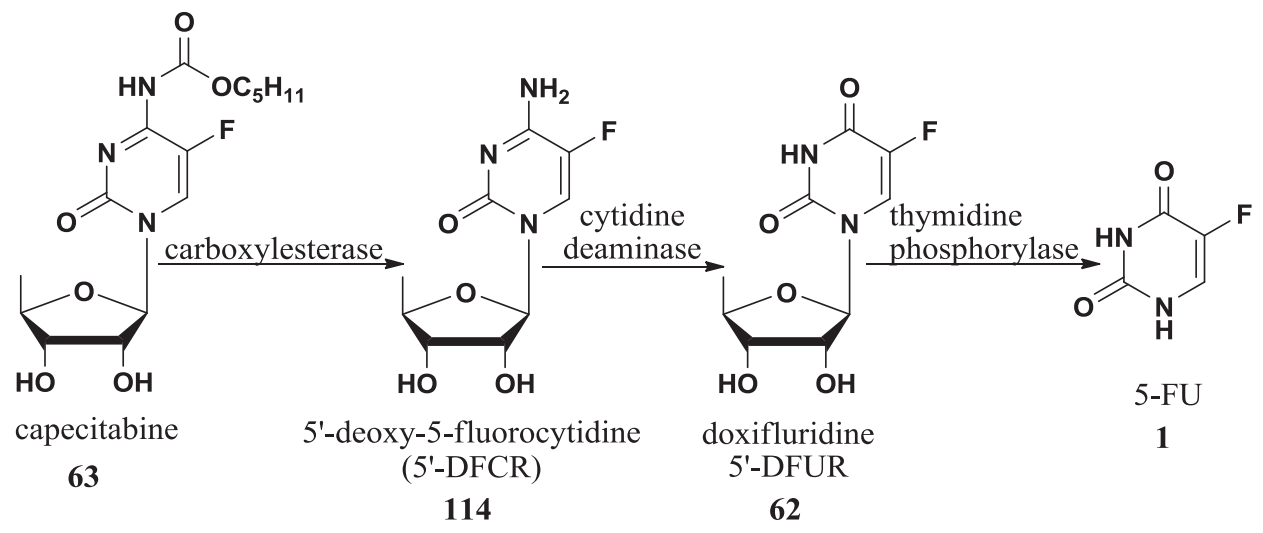

Scheme 61

Capecitabine $\mathbf{6 3}$ is approved in the European Union, USA, Canada and Australia for the treatment of advanced or metastatic colorectal carcinoma. ${ }^{19-122}$ In combination with

545 other antineoplastic agents, it can be utilized also in metastatic breast cancer. ${ }^{123-127}$ Syntheses of capecitabine were reviewed in 2010 in a book chapter. ${ }^{128}$

In the molecule of capecitabine 63 three moieties can be recognized: the 5'-deoxy-D-ribose, the 5-fluoropyrimidine and the pentyloxycarbonyl group. Similarly to the doxifluridine synthesis, the N-glycosylation can be carried out starting from D-ribose, postponing the formation of the $5^{\prime}$ -

550 deoxy group to a subsequent step, or from the previously prepared $5^{\prime}$-deoxy-D-ribose. Also the $\mathrm{N}^{4}$-carbamoyl function can be introduced in the course of different steps of the synthesis.

Several syntheses start from triacetyl-5-deoxy-D-ribose 105 that, in turn, can be prepared from methyl 2,3-O-isopropylidene-D-ribofuranoside 115 through the formation of 5-O-mesyl derivative 116, the substitution of the mesylate group by an iodine atom (compound 117) and

555 the reductive removal of the latter. Deprotection and acetylation followed by crystallization afforded the $\beta$-anomer of 1,2,3-O-triacetyl-5-deoxy-D-ribose 105 (Scheme 62). ${ }^{129}$

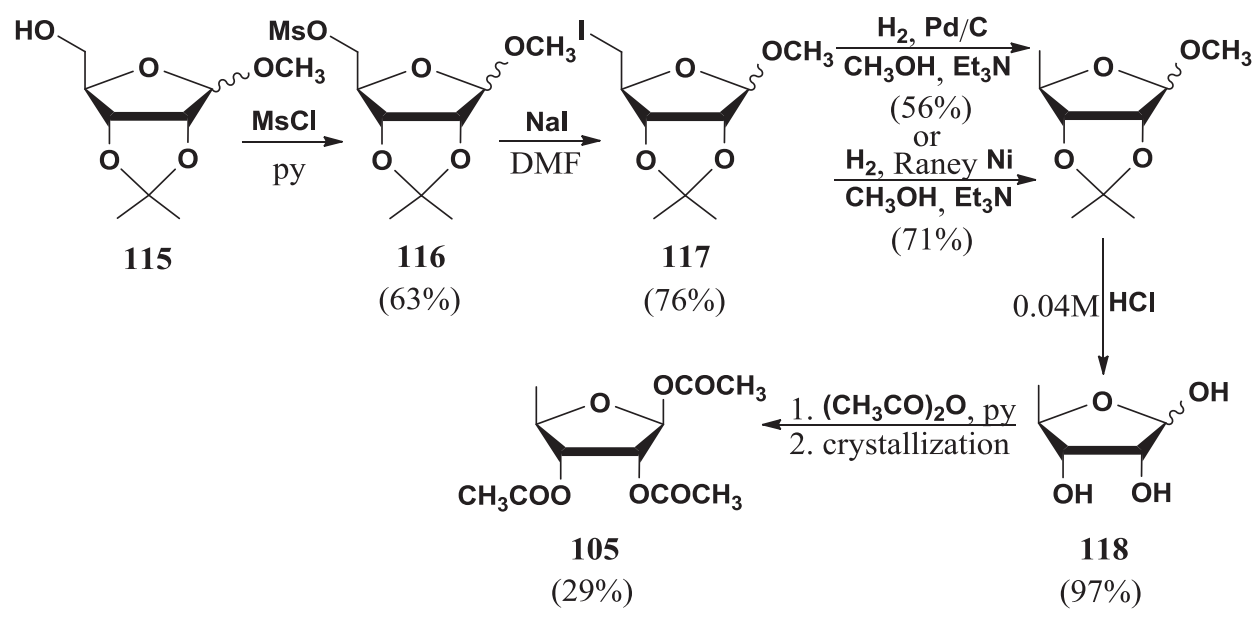

Scheme 62 
Peracetylated 5-deoxy-D-ribofuranoside $\mathbf{1 0 5}$ was also prepared in a different way, starting from 2,3-O-isopropylidene-D-ribofuranoside 115, through the 5-bromo-derivative and used in the $\mathrm{N}$-glycosylation step, as described in the case of doxifluridine synthe560 sis (see Scheme 56 ). ${ }^{106}$

In more recent work ${ }^{130}$ the removal of the 5-hydroxy group was realized through the reduction of suitably protected 5-O-tosyl ester $\mathbf{1 1 9}$ by means of lithium aluminum hydride (Scheme 63); after deprotection and acetylation the 1,2,3-O-triacetyl-5-deoxy-D-ribose 105 was obtained as a $1: 3 \alpha / \beta$ anomeric mixture. A ratio more favorable to the $\beta$-anomer 565 was observed ${ }^{131}$ by modification of the reaction conditions of 5-deoxy-D-ribose acetylation; indeed, using triethylamine in dichloromethane solution as the base, instead of pyridine, the acetylation afforded a 1:13.8 $\alpha / \beta$ anomeric mixture (Scheme 63). Pure $\beta$-isomer $\mathbf{1 0 5}$ was recovered in $80 \%$ overall yield by crystallization.
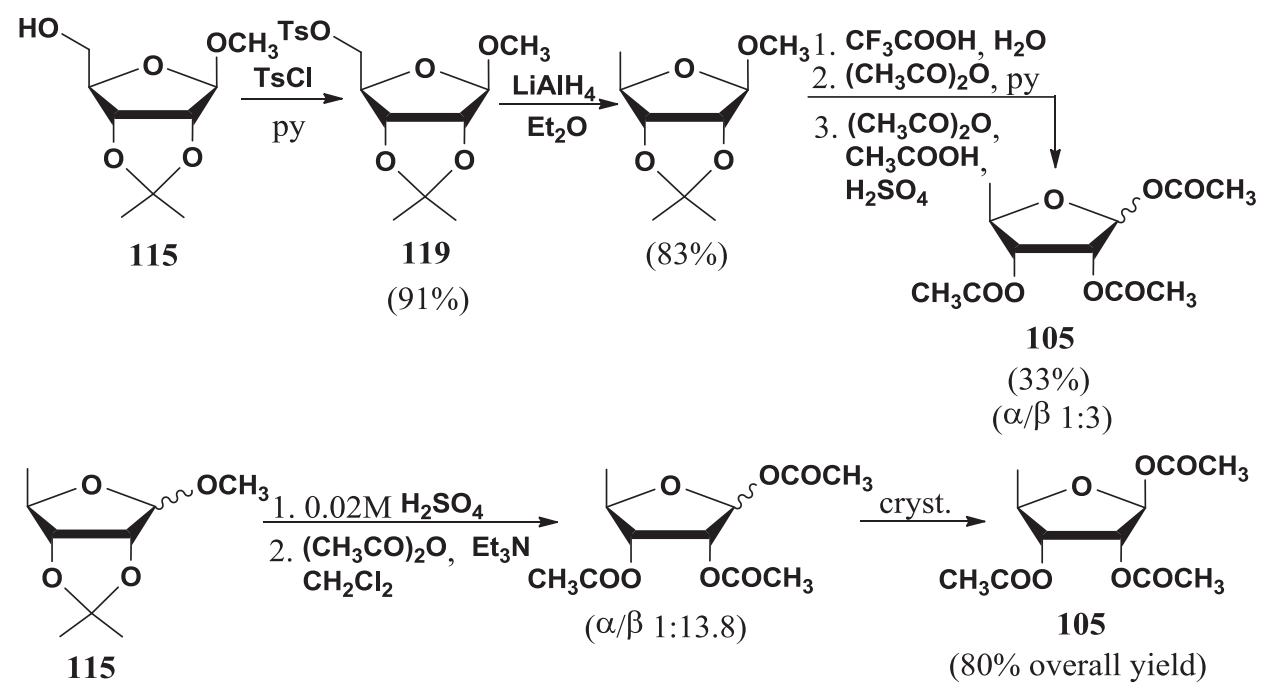

Scheme 63

A different reducing agent for $\mathbf{1 1 9}$ (sodium borohydride in dimethylsulfoxide) ${ }^{132}$ 570 allowed the synthesis of 1,2,3-O-triacetyl-5-deoxy-D-ribose $\mathbf{1 0 5}$ in 56\% overall yield from D-ribose (Scheme 64$)$. Pure $\beta$-anomer was recovered after crystallization (60\%).

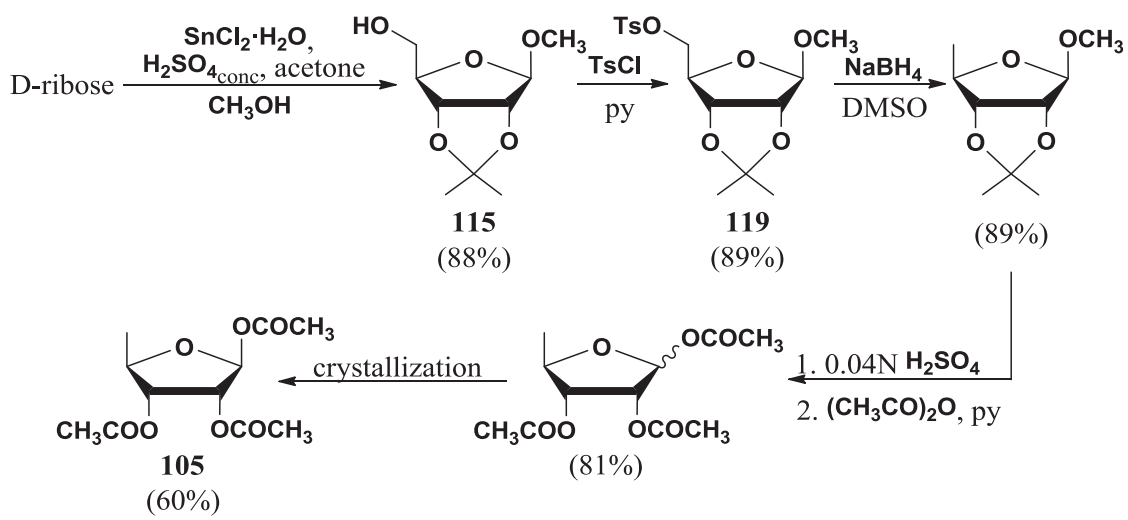

Scheme 64 
An improvement of this method was described in a 2013 Indian patent: ${ }^{133}$ 5-O-Tosyl derivative 119 was obtained, avoiding the use of pyridine, by reaction of 1-O-methyl-2,3O-isopropylidene-D-ribose $\mathbf{1 1 5}$ with para-toluensulfonyl chloride and sodium hydroxide in toluene, in the presence of tetrabutyl ammonium bromide (Scheme 65).

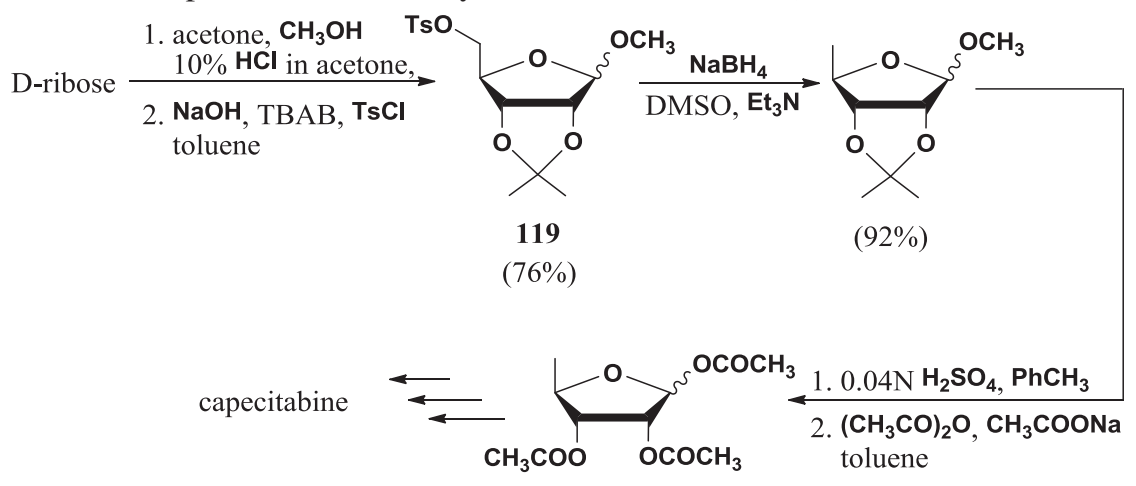

$(82 \%)$

Scheme 65

In $2000,{ }^{134}$ 1,2,3-O-triacetyl-5-deoxy-D-ribose $\mathbf{1 0 5}$ was used as starting material for the glycosylation of the silyl derivative of 5-fluorocytosine $\mathbf{1 2 0}$ in the presence of stannic tetrachloride or trimethylsilyl iodide. Reaction with $n$-pentyl chloroformate and removal of protecting groups afforded the desired capecitabine $\mathbf{6 3}$ (Scheme 66). Instead of stannic tetrachloride, triflic acid can be used as acid catalyst. ${ }^{135}$

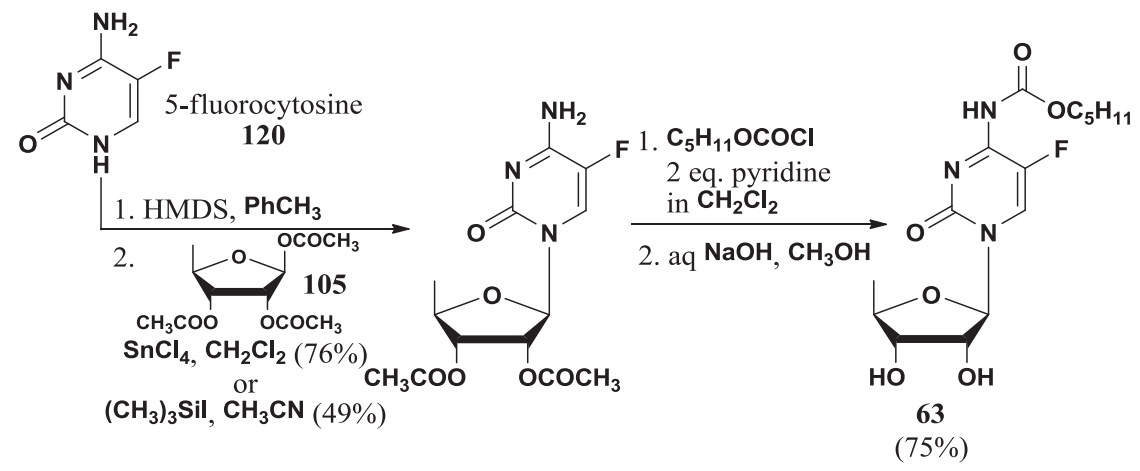

Scheme 66

The N-glycosylation was also carried out without silylating agent, in a "one-pot" procedure that afforded capecitabine $\mathbf{6 3}$ in $60 \%$ yield (Scheme 67). ${ }^{136}$

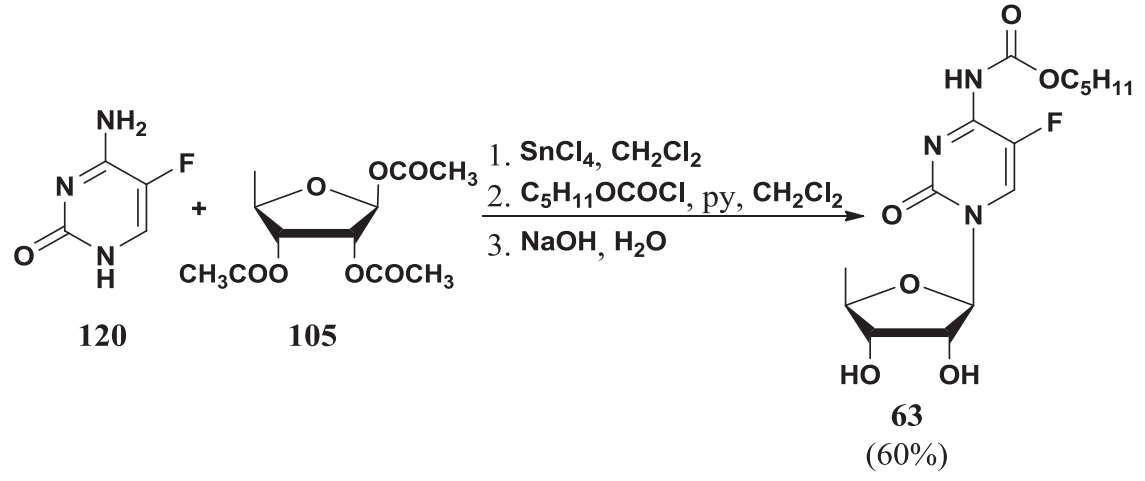


Other syntheses were designed starting from a differently protected 5-deoxy-Dribose. For example 5-deoxy-D-ribose 118 was transformed into corresponding ace585 tonide $\mathbf{1 2 1}$ by reaction with 2,2-dimethoxypropane in the presence of para-toluensulfonic acid, in dimethylformamide as solvent. Acetylation of the 1-hydroxy group afforded the suitable intermediate, compound 122, for the glycosylation of $\mathrm{N}^{4}$-pentyloxycarbonyl-5-fluorocytosine $\mathbf{1 2 3}$ under the usual conditions. Acidic treatment (Amberlyst 15) of obtained $\mathbf{1 2 4}$ afforded final capecitabine $\mathbf{6 3}$ 590 (Scheme 68). ${ }^{137}$

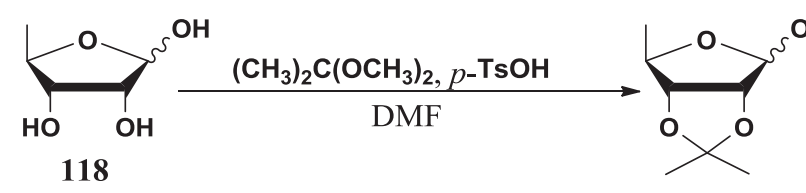<smiles>C[SbH2]C(=O)OCCSC(=O)Cl</smiles>

120
121<smiles>CCCCCOC(=O)Nc1nc(=O)[nH]cc1F</smiles><smiles>CN=CC=NC</smiles>

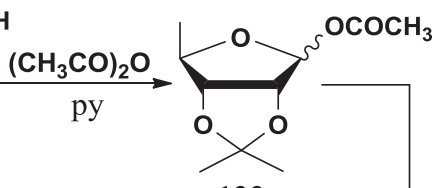
122 (72\%)
123

(56\%) (29\%)

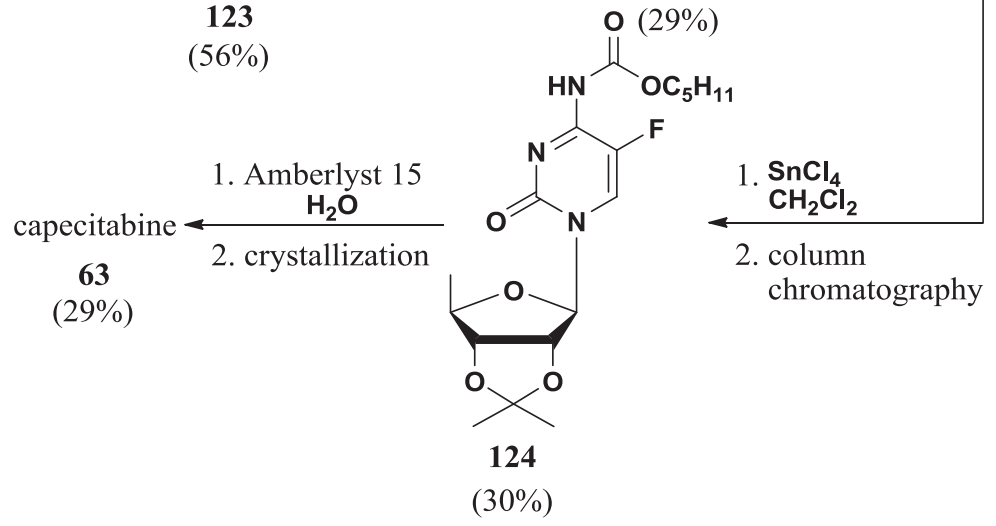

Scheme 68

The 1,2,3-hydroxy groups of 5-deoxy-D-ribose 118 were also protected as methyl carbonates (compound 125) providing a $1: 2.7 \alpha / \beta$ anomeric mixture (63\%) that was directly used in the glycosylation step. $2^{\prime}, 3^{\prime}$-Protected-5'-deoxy-5-fluorocytidine $\mathbf{1 2 6}$ was recovered, after precipitation of undesired by-products, and submitted to the reaction 595 with pentyl chloroformate; removal of $2^{\prime}, 3^{\prime}$-carbonates under basic conditions and crystallization afforded capecitabine $\mathbf{6 3}$ (Scheme 69). ${ }^{138}$

A mixture of $\alpha$ - and $\beta$-anomers of 1,2,3-tri-O-acetyl-D-5-deoxy-ribose 105, was also used in the glycosylation of $\mathrm{N}^{4}$-pentyloxycarbonyl-5-fluorocytosine $\mathbf{1 2 3}$, that is on the 5fluorocytosine already derivatized on the $4-\mathrm{NH}_{2}$ (Scheme 70). ${ }^{139}$ 


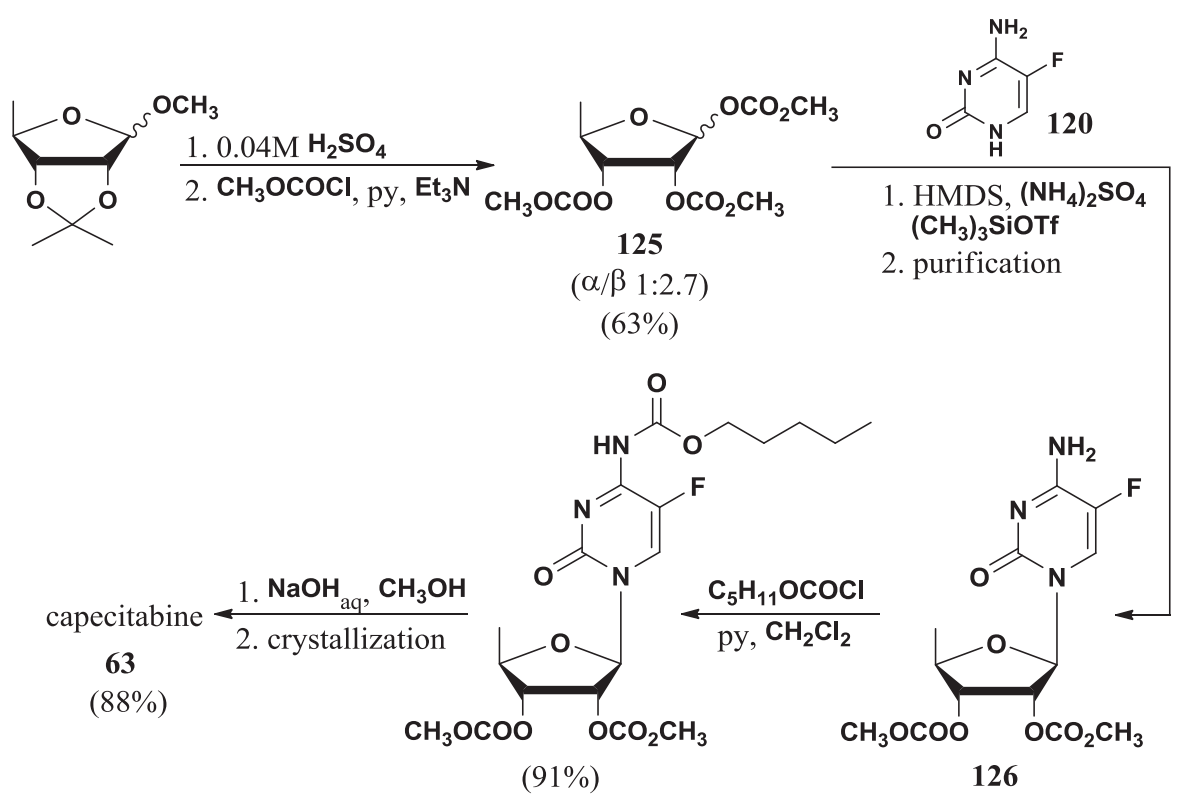

Scheme 69

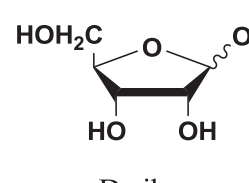

D-ribose

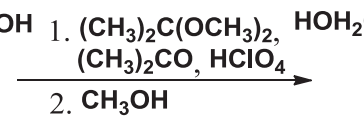

(n)

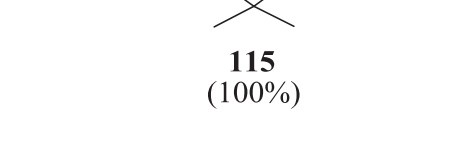

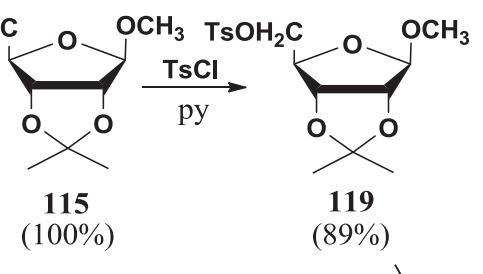

$\mathrm{NaBH}_{4} \backslash \mathrm{DMSO}$

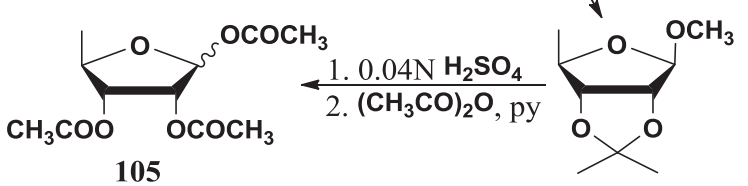

$(49 \%)$

$(100 \%)$<smiles>Cc1c[nH]c(=O)nc1N</smiles><smiles>CCCCCOC(=O)Nc1nc(=O)[nH]cc1F</smiles>

(2 equiv.)<smiles>CO[C@H](OC(C)=O)C(OC(C)=O)OC(C)=O</smiles>

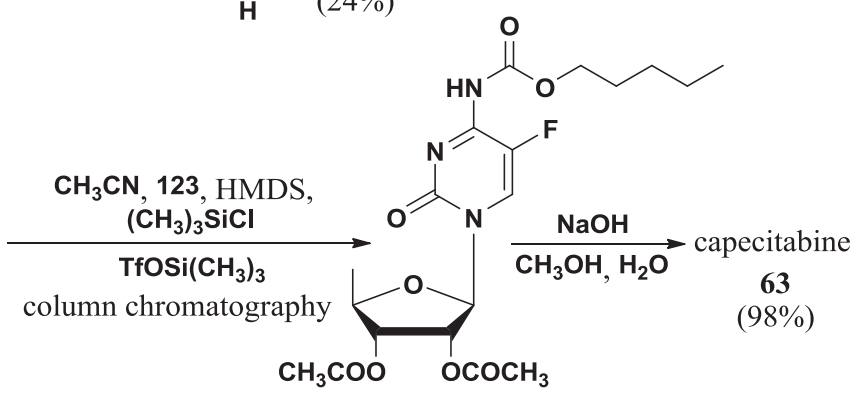


600 The preparation of the $\mathrm{N}^{4}$-pentyloxycarbonyl derivative seems to be the crucial step of this synthesis.

The introduction of the carbamoyl function, according to two Hoffman-La Roche patents, published in $1995,{ }^{140,141}$ was postponed to the last step of the synthesis. In one case ${ }^{141}$ the $\mathrm{N}^{4}$-functionalization was realized directly on $5^{\prime}$-deoxy-5-fluorocytidine $\mathbf{1 1 4}$

605 affording in $92 \%$ yield $5^{\prime}$-deoxy-2 $2^{\prime}, 3^{\prime}$-di-O-pentyloxycarbonyl-5-fluoro- $\mathrm{N}^{4}$-pentyloxycarbonylcytidine 128 . The $2^{\prime}, 3^{\prime}$-carbonates were removed with aqueous sodium hydroxide in methanol (Scheme 71).

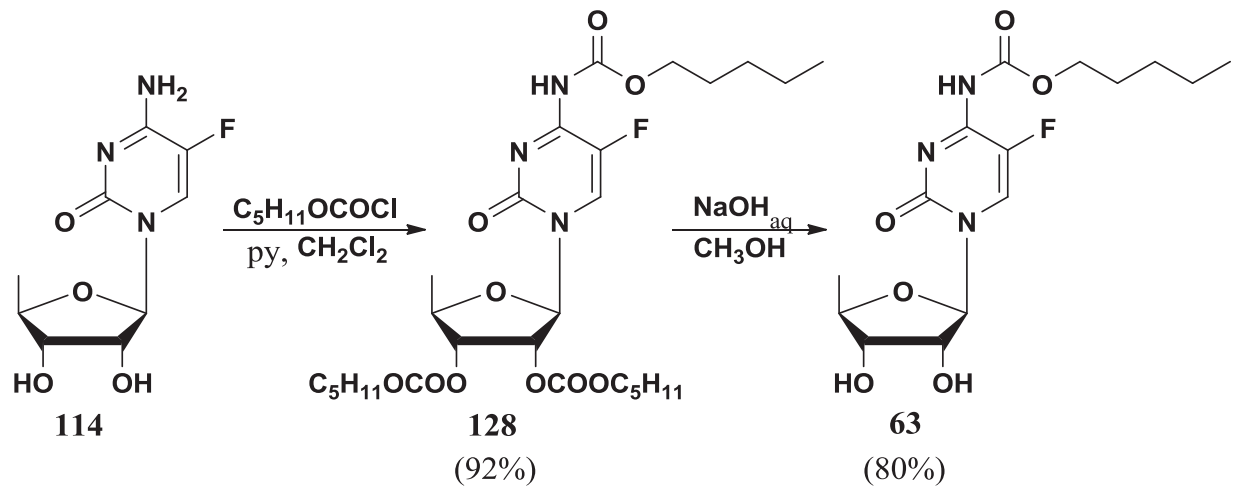

Scheme 71

An improvement of the preparation of the $\mathrm{N}^{4}$-pentyloxycarbonyl derivative was obtained by Teva by modifying the reaction conditions: ${ }^{142}$ choosing 2 -methyltetrahydro-

610 furan as solvent, the pyridine amount was significantly reduced (1.7 eq), avoiding its removal by evaporation in the course of work-up. After removal of acetates from compound $\mathbf{1 2 9}$ pure capecitabine $\mathbf{6 3}$ in $86 \%$ yield was obtained (Scheme 72).

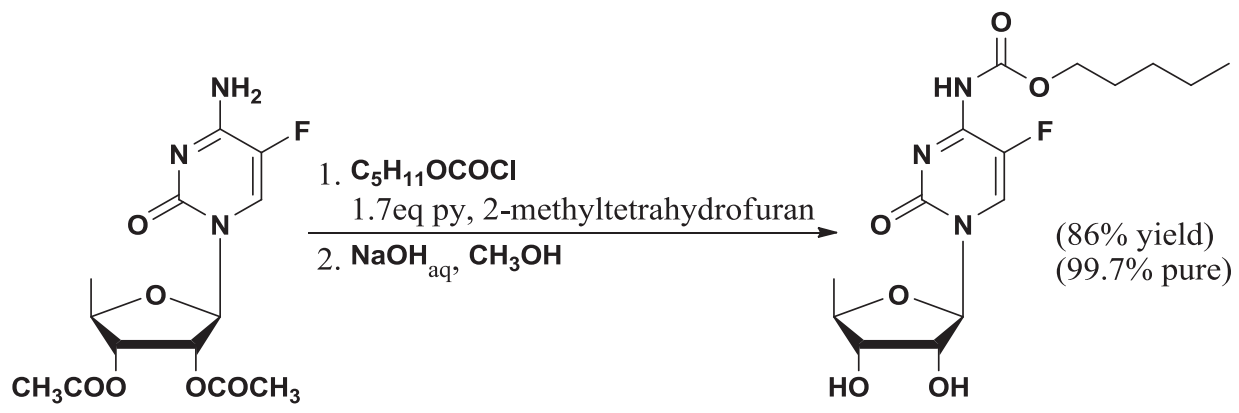

129
63

Scheme 72

Attempts to introduce the pentyloxycarbonyl group directly on an unprotected $5^{\prime}$ deoxy-fluorocytidine led to the development of new reagents, different from the usual

615 pentylchloroformate, able to selectively functionalize the N-4. With this purpose in mind, starting from $\mathrm{N}$-hydroxysuccinimide ${ }^{143}$, a new pentylcarbonate $\mathbf{1 3 0}$ was recently prepared in $98 \%$ yield that selectively functionalized the unprotected $5^{\prime}$-deoxy-fluorocytidine at $\mathrm{N}$ 4, affording capecitabine $\mathbf{6 3}$ in $44 \%$ yield (Scheme 73 ). 


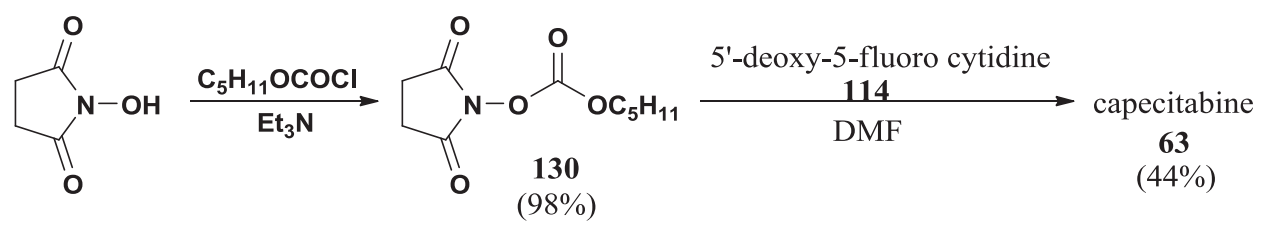

Scheme 73

With the same aim, some pentyloxycarbonylation reagents like hydroxybenzotria620 zole-131 and pentafluorophenoxyderivative, 132 were prepared ${ }^{144}$ and used to selectively form capecitabine 63 from 5'-deoxy-fluorocytidine 114, in 66 and 67\% yield, respectively (Scheme 74).

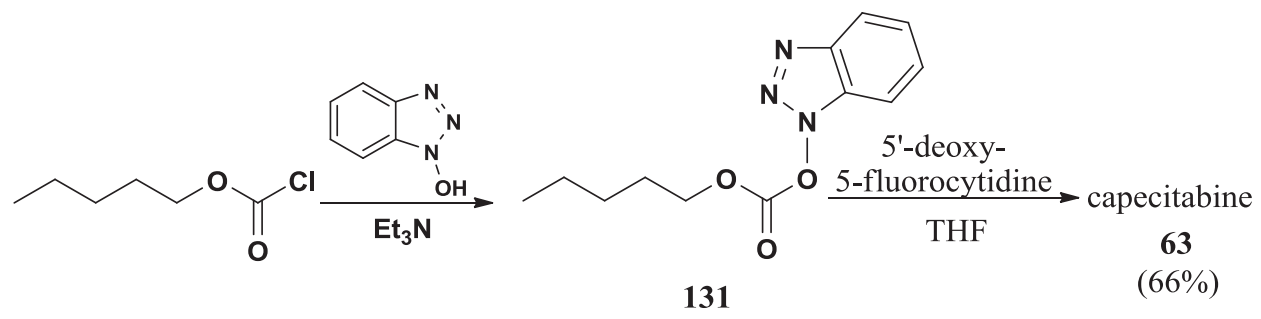

$(84 \%)$<smiles>CCCCCOC(=O)Cl</smiles>

132

$(94 \%)$

\section{Scheme 74}

The same authors also published a method ${ }^{145}$ for the preparation of $\mathrm{N}$-functionalized cytidine that, using pentylchloroformate, required the protection of $2^{\prime}$ and $3^{\prime}$-hydroxy 625 groups, obtained through the formation, by reaction with thionyl chloride, of cyclic sulfinyl ester 133, easily purified by crystallization (85\% yield). After the $\mathrm{N}^{4}$-functionalization $(85 \%)$, the sulfinyl ester of compound 134 was removed by treatment with $1 \mathrm{M}$ sodium hydroxide and methanol affording capecitabine $\mathbf{6 3}$ (82\%) (Scheme 75).

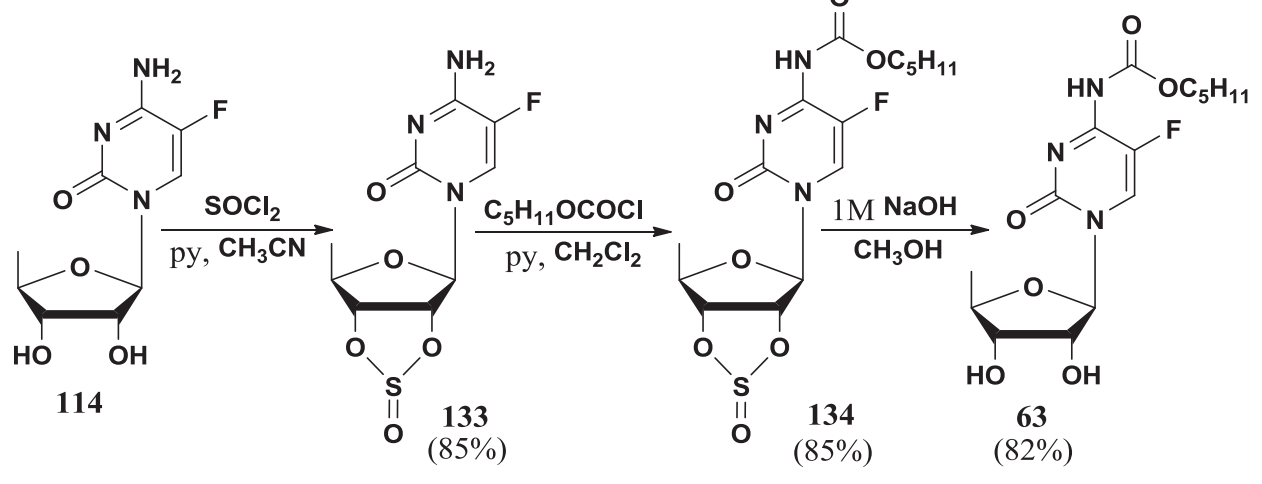

Scheme 75 
Recently a continuous synthesis ${ }^{146}$ (Scheme 76 ) was reported: the synthetic pathway starts 630 from 1,2,3-O-triacetyl-5-deoxy-D-ribose $\mathbf{1 0 5}$ and the glycosylation is catalyzed by a Brønsted acid chosen from among the piridinium triflates. Capecitabine $\mathbf{6 3}$ is recovered at the end of the one-flow, multistep synthesis in $72 \%$ yield. This method was applied also to other $5^{\prime}$-deoxyribonucleosides as the previously reported doxifluridine $\mathbf{6 2}$ (89\%) and galocitabine 135 (see below).

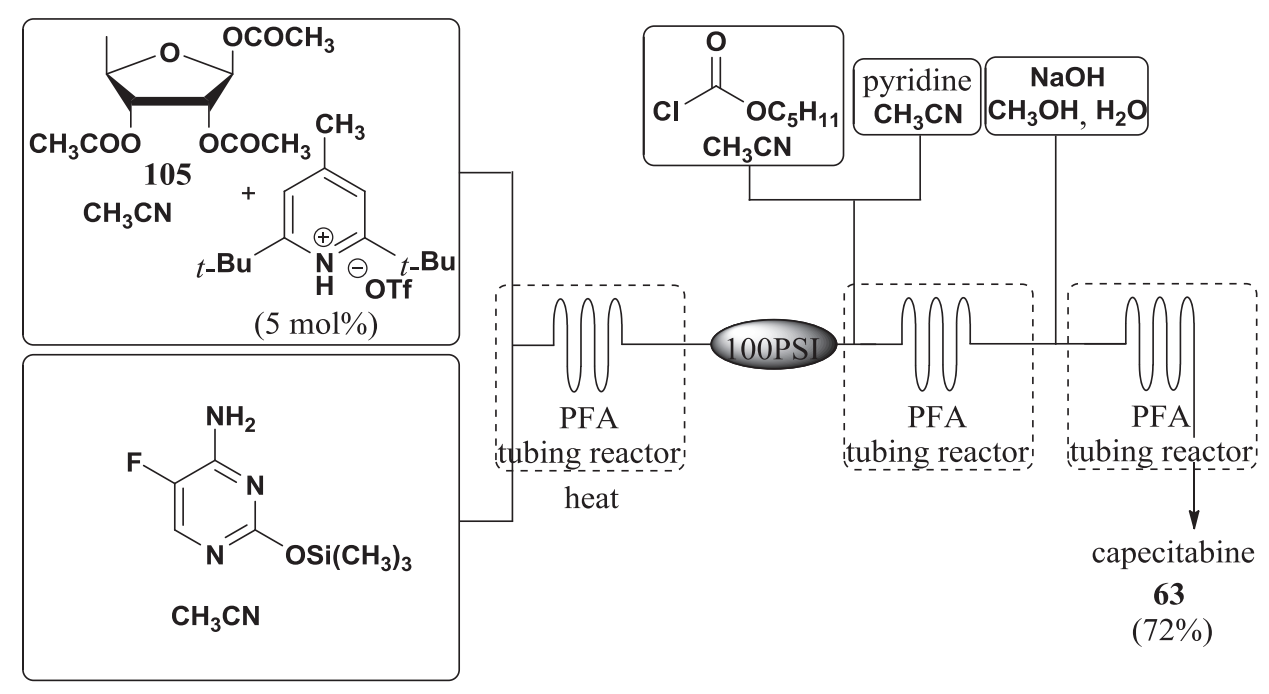

PFA $=$ perfluoroalkoxy

Scheme 76

Since capecitabine $\mathbf{6 3}$ is an active pharmaceutical ingredient the identification and 635 the determination of its impurities, as well as the optimization of HPLC methods are very important aspects to be considered together with the synthetic procedures. Some HPLC methods ${ }^{142,147}$ and some purification processes utilized for the preparation of substantially pure capecitabine were reported. ${ }^{148,149}$ In one of these patents ${ }^{149}$ is mentioned the possibility of removing the $2^{\prime}, 3^{\prime}$-O-acetyl groups by means of a hydrolytic enzyme, an

640 unspecified lipase. On the other hand the chemo-enzymatic approach is very attractive for a polyfunctional compound such as capecitabine 63, considering the capability of enzymes to catalyze selective transformations.

The enzyme-catalyzed regioselective hydrolytic removal of $5^{\prime}$-acetate from nucleoside triacetate 110 (See Scheme 60) ${ }^{112}$ allowed workers to obtain the $5^{\prime}$-hydroxy-2', $3^{\prime}$ di-

645 O-acetyl derivative $\mathbf{1 1 1}$ suitable for the reductive removal of the $5^{\prime}$-hydroxy group, necessary to obtain the $5^{\prime}$-deoxy nucleoside. In a previous patent ${ }^{150}$ the same research team reported the results about the selective deprotection of hydroxy groups of nucleosides polyesters by means of immobilized lipases; moreover, the topic of regioselective lipase catalyzed transformations of nucleosides is treated exhaustively. In $2008,{ }^{151}$ they applied the 650 enzymatic regioselective hydrolysis of $5^{\prime}$-O-acetyl group to the $2^{\prime}, 3^{\prime}, 5^{\prime}$-tri-O-acetyl-5-fluorocytidine 136 and to $\mathrm{N}^{4}$-pentyloxycarbonyl-5-fluoro-2', $3^{\prime}, 5^{\prime}$-tri-O-acetyl cytidine 137 (Scheme 77) obtaining advanced intermediates of capecitabine synthesis. High yields were obtained in both $4-\mathrm{NH}_{2}$ compound 136 (80-97\%, immobilized Candida rugosa lipase as enzyme) and $\mathrm{N}^{4}$-derivativative 137. On this last substrate the highest yield $655(92 \%)$ was obtained by using the immobilized protease $\mathrm{N}$ from Bacillus subtilis. 


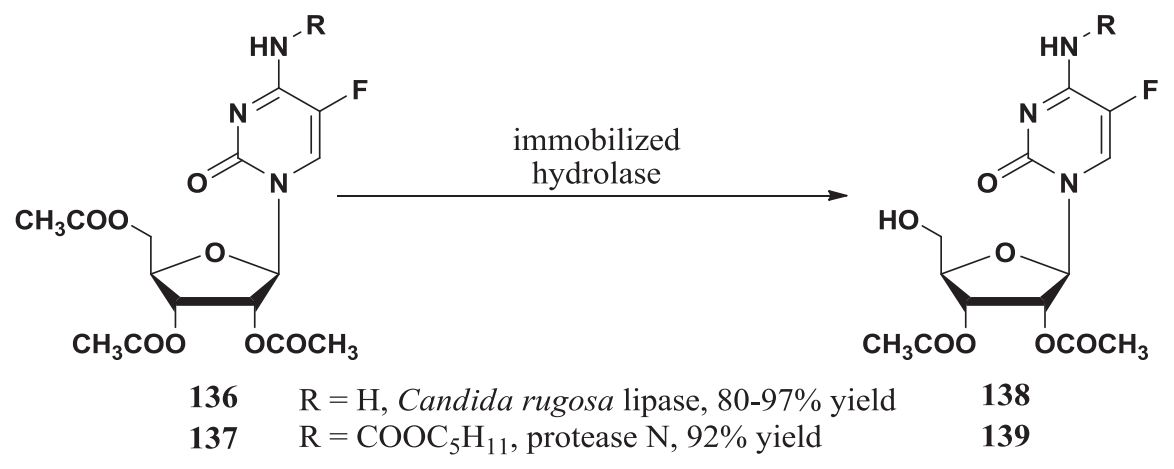

Scheme 77

The same regioselective hydrolysis was also studied comparing immobilized recombinant or commercially available lipases from Candida rugosa. ${ }^{152}$

More recently, ${ }^{153}$ the chemo-enzymatic approach to a capecitabine intermediate, compound 140, quite similar to that prepared by Cook and co-workers in $1979^{110}$ 660 (Scheme 78) for doxifluridine 62 synthesis, was studied.

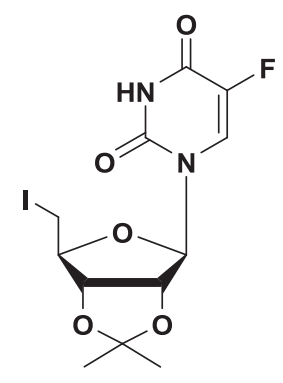

Cook's intermediate

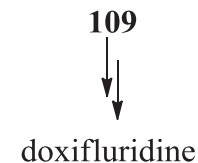

62

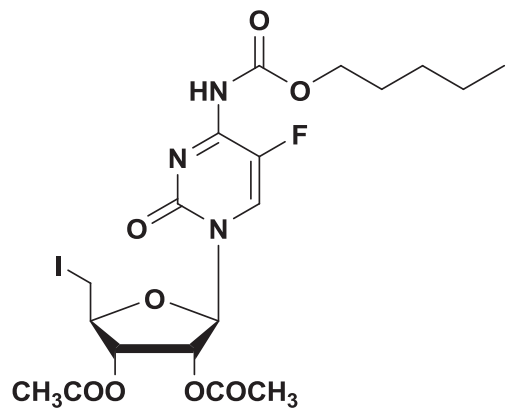

intermediate from chemoenzymatic approach

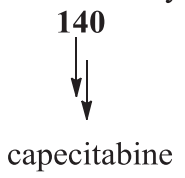

63

Scheme 78

$2^{\prime}, 3^{\prime}, 5^{\prime}$-Tri-O-acetyl-5-fluoro- $\mathrm{N}^{4}$-pentyloxycarbonyl-cytidine 137 , substrate of the enzymatic reaction, was prepared as depicted in enzymes, the best results being observed in the case of a cross linked aggregate preparation of the protease from Bacillus licheniformis (subtilisin), the Alcalase-CLEA ${ }^{\circledR}$ : at $96 \%$ conversion the $5^{\prime}$-acetate was removed 665 almost exclusively (91\%). In order to transform advanced intermediate 139 into the final capecitabine a careful study about the more suitable $5^{\prime}$-functional group and reducing agent was necessary. The $5^{\prime}$-deoxynucleoside was obtained starting from $5^{\prime}$ - 


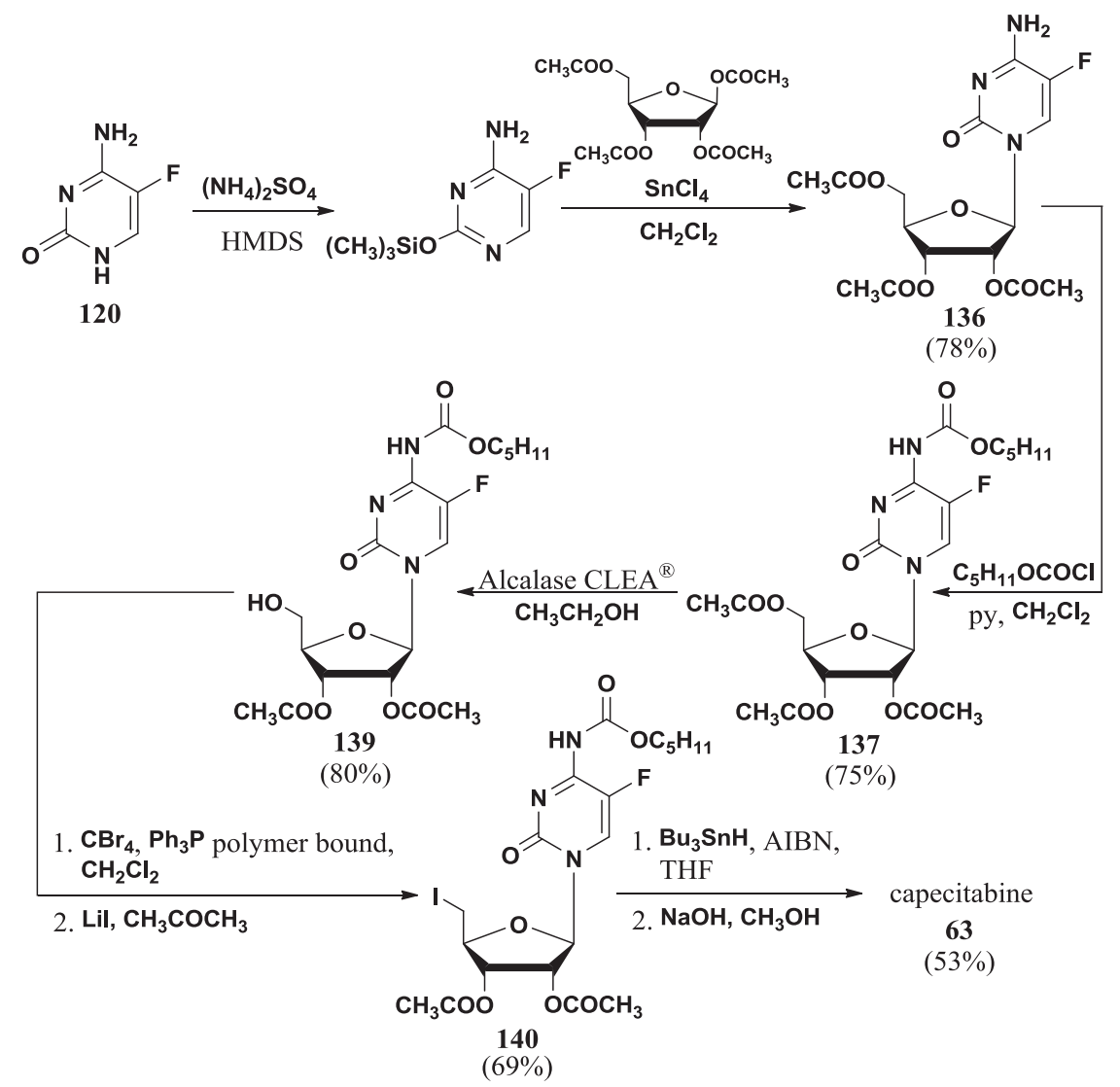

Scheme 79

iododerivative $\mathbf{1 4 0}$ by reaction with tributyltin hydride, followed by deprotection of the $2^{\prime}, 3^{\prime}$-O-diacetyl groups (Scheme 79). The CLEA preparation increases the stability of the 670 enzyme in alcoholic solutions and allows an easier work-up. The work includes the ${ }^{1} \mathrm{H}$ and ${ }^{13} \mathrm{C}$ NMR analyses of the nucleosidic intermediates and of the final capecitabine. Scheme 79, starting from commercially available intermediates. Triacetate $\mathbf{1 3 7}$ was treated, under alcoholysis conditions, with some hydrolytic

Finally, another chemo-enzymatic approach was described in $2015 .^{154}$ In this 675 case, similarly to an already described doxifluridine 62 synthesis ${ }^{112}$ the biocatalyzed reaction was a transglycosylation reaction of $5^{\prime}$-deoxyuridine $\mathbf{1 1 3}$ and the preformed nucleobase of capecitabine, namely $\mathrm{N}^{4}$-pentyloxycarbonyl-5-fluorocytosine 123; the employed enzyme was a pyrimidine nucleoside phosphorylase (Scheme 80).

After the introduction in therapy of capecitabine 63, several analogues were synthe680 sized and submitted to biological tests with the aim of enhancing its efficacy. Mainly, the modifications were carried out on the N-4 position where different groups, such as for instance $\mathrm{BOC}^{155}$, were introduced instead of the pentylcarbamate.

The substitution of an N-4 bonded group can lead to a prodrug that, in hypoxic environments typical of solid tumors, can be reduced by one-electron processes that are 685 inhibited in the normoxic environment of normal tissues. Radiolysis can activate a 


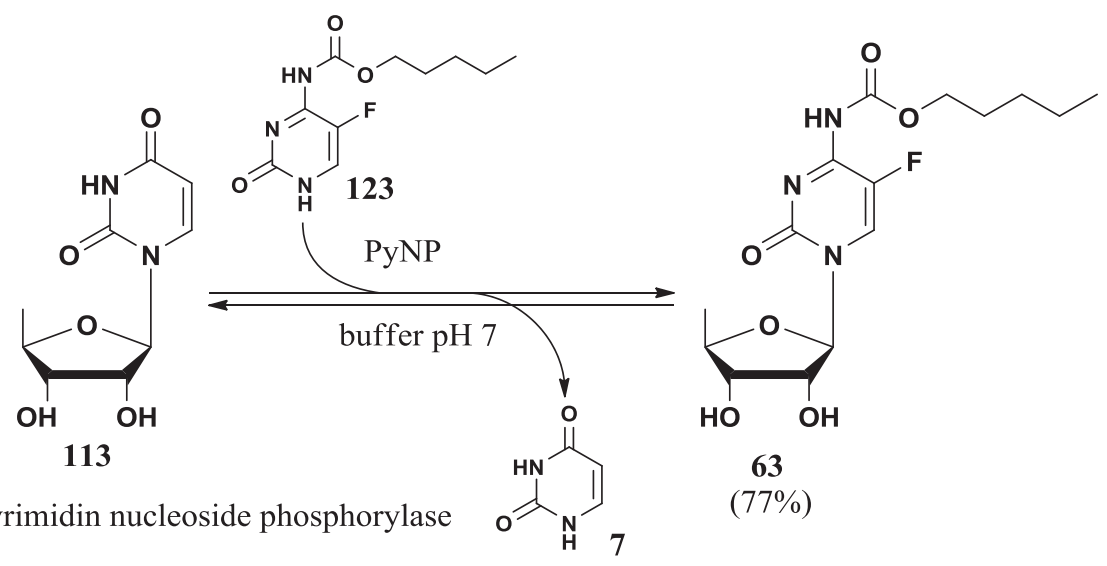

Scheme 80

prodrug to release the active drug after one-electron reduction. An example of a suitable prodrug for radiolysis is $\mathrm{N}^{4}$-nitrothienylderivative $\mathbf{1 4 1}$ described in a 2006 patent (Scheme 81). ${ }^{156}$<smiles>CCCCCOC(=O)Nc1nc(=O)n([C@@H]2O[C@@H]3O[C@@H]([C@@H](O)C3O)[C@H]2O)cc1F</smiles>

63<smiles></smiles>

114 $(90 \%)$

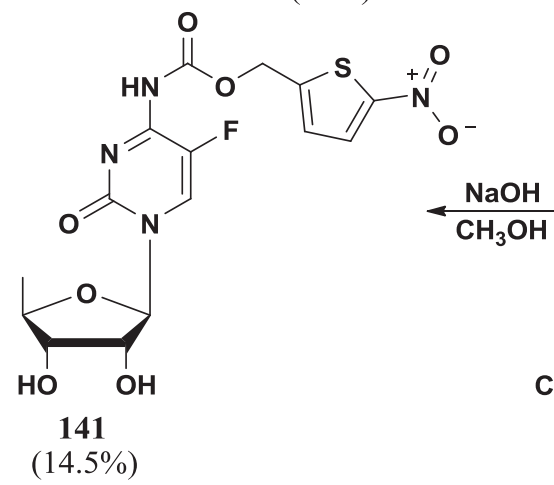

129
$(90 \%)$

Scheme 81

Some 2',3'-O-cyclic carbonates $\mathbf{1 4 2}$ modified at N-4 showed potent antitumor activ690 ity against a leukemia cell line. ${ }^{157}$ Their synthesis is reported in Scheme 82. 


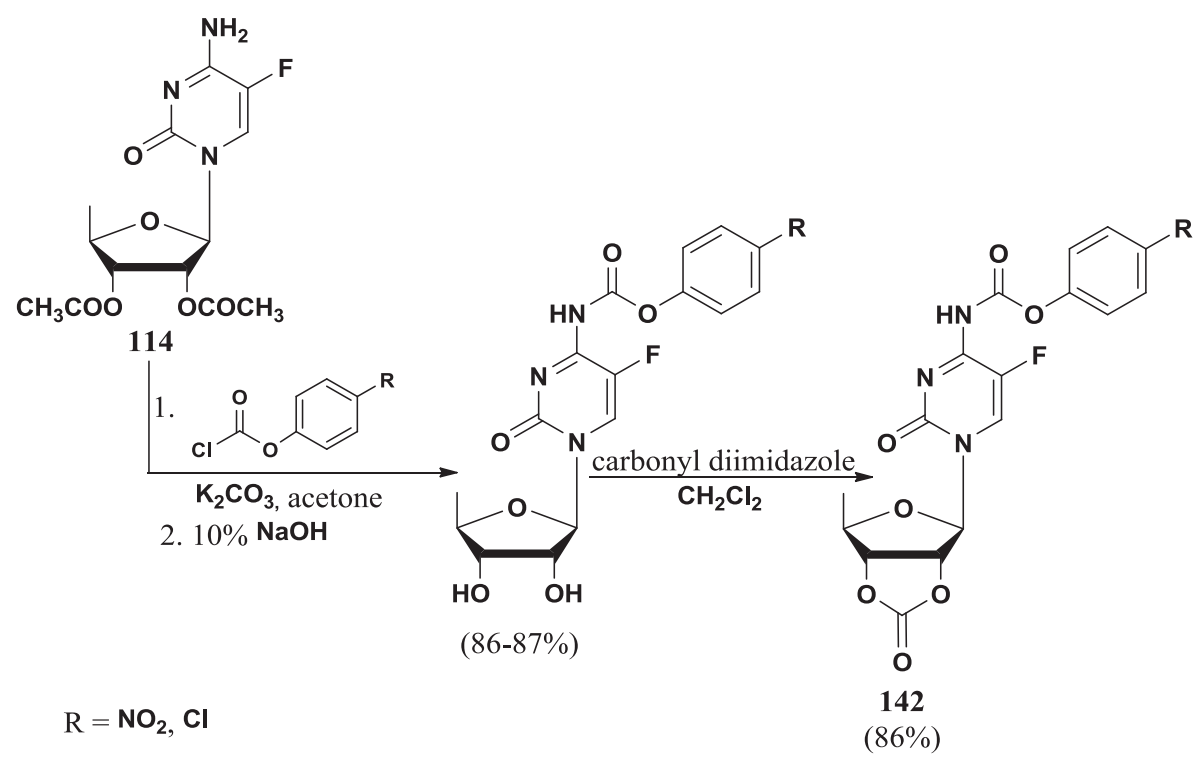

Scheme 82

\section{Galocitabine}

Galocitabine (5'-deoxy-5-fluoro- $\mathrm{N}^{4}$-(3,4,5-trimethoxybenzoyl)cytidine), (Ro 09-1390) 135, can be considered as a capecitabine derivative with a different $\mathrm{N}^{4}$-substituent or as a doxifluridine prodrug, since at $\mathrm{pH} 2.1$ it rapidly decomposes affording the latter compound. ${ }^{158}$

695 Galocitabine was synthesized from $2^{\prime}, 3^{\prime}$-diacetate-5'-deoxy-5-fluorocytosine 129 in $1995^{159}$ according to Scheme 83. Instead of trimethoxybenzoyl chloride a different derivative of trimethoxybenzoic acid can be used, ${ }^{144}$ for example the pentafluorophenoxy ester.

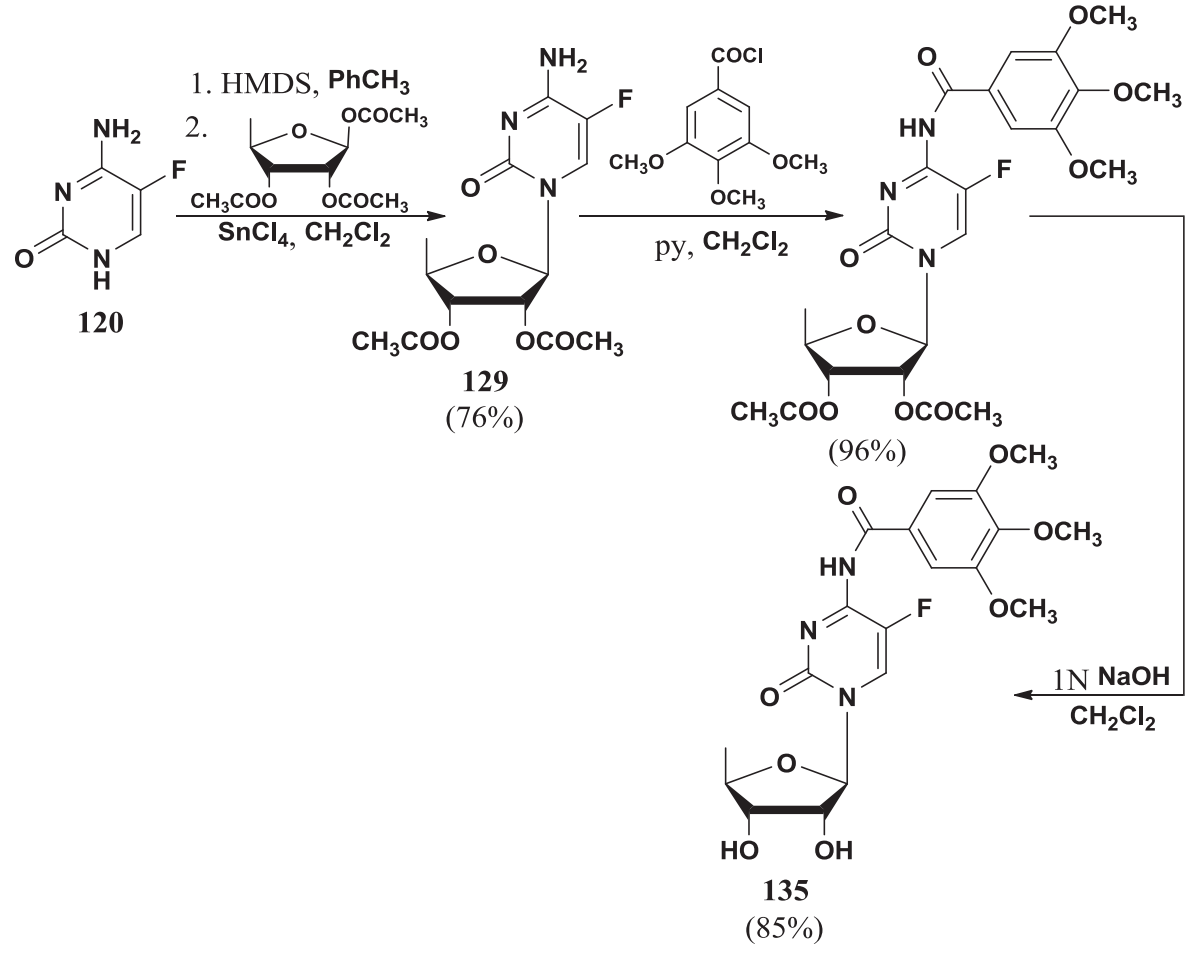

Scheme 83 
The $2^{\prime}, 3^{\prime}$-O-cyclic sulfinyl ester ${ }^{145}$ of $5^{\prime}$-deoxy-5-fluorocytidine $\mathbf{1 1 4}$ was an alternative protecting group, utilized during the introduction of $\mathrm{N}^{4}$-acyl group.

700 The continuous flow synthesis, like in the case of capecitabine $\mathbf{6 3}$, was also applied to the preparation of galocitabine $\mathbf{1 3 5}(89 \%) .{ }^{146}$

\section{1-Ethoxymethyl-5-Fluorouracil and Emitefur}

1-Ethoxymethyl-5-fluorouracyl 143 and emitefur 144 (Scheme 84) have in common the same $\mathrm{N}^{1}$-substitution, namely an ethoxymethyl moiety, which is an acyclic ether, instead

705 of the tetrahydrofuran ring present in tegafur 60. Moreover, emitefur (more commonly called BOF-A2) 144 is also functionalized on N-3. Both were designed to explore 5-fluoropyrimidine analogues of nucleosides endowed with improved antitumor activity.<smiles>CCOCn1cc(F)c(=O)[nH]c1=O</smiles>

1-ethoxymethyl-5-fluorouracil

143<smiles>CCOn1cc(F)c(=O)n(C(=O)c2cccc(C(=O)Oc3nc(OC(=O)c4ccccc4)ccc3C#N)c2)c1=O</smiles>

emitefur

144

\section{Scheme 84}

1-Ethoxymethyl-5-fluorouracyl 143 was synthesized in 1978 in very poor yield (4\%) by reaction of ethoxychloromethane with 5 -FU $\mathbf{1}^{160}$ or by reaction of the silylderivative 710 of 5-FU 47 with diethoxymethane and sodium iodide $(44 \% \text { yield })^{161}$ or stannic chloride (14\% yield), ${ }^{162}$ as depicted in Scheme 85 .

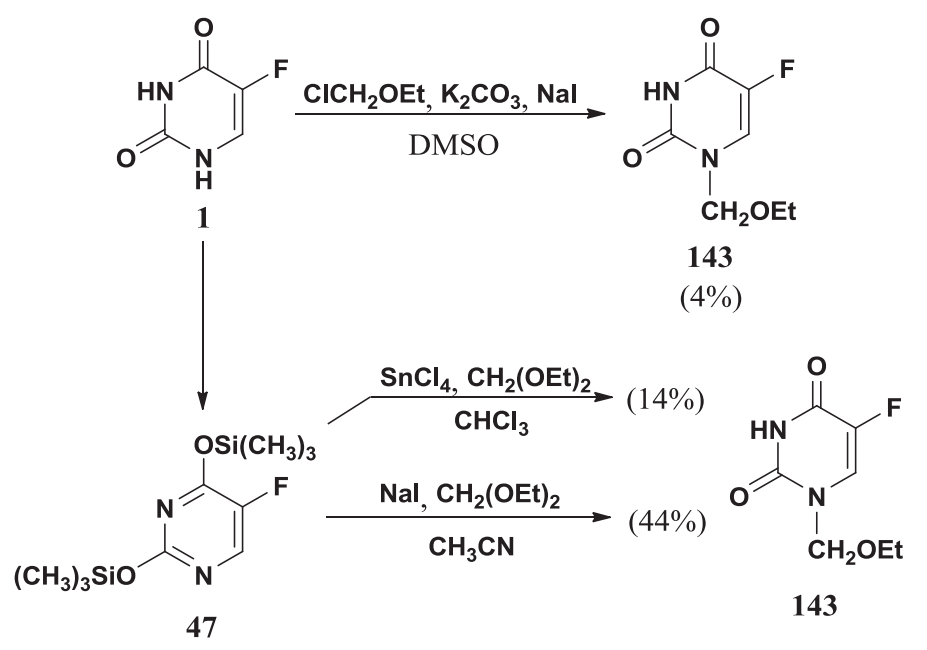

Scheme 85 
Starting from 1-ethoxymethyl-5-fluorouracil 143 emitefur 144 was prepared in 25\% yield (Scheme 86) ${ }^{163,164}$ by reaction with the isophthaloyl chloride 145 followed by reaction with 6-benzoyloxy-3-cyano-2-pyridone 146. Emitefur 144 is degraded in vivo into 1-ethoxy715 methyl-5-fluorouracyl 143, a prodrug of 5-FU, and 3-cyano-2,6-dihydroxypyridine (CNDP) $\mathbf{1 4 7}$, a competitive inhibitor of DPD, the enzyme responsible for rapid degradation of 5-FU $1 .^{5}$<smiles>CCOCCN(CC)CCn1cc(F)c(=O)n(C(=O)c2cccc(C(=O)Oc3nc(OC(=O)c4cccc(OC(=O)OCC)c4)ccc3C#N)c2)c1=O</smiles>

Scheme 86

\section{Carmofur}

Carmofur $\mathbf{1 4 8}$ is the international non-proprietary name of 1-hexylcarbamoyl-5-fluorouracil (HCFU), an antineoplastic agent orally administered in resected colorectal cancer patients. It has some anticancer activity of its own and it is ultimately transformed in vivo to 5 -FU 1. ${ }^{165}$ It was prepared ${ }^{165}$ starting from 5-FU 1 by reaction with hexyl isocyanate in pyridine or in dimethylacetamide solution, or by reaction with phosgene followed by treatment with 1-hexylamine (Scheme 87). The hexyl isocyanate was, in turn, prepared starting from heptanoyl chloride by reaction with sodium azide, ${ }^{165}$ or by treatment of 1 hexylamine with trichloromethyl chloroformate, followed by distillation. ${ }^{166}$

In a polar solvent, like dimethylsulfoxide, carmofur 148 exists as two mixed structures (presumably a hydrogen-bonded structure and a non-hydrogen-bonded structure) at room temperature, as demonstrated by ${ }^{1} \mathrm{H}$ NMR analyses ${ }^{166}$ in DMSO- $\mathrm{d}_{6}$ at room temperature and at $80^{\circ} \mathrm{C}$ or in $\mathrm{CDCl}_{3}$. Deuterated derivatives of carmofur bearing deuterium atoms on the hexyl chain were prepared in order to evaluate the isotopic effect on the metabolism rate. ${ }^{165}$ 


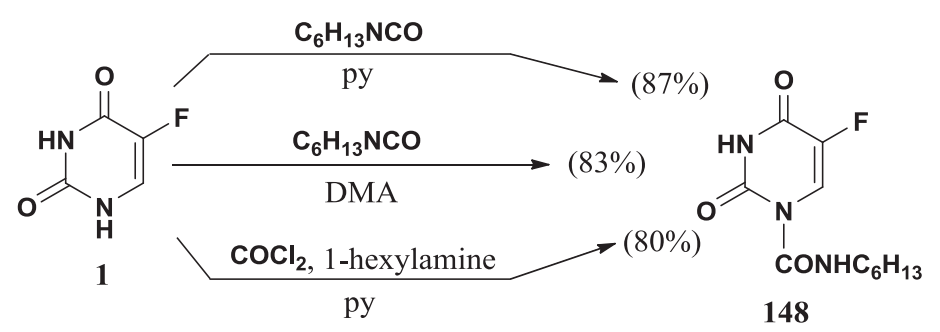<smiles></smiles><smiles>CCCCCCCCC(=O)NC(=O)n1cc(F)c(=O)[nH]c1=O</smiles>

Scheme 87

\section{Related Non-Clinical Fluoropyrimidine Nucleosides}

New syntheses of fluoropyrimidines nucleosides are usually aimed at the preparation of new potential antitumor, antiviral or antibacterial compounds and their destiny depends on the results of clinical investigations. The fluorination in most cases takes place at the

735 5-position, namely the position involved in the thymidine biosynthesis. In the previously examined compounds the fluorine atom is directly linked to C-5 of heteroaromatic ring. In the case of 5-trifluorothymidine (TFT) 149 a trifluoromethyl group instead of the 5methyl group is present.

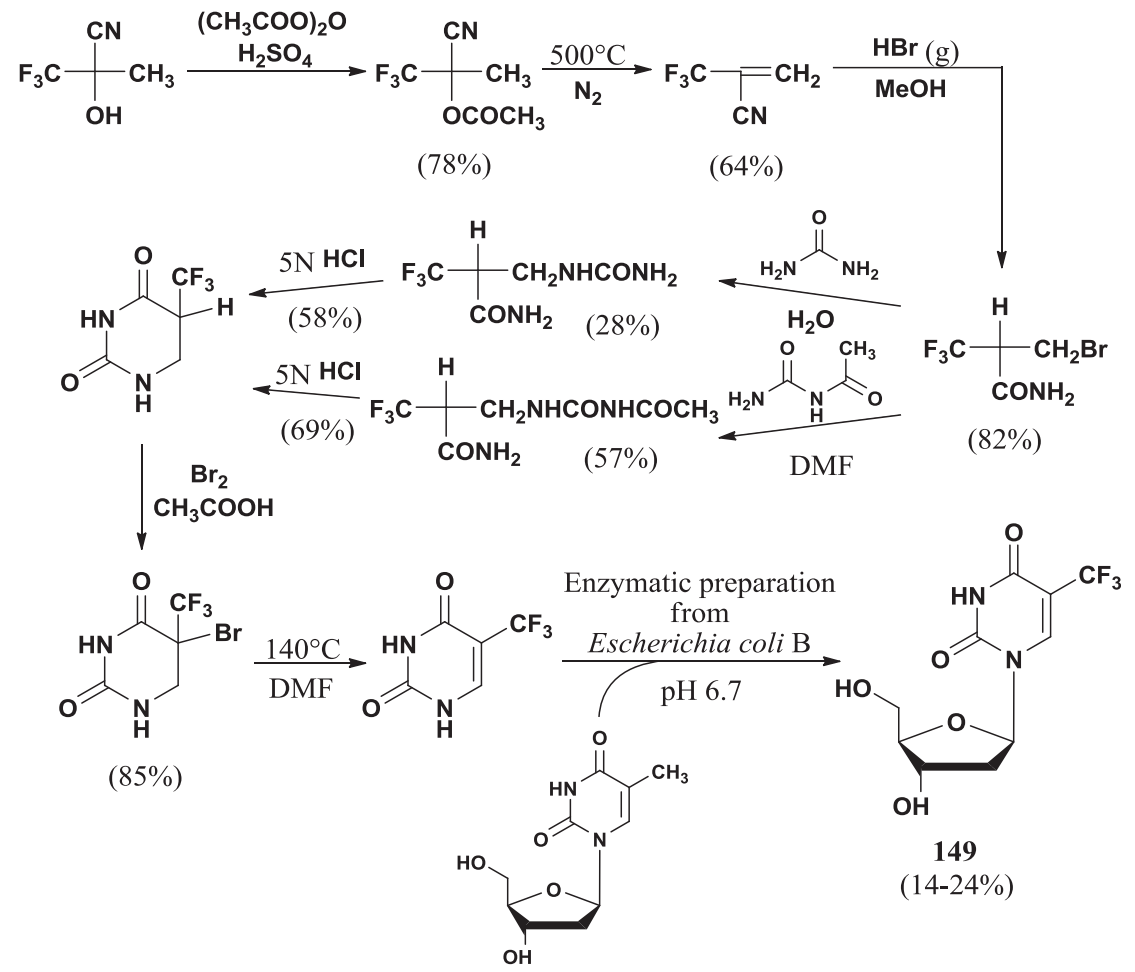

Scheme 88 
TFT 149 was synthesized in 1964 by Heidelberger ${ }^{167}$ according to Scheme 88 , but its 740 development as antineoplastic agent was early hampered by its short half-life (12 min). ${ }^{168}$

The renewed recent interest for TFT 149, prompted the synthesis of a convenient prodrug. In a 2016 patent ${ }^{169}$ the silylation of $3^{\prime}$ and $5^{\prime}$-hydroxy group of TFT was realized in order to prolong the TFT 149 circulatory half-life. Two methods of silylation affording compound 150 (Scheme 89) were described.

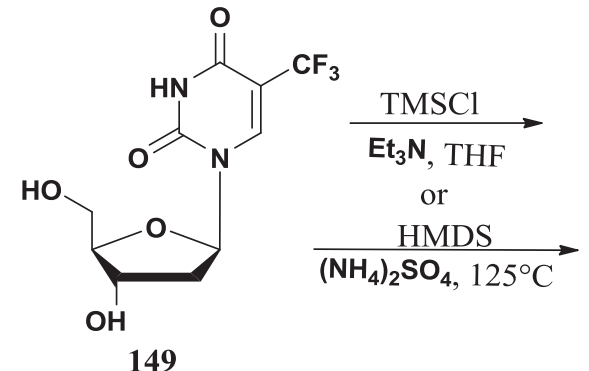

149

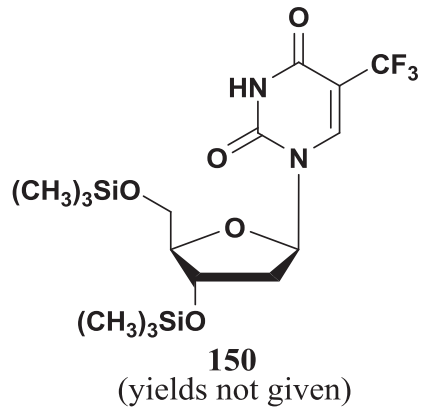

(yields not given)

Scheme 89

\section{III. Pyrimidine Nucleosides Fluorinated at the Sugar Moiety}

Fluorine atom introduction at nucleosides can occur not only at the pyrimidine moiety but also at the glycone moiety, modifying the biological activity to an equally significant extent, leading to antiviral or antitumoral molecules. The sugar can be fluorinated at $2^{\prime}, 3^{\prime}, 4^{\prime}, 5^{\prime}$-positions or can bear an exocyclic fluorocarbon substituent. Considering that

750 some reviews ${ }^{170-173}$ already cover the topic of nucleosides fluorinated at the sugar moiety, we focused on an antitumor pyrimidine nucleosides difluorinated at the 2 '-position, namely gemcitabine. The presence of fluorine at the $2^{\prime}$-position can provide acidic and enzymatic stabilities to the glycosidic bond ${ }^{174}$ and the gem-difluoromethylene group is an isopolar and isosteric substituent for oxygen. ${ }^{175}$ Extensive studies about the $2^{\prime}$-position

755 modification with atoms or groups other than hydrogen or hydroxy (for example $\mathrm{Cl},{ }^{176}$, $\mathrm{N}_{3},{ }^{177} \mathrm{Se},{ }^{178} \mathrm{CH}_{3},{ }^{179,180}$ ) have been performed, since the presence of a hydroxy or a hydrogen distinguishes nucleosides as components of RNA or DNA.

\section{Gemcitabine}

Gemcitabine 151 hydrochloride $\left(2^{\prime}, 2^{\prime}\right.$-difluoro- $2^{\prime}$-deoxycytidine hydrochloride) is cur-

760 rently produced and marketed as Gemzar $^{\circledR}$ for the treatment of various cancers such as pancreatic, breast, non-small cell lung and ovarian cancers. It is administered by intravenous infusion, the oral use of gemcitabine being limited by poor bioavailability.

Gemcitabine is intracellularly converted by deoxycytidine kinase into its therapeutically active metabolites, the $5^{\prime}$-diphosphate $\mathbf{1 5 2}$ and the $5^{\prime}$-triphosphate derivatives $\mathbf{1 5 3}$

765 (Scheme 90).

$5^{\prime}$-Diphosphate $\mathbf{1 5 2}$ inhibits the ribonucleotide nuclease, the enzyme responsible for regulating the total rate of DNA synthesis, while $5^{\prime}$-triphosphate 153 can become incorporated into the DNA and inhibits the nuclear replication. The $5^{\prime}$-position is directly involved in the action of gemcitabine 151, while the $4-\mathrm{NH}_{2}$ group plays a role in the 


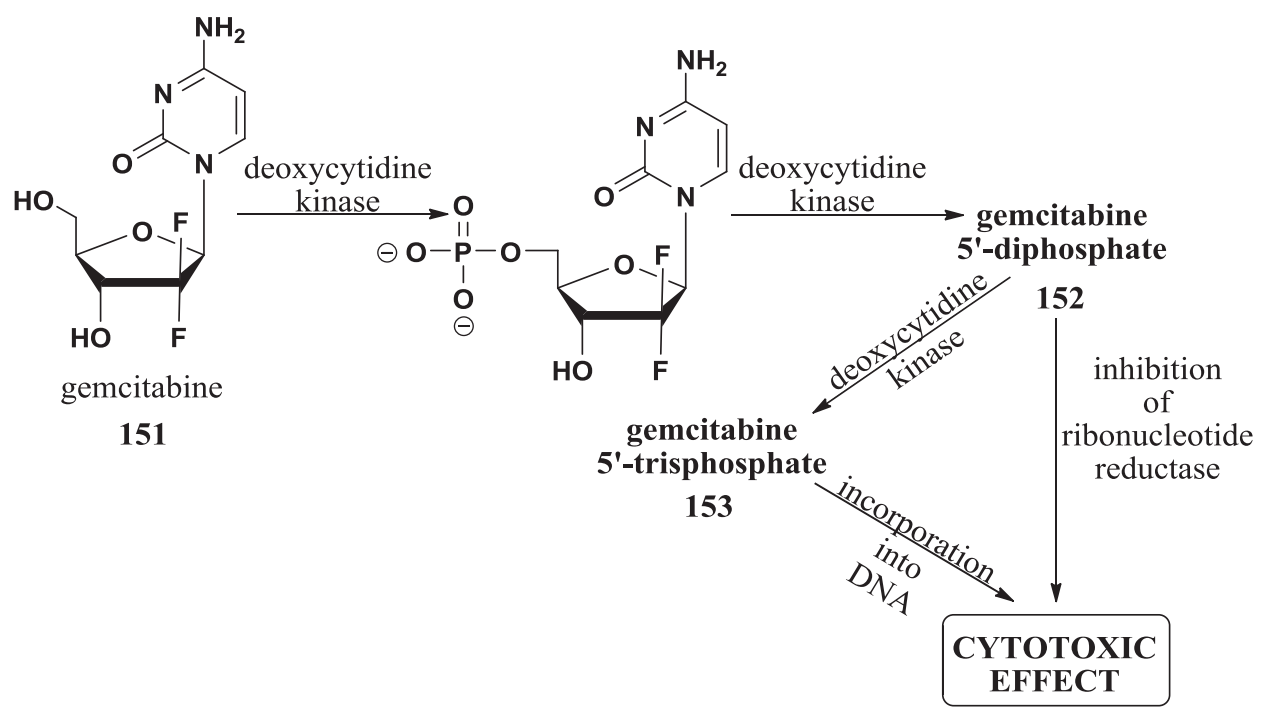

Scheme 90

770 enzyme-substrate recognition through the formation of hydrogen bonding interactions with the kinase; the removal of the amino group by the liver enzyme cytidine deaminase ${ }^{117}$ leads to the inactive metabolite $2^{\prime}, 2^{\prime}$-difluorouridine.

The preparation of the $2^{\prime}, 2^{\prime}$-difluorosugar is the main target in gemcitabine 151 synthesis and many different approaches have been proposed (some of that described in a 775 minireview $^{181}$ ) since the first synthesis reported by Hertel in $1988 .^{182}$

The starting material for this synthesis (Scheme 91) was protected $(R)$-glyceraldehyde 154 prepared from D-mannitol; its reaction with ethyl bromodifluoroacetate led to a diastereomeric mixture of $(3 R)$ - and ( $3 S)$-propionate $(3 R / 3 S 3: 1)$ derivatives 155 that were separated by silica gel column chromatography. The $(3 R)$-isomer,

780 under acidic conditions afforded lactone 156 that, after protection of 3- and 5hydroxy groups (compound 157), was reduced with diisobutylaluminum hydride to a mixture of $\alpha$ - and $\beta$-anomers (158); the anomeric mixture was transformed into the corresponding 1-O-mesylate (compound 159) necessary for the substitution by the silyl derivative of cytidine. The formation of the $\mathrm{N}$-glycosidic bond was the crucial

785 step of the synthesis since the required $\beta$-anomer of $\mathbf{1 5 1}$ was the minor product (10\%). The undesired $\alpha$-anomer was obtained in $40 \%$ yield, after removal of the protecting group and separation by reverse phase column chromatography.

An improvement to this synthesis was achieved by Chou and co-workers, ${ }^{183}$ some years later, through the selective crystallization of the diastereomeric mixture 790 of 3,5-di-O-benzoyl-difluororibono-lactone 161 obtained by esterification of 3'-benzoate 160 (Scheme 92). The choice of benzoyl as protecting group of 3- and 5hydroxy groups allowed selective crystallization of the desired erythro-isomer. Reduction of the 1-carbonyl group afforded a mixture of $\alpha$ - and $\beta$-anomers 161 that was transformed into the corresponding mesylates $\mathbf{1 6 2}$. The glycosylation reac-

795 tion afforded a 1:1 $\alpha / \beta$ anomeric mixture of nucleosides 163 instead of the $4: 1$ mixture observed by Hertel which used tert-butyldimethylsilyl ether as protecting group.

Starting from protected $(R)$-glyceraldehyde 154 many modifications, aimed to improve the yield and the purity of the final $\beta$-anomer, were proposed relating to the 


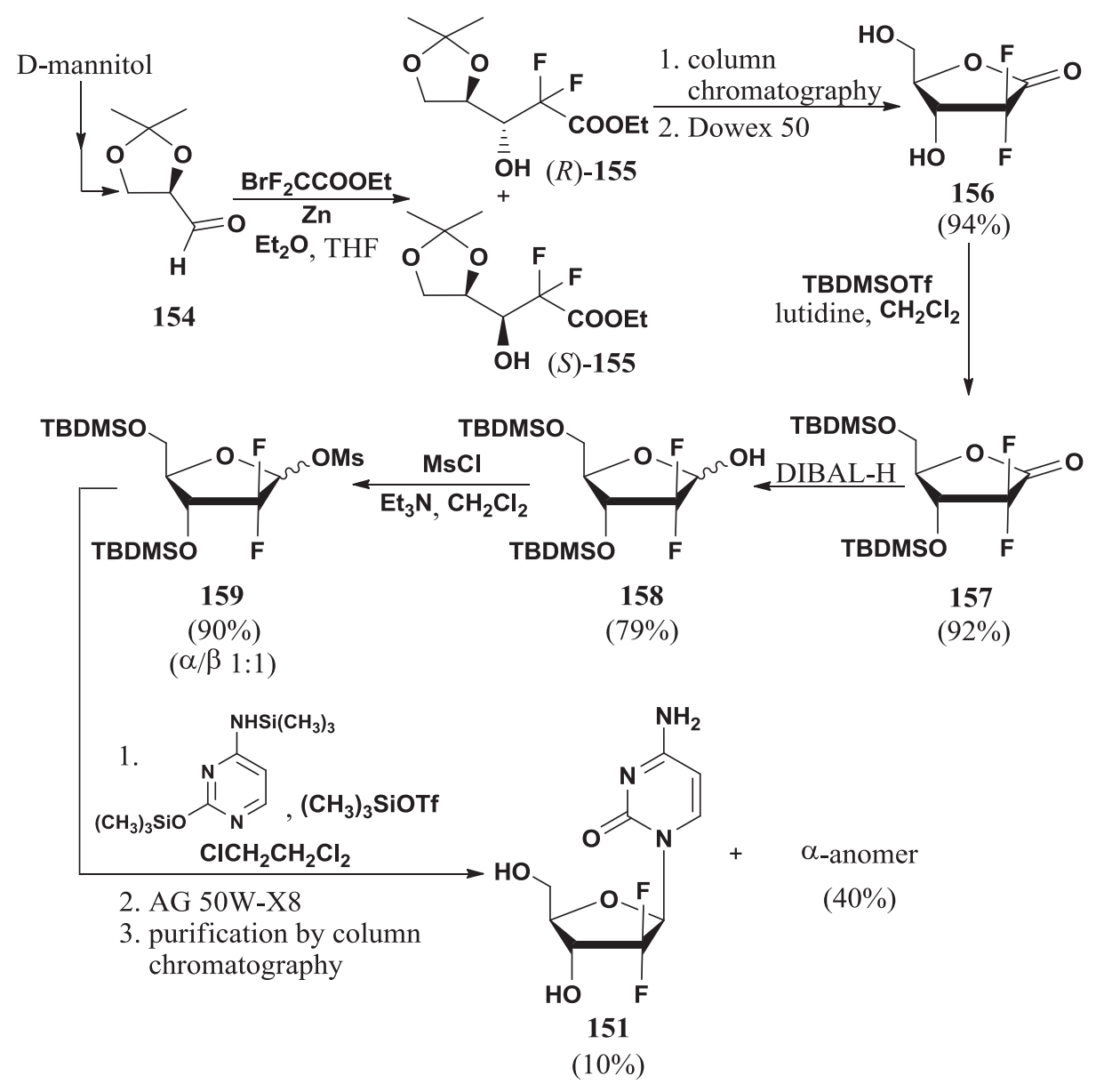

Scheme 91

800 use of different reducing agents of the lactone, to the introduction of alternative protecting groups, to the transformation of 1-hydroxy into a different leaving group and, finally, to the purification process of the obtained gemcitabine 151. More than ten patents have been published in 2005-2015 about this topic. For example, an Indian team ${ }^{184,185}$ was able to obtain 3,5-di-O-benzoyl-2,2-difluoro-lactone with a 805 high purity (99.8\% erythro-isomer) by treatment of the diastereomeric mixtures of lactones $\mathbf{1 6 4}$, containing also the corresponding hydroxyacid $\mathbf{1 6 5}$, with para-toluensulfonic acid in toluene, at reflux, removing the water by means of the Dean-Stark apparatus, followed by crystallization (Scheme 93). Reduction with Vitride ${ }^{\circledR}$ (sodium bis(2-methoxy)aluminum hydride, also known as Red-Al ${ }^{\circledR}$ or SMEAH) followed by

810 treatment with mesyl chloride afforded usual intermediate 162 for the accomplishment of the synthesis. The gemcitabine hydrochloride showed a $95 \%$ diastereomeric purity that was increased to $99.9 \%$ by means of crystallization by water/acetone or water/2-propanol.

Another approach ${ }^{186}$ made use of DIBAL as reducing agent of protected lactone 166

815 and mesylate as leaving group in compound $\mathbf{1 6 7}$, postponing all purification processes until the end of the synthesis. By this method, $92.6 \%$ pure gemcitabine was obtained after 

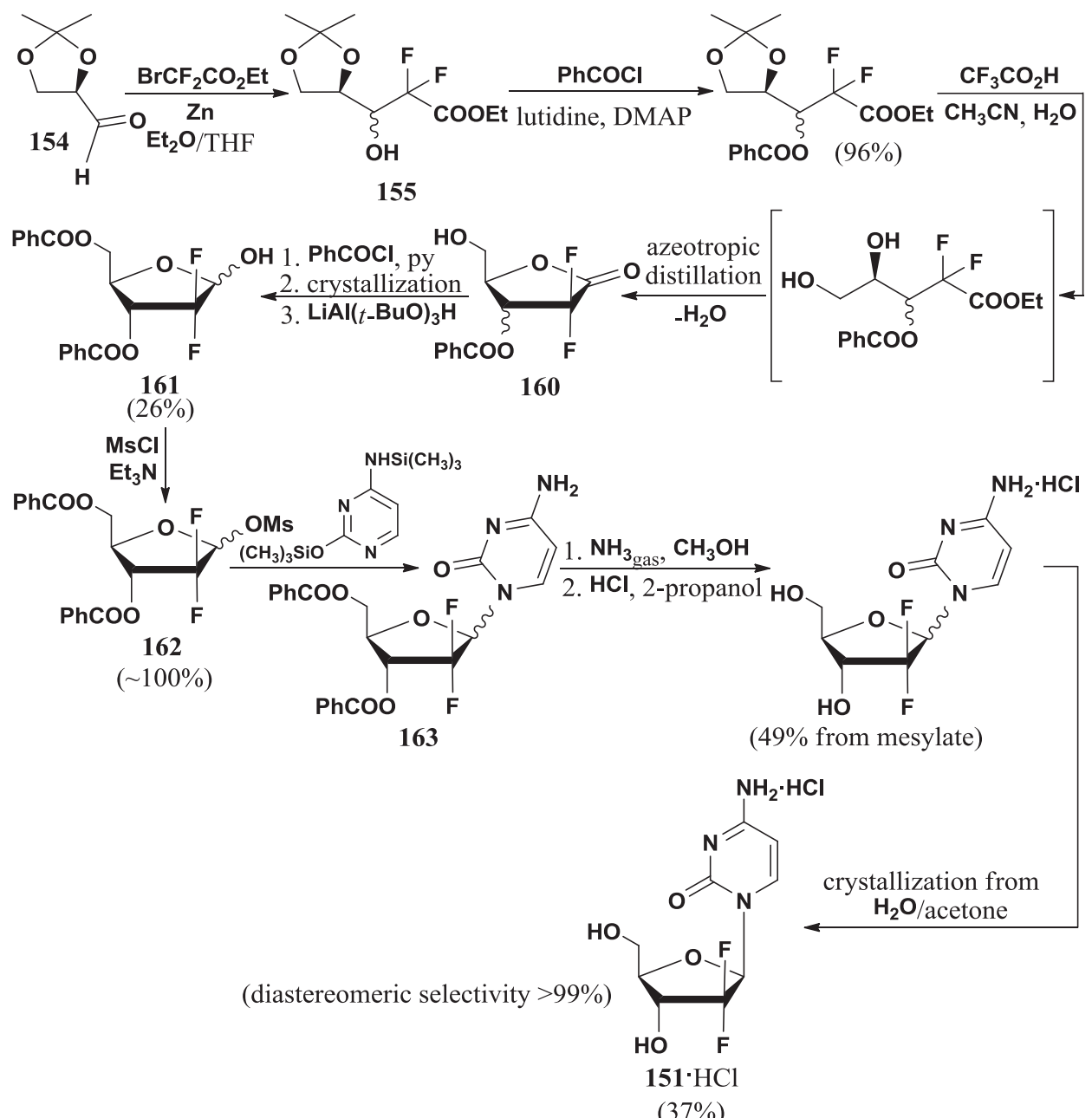

Scheme 92

column chromatography. The final crystallization of gemcitabine hydrochloride from water/acetone afforded $99.6 \%$ pure gemcitabine hydrochloride (Scheme 94 ).

The choice of a suitable protecting group ${ }^{187}$ for the 3- and 5-hydroxys (benzoyl 820 substituted with an electron withdrawing group), with the aim to obtain solid compounds, allowed preparation of the pure erythro-lactone 168 by crystallization from ethyl acetate/ hexane. The synthesis was then finished in the usual way; the precipitation of gemcitabine hydrochloride afforded $99.9 \%$ pure product (Scheme 95).

Tri-tert-butoxyaluminum hydride was used in the course of the reduction of the lactone 825 protected as 3,5-di-O-(3-fluorobenzoyl) ester ${ }^{187}$ or 3,5-di-O-(4-phenyl)benzoyl ester. ${ }^{188}$ By means of Red-Al ${ }^{\circledR}$ was instead obtained the lactol, protected at the hydroxy groups as tertbutyldimethylsilyl ethers ${ }^{189}$ or benzoates, ${ }^{190,191}$ or naphthoyl esters, ${ }^{192}$ or as 3-O-benzoate and 5-carbamate. ${ }^{193}$ In this last case, the trichloroacetimidate was chosen as the leaving group. If the same leaving group was introduced and the obtained trichloracetimidate directly 830 submitted to the reaction with protected cytidine, in a "one-pot" process, ${ }^{190}$ the protected 
<smiles>CCOC(=O)C(F)(F)[C@H](O)[C@H]1COC(C)(C)O1</smiles>

151

$(3 \mathrm{R} / 3 \mathrm{~S} 3: 1)$

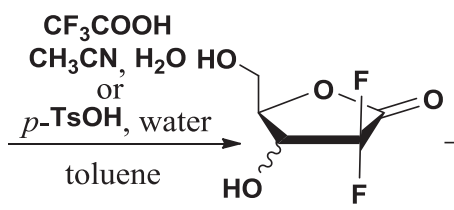

Ho
PhCOCl

4-DMA pyridine

ethyl acetate

PhCOO

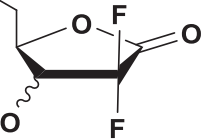

1. $p$-TsOH, toluene $\mathrm{PhCOO}$

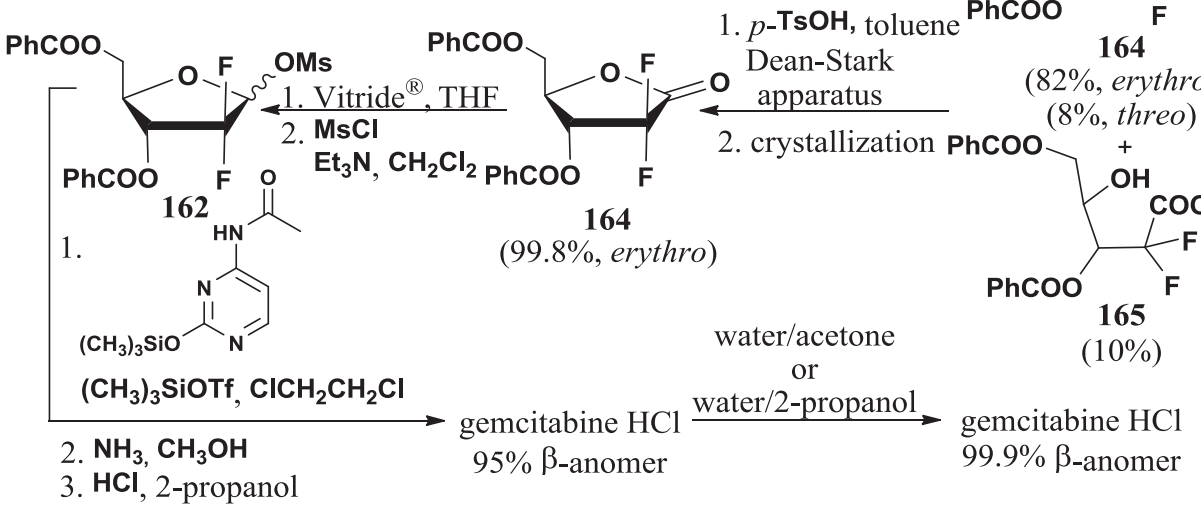

Scheme 93<smiles>CC1(C)OC[C@@H]([C@@H](O)C(F)(F)Cl)[C@H]1C(=O)Cl</smiles>

151

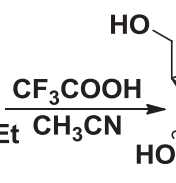

$\mathrm{HO}$

156

$(100 \%)$
TBDPSO

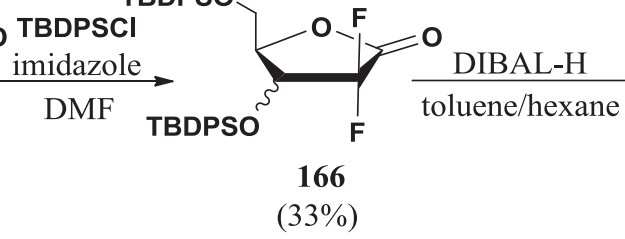

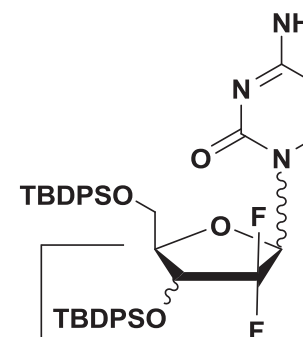

$(98 \%)$

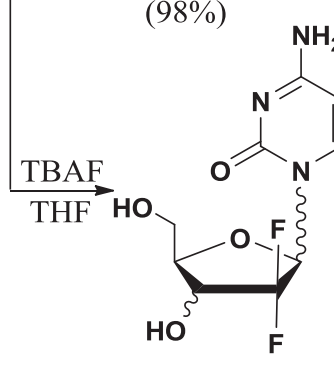

$\mathrm{NHCOCH}_{3}$

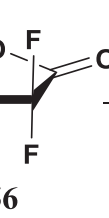

(1) 


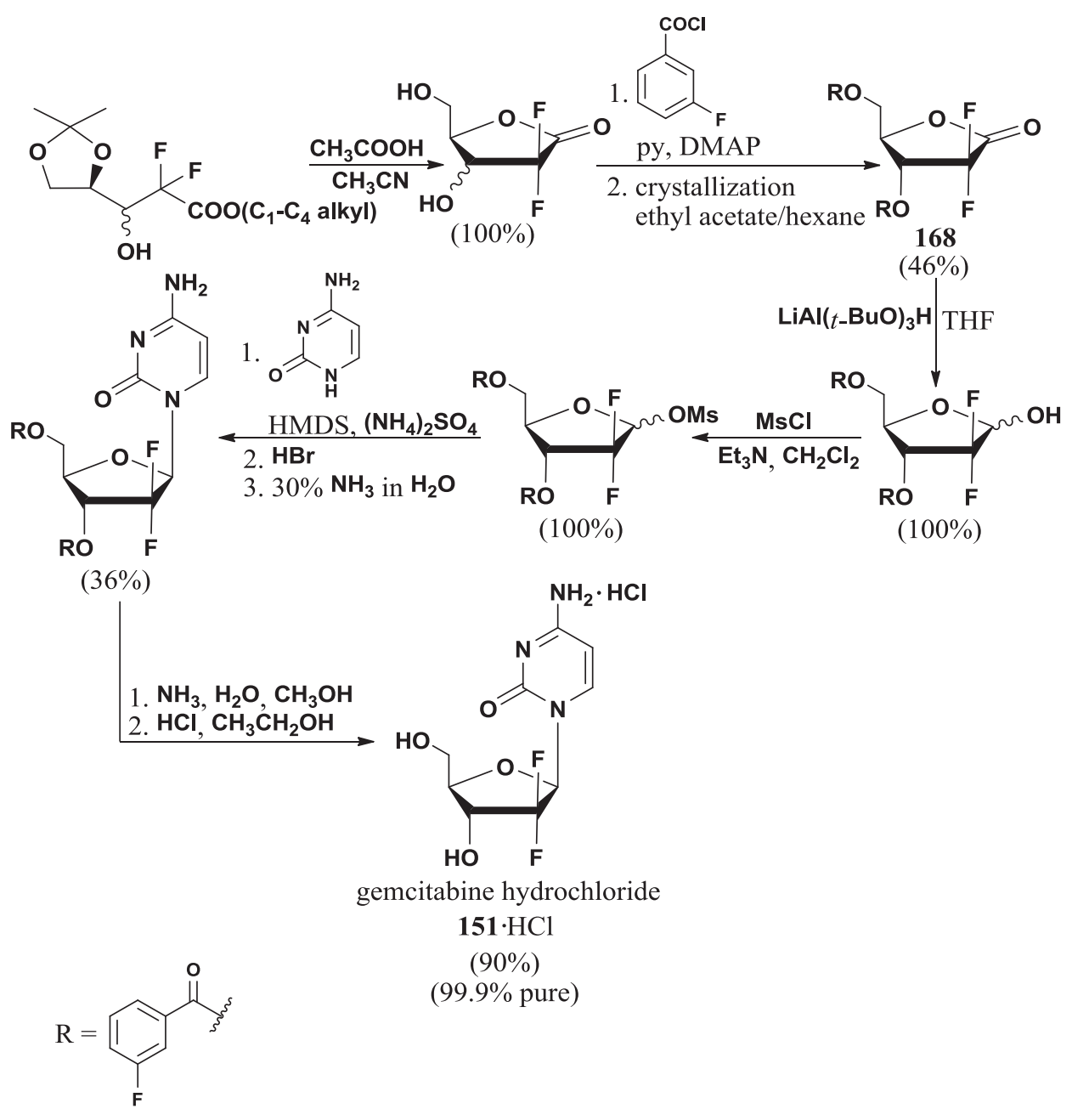

Scheme 95

nucleoside was obtained in high yield (89\%); gemcitabine hydrochloride was obtained (99.94\% $\beta$-anomer) in $30 \%$ yield after deprotection and purification process.

The use of the cinnamoyl ester as protecting group of 3- and 5- hydroxyl allowed the selective precipitation of an anomer at different steps of the synthesis. ${ }^{194,195}$

835 In order to avoid the energy waste required to maintain the low temperatures (between -80 and $-60^{\circ} \mathrm{C}$ ) during the reduction of the 1-carbonyl group with DIBAL, in a 2010 patent the use of calcium borohydride in tetrahydrofuran (90\% yield) or sodium borohydride in ethyl acetate ( $88 \%$ yield) was proposed. ${ }^{196}$

In order to increase the $\beta / \alpha$ anomer ratio, 1-iodido-2,2-difluoro derivative 169, 840 as substrate of the $\mathrm{N}$-glycosylation, was prepared through two alternative ways: directly from 1-hydroxy $\mathbf{1 7 0}$ by reaction with iodine and triphenylphosphine in dichloromethane, or through its mesylate, with sodium iodide in acetone. The addition of a silver salt to the glycosylation reaction mixture led to the formation of oxonium intermediate, $\mathbf{1 7 1}$ that underwent the attack of nucleobase from the top of the 845 molecule, favoring the formation of the $\beta$-anomer $(\alpha / \beta 1: 5.6) .{ }^{197}$ In a more recent patent ${ }^{198}$ the authors reported that even more favorable ratios can be obtained adding 
an oxidizer; for example, a 1:18 $\alpha / \beta$ anomer ratio was observed using $\left(\mathrm{NH}_{4}\right)_{2} \mathrm{~S}_{2} \mathrm{O}_{8}$ in acetonitrile. (Scheme 96).

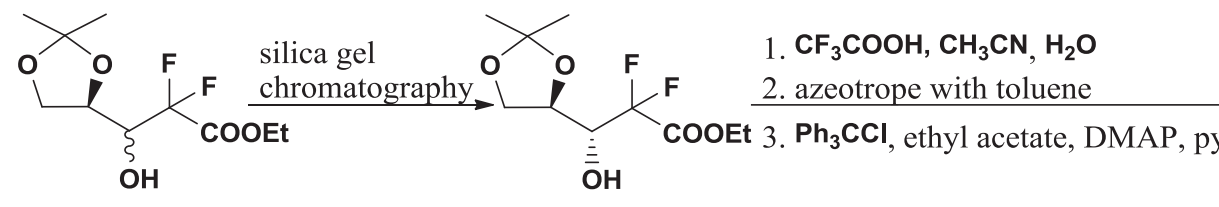

151

$(57 \%)$

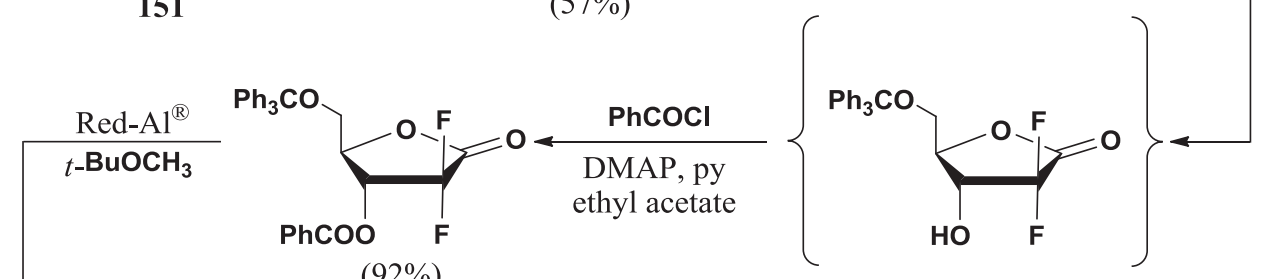

$(92 \%)$
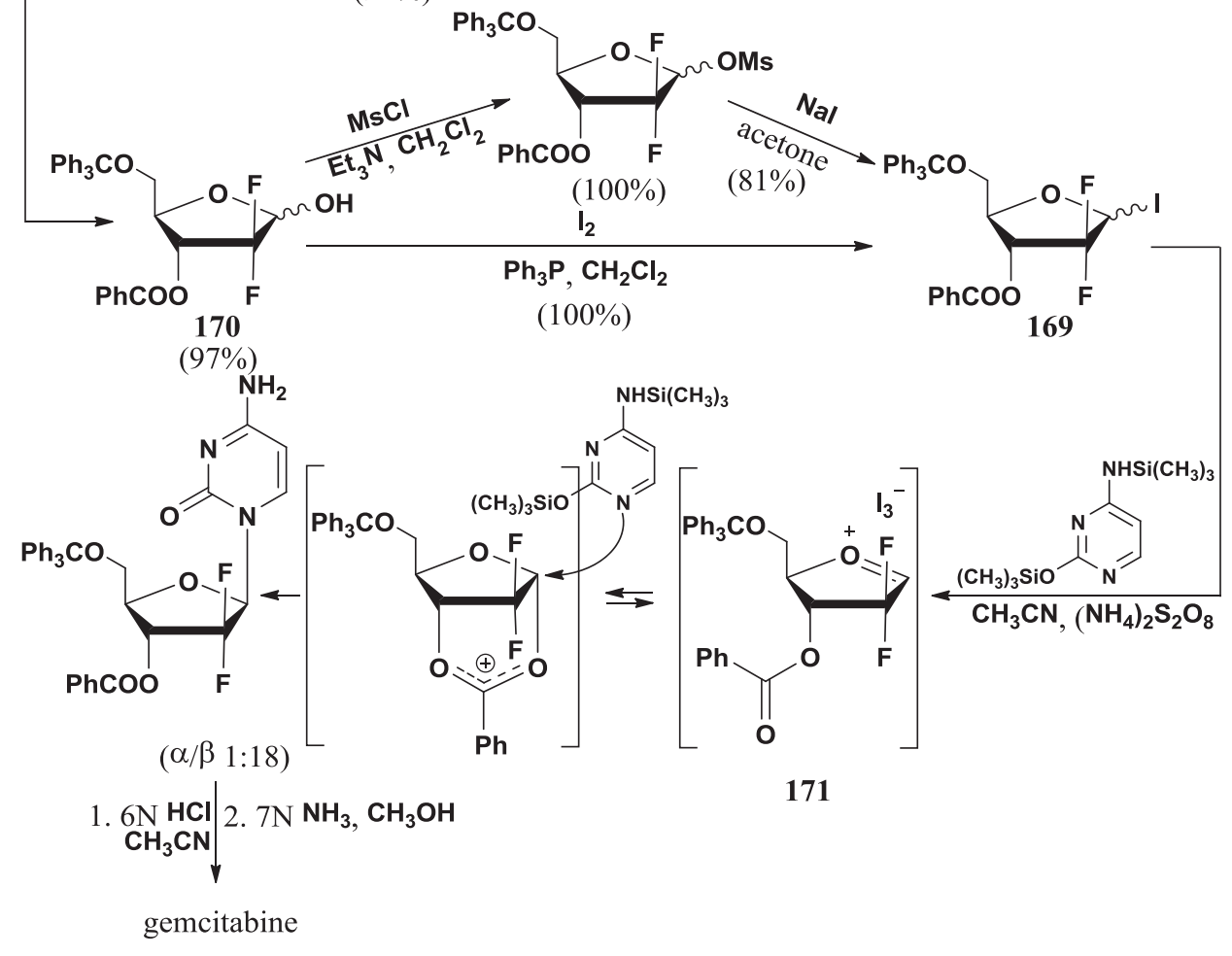

$(17 \%)$

Scheme 96

The presence of a bulky protecting group (para-phenylbenzoate) ${ }^{199,200}$ of the 3 850 hydroxy group allowed workers to obtain a solid 1-phosphate, compound 172 showing a $1: 10.8 \alpha / \beta$ ratio, that by a simple crystallization afforded in $77 \%$ yield the $\beta$-anomer (98.24\% pure). The $\beta$-phosphate was easily converted into the corresponding $\alpha$-bromo derivative $\mathbf{1 7 3}$, which is a suitable precursor, after crystallization, of the N-glycosylated product with the desired $\beta$-stereochemistry. In order to avoid pos855 sible anomerization of $\alpha$-bromo sugar $\mathbf{1 7 3}$ the trimethylsilyl bromide, generated in 
the course of substitution with the protected nucleobase, was removed by distillation using heptane as carrier. By this method, glycosylation occurred in high yields (92\%) giving compound $\mathbf{1 7 4}$ showing a 1:5.5 $\alpha / \beta$ ratio. Pure gemcitabine $\mathbf{1 5 1}$ was obtained, after removal of protecting groups and crystallization in $65 \%$ yield from $860 \alpha$-bromo sugar 173 (Scheme 97).

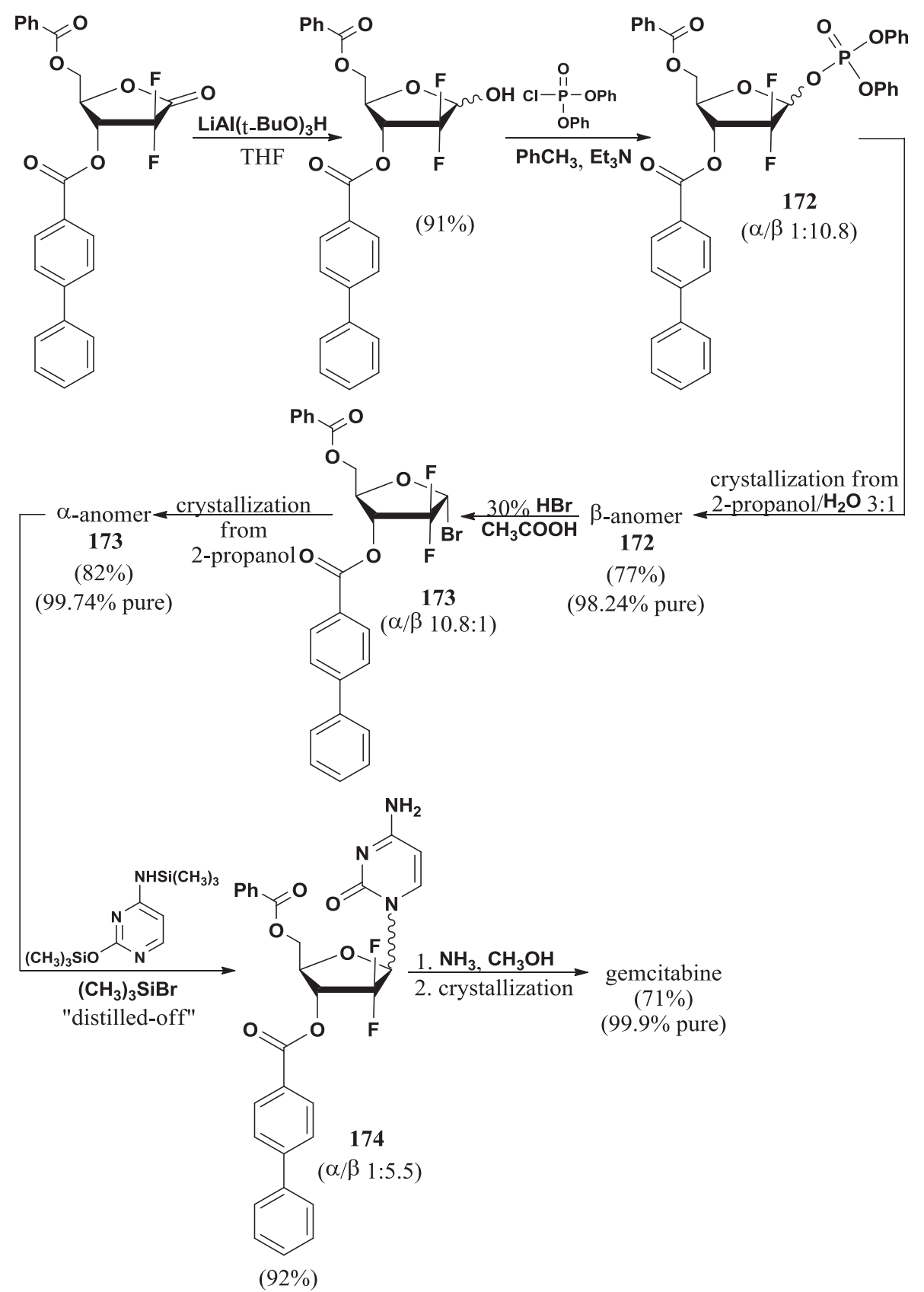

Scheme 97 
According to a different approach, instead of the usual protected $(R)$-glyceraldehyde $\mathbf{1 5 4}, 1,6$-anhydro- $\beta$-D-glucose $\mathbf{1 7 5}$, prepared by thermal degradation of starch, was used as starting material. ${ }^{201}$

2,4-Trimethylsilyl ether $\mathbf{1 7 6}$ was oxidized to 3-keto derivative $\mathbf{1 7 7}$ by means of Dess-Mar865 tin reagent. After removal of the silyl ether the 2- and 4-hydroxy groups were transformed into corresponding methyl ethers $\mathbf{1 7 8}$ (96\% yield) and the 3-ketoderivative was converted into gemdifluoro derivative 179 by reaction with diethylaminosulfuryl trifluoride (DAST) and N,Ndimethylpropylene urea-hydrogen fluoride (DMPU-HF) (90\% yield). Opening the anhydro ring under acidic conditions (compound 180) and oxidation with sodium periodate afforded 2-

870 deoxy-2,2-difluoro-D-ribose $\mathbf{1 8 1}$ in $68 \%$ yield. The synthesis was accomplished as reported in Scheme 98. 1,3,5-Tri-O-acetyl-D-ribose difluoroderivative 182 was condensed with the $\mathrm{N}^{1}$-cis(2-cyanovinyl)-N,N-bistrimethylsilyl urea and the obtained intermediate was cyclized under strong alkaline conditions to the final $\beta$-nucleoside in $11 \%$ yield, after column chromatography. The overall yield from 1,6-anhydro- $\beta$-D-glucose 175 was $4.4 \%$, confirming the difficulties 875 encountered in other synthetic approaches, deriving from the presence of two stereogenic centers, in the 1- and 3-positions, generated or modified in the course of the synthesis.

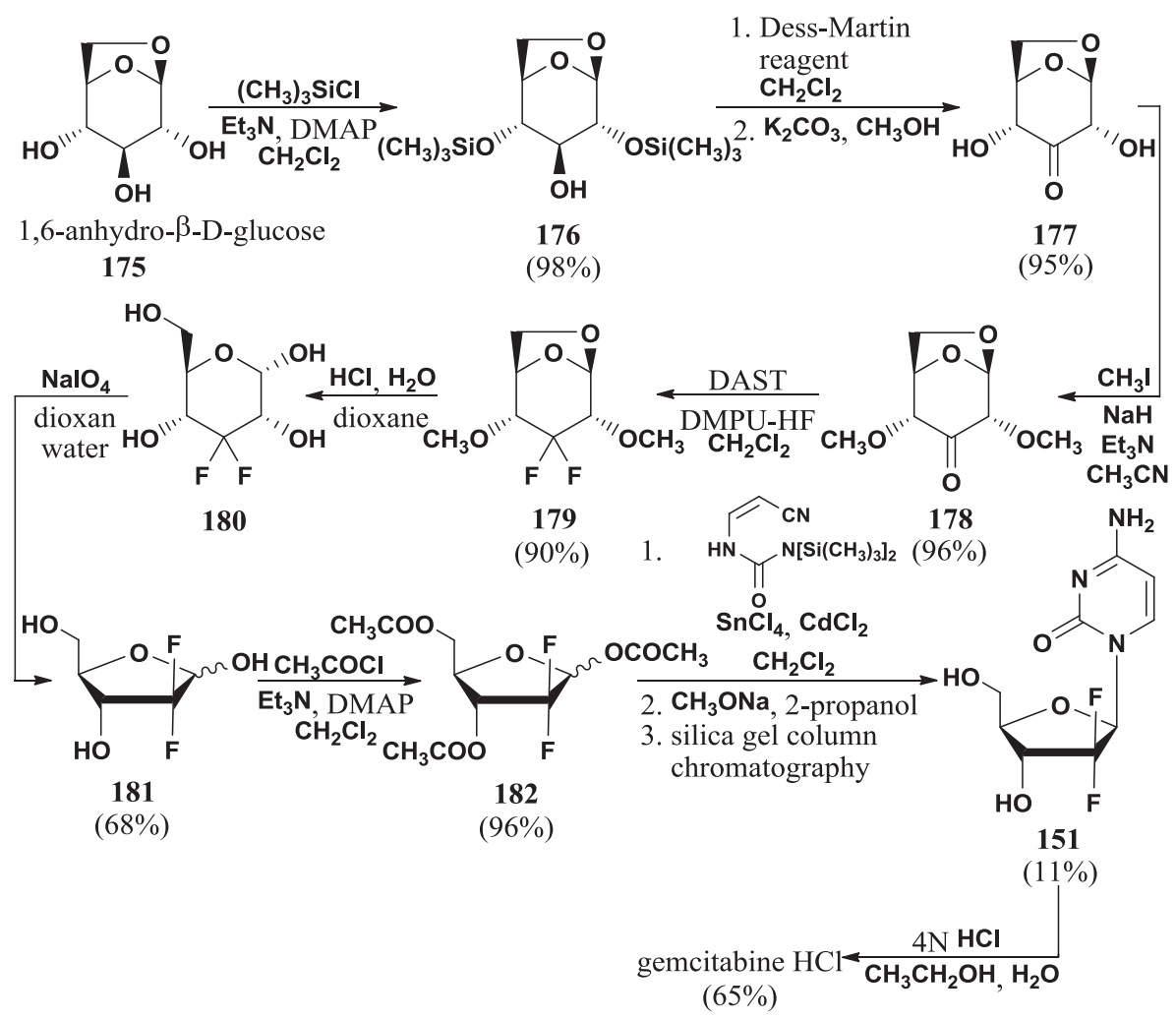

Scheme 98

The direct fluorination of a preformed nucleoside can overcome the formation of the erythro and threo-diastereoisomers encountered starting from $(R)$-glyceraldehyde 154; in addition, the $\mathrm{N}$-glycosylation with a non-fluorinated sugar can afford a more favorable $\alpha / \beta$ anomers ratio. To this end, a suitably protected $2^{\prime}$-ketonucleoside $\mathbf{1 8 3}$ was prepared starting from the commercially available cytidine and submitted to the reaction with 
DAST in presence of pyridine-hydrogen fluoride (Scheme 99). ${ }^{202} \mathrm{~N}^{4}, 3^{\prime}, 5^{\prime}$-Tri-(orthotoluyl)-2'-ketocytidine $\mathbf{1 8 3}$ was prepared in 53\% overall yield from cytidine. Reaction with the fluorinating agent afforded protected difluoronucleoside 184 (80\% from HPLC and NMR) that was converted into gemcitabine $\mathbf{1 5 1}$ by removal of protecting groups.<smiles>Nc1ccn(C2(O)O[C@@H](CO)[C@@H](O)[C@H]2O)c(=O)n1</smiles>

cytidine

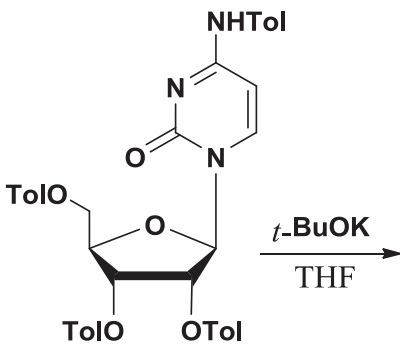

$(88 \%)$

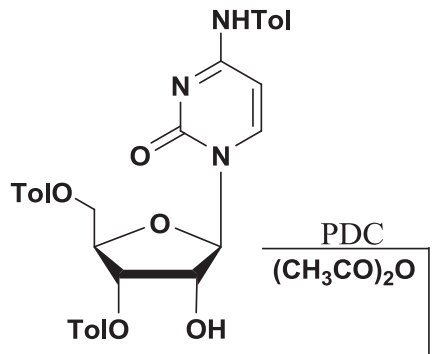

$(74 \%)$

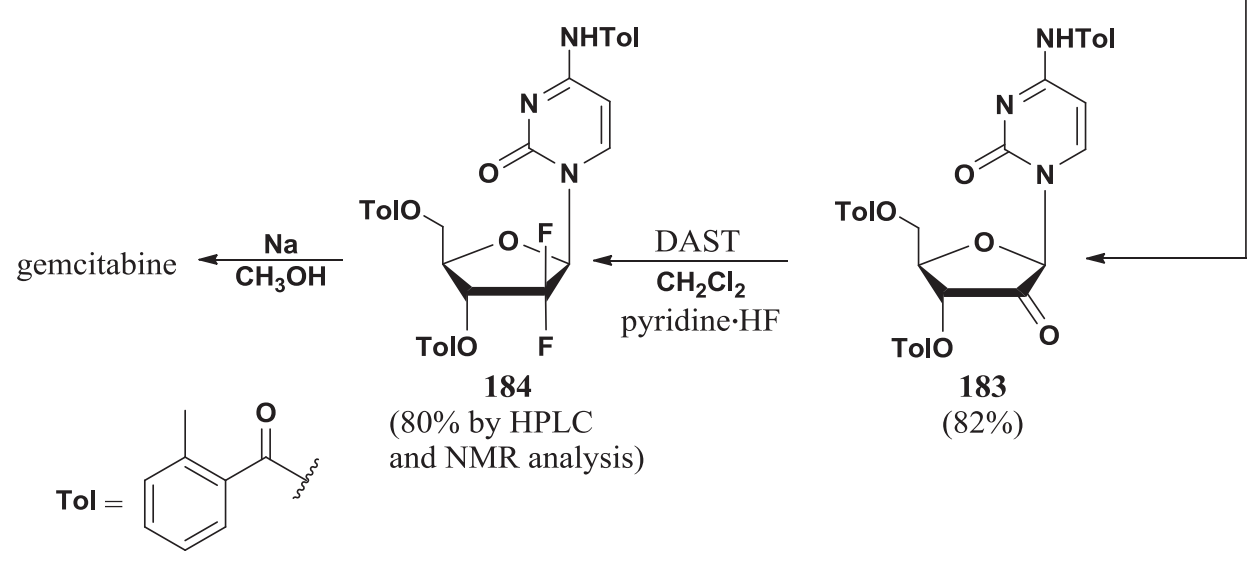

Scheme 99

In another example 2-deoxy-D-ribonolactone $\mathbf{1 8 5}$ was chosen as the substrate of the fluorination, which was carried out in two steps with $\mathrm{N}$-fluorodibenzenesulfonimide (NFSi) in presence of lithium bis(trimethylsilyl)amide (LiHMDS) (Scheme 100). ${ }^{203}$ Protected gem-difluororibonolactone 186, obtained in $47 \%$ yield from 2-deoxy-D-ribonolactone $\mathbf{1 8 5}$, was then transformed into gemcitabine $\mathbf{1 5 1}$ as depicted in Scheme 100.

In 2014, a team of Merck researchers published the synthesis of 2-deoxy-2,2-difluoro-Dribose according to their "de novo" approach (Scheme 101). ${ }^{204}$ Optically active aldehyde $\mathbf{1 8 7}$ ( $83 \%$ ee) prepared through an enantioselective method, developed by the authors, was coupled with isopropyl bromodifluoroacetate under Reformatsky conditions: the suitably functionalized pentanoate was obtained as a mixture of diastereoisomers 188. Purification by flash chromatography provided the required diastereoisomer in 59\% yield. Removal of the 2,2,6,6-tetramethylpiperidinyl group (TMP) and concomitant cyclization afforded the difluorolactone 189 precursor of the ribose ring. Gemcitabine synthesis was then carried out through 1-iodine derivative 190, in the presence of persulfate, as previously reported. ${ }^{197,198}$ (see Scheme 96). At the end of the synthetic sequence gemcitabine was isolated in $23 \%$ overall yield, from optically active aldehyde 187, and a $1: 4 \alpha / \beta$-anomers ratio. This synthesis offers a promising approach to gemcitabine preparation; indeed the final purification could be carried out according to published methods. 
<smiles>C[C@H]1C[C@@H](O)[C@@H](CO)O1</smiles>

2-deoxy-ribonolactone

185

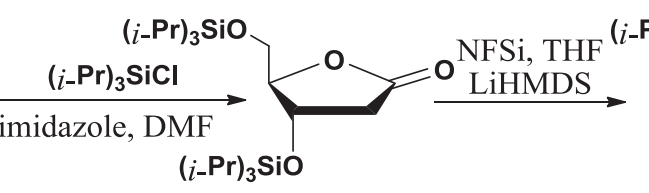

$(92 \%)$

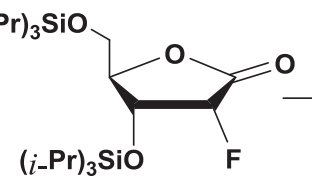

$(72 \%)$

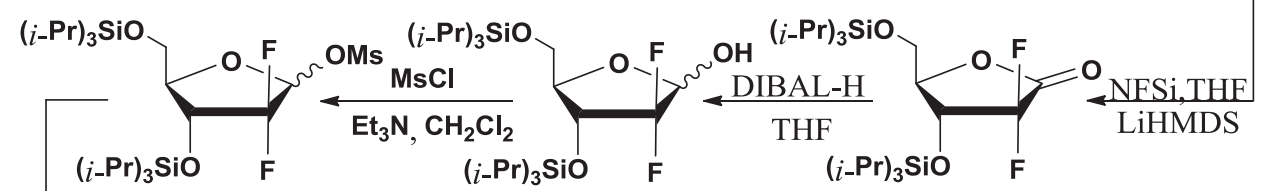

(quant.)

(91\%)

186

$(71 \%)$

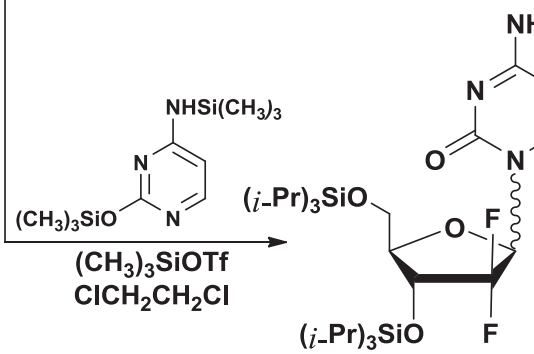

$(\alpha / \beta$ 1:1)
1. TMAF $\longrightarrow$ gemcitabine

2. DMF, ethyl acetate
purification by HPLC

\section{Scheme 100}

Beside the synthetic work, there are some publications dedicated exclusively to the 905 purification of gemcitabine base or hydrochloride. For example $99.8 \%$ pure gemcitabine hydrochloride was obtained by fractional crystallization at acidic $\mathrm{pH}(\leq 0.5) .{ }^{205}$

\section{Gemcitabine Derivatives}

Gemcitabine chemotherapeutic efficacy is limited by its high toxicity to normal cells and short plasma half-life (9-13 min for human plasma) depending on the rapid deamination by cytidine

910 deaminase in the liver, kidneys and plasma to less cytotoxic metabolites. Various prodrug strategies have been developed to overcome these adverse aspects and to allow for oral delivery.

Protection of the 4-amino group, for example as the amide, can facilitate a slower release of gemcitabine, increasing the bioavailability and uptake and providing resistance to enzymatic deamination. A series of 4-N-alkyl and 4-N-alkanoyl compounds were pre915 pared in $2014^{206}$ and their activity evaluated. $\mathrm{N}$-alkanoyl gemcitabine derivatives 191 showed potent cytostatic activity in the nanomolar range, whereas $\mathrm{N}$-alkyl derivatives 192 required micromolar range. The $\mathrm{N}$-alkanoyl derivatives 191 were prepared in 40$66 \%$ yield by reacting gemcitabine with a carboxylic acid in dimethylsulfoxide, in presence of $\mathrm{N}$-methylmorpholine, 1-hydroxybenzotriazole and (N-dimethylaminopropyl)- $\mathrm{N}^{1}$ 920 ethyl-carbodiimide (Scheme 102). The $\mathrm{N}^{4}$-alkyl derivatives 192 were prepared from protected gemcitabine $\mathbf{1 9 3}$ through its $\mathrm{N}^{4}$-tosylate by reaction with an amine.

$\mathrm{N}^{4}$-(2-Propyl-1-oxopentyl) derivative 194 was prepared in $2006,{ }^{207}$ by Eli Lilly (Scheme 103), designed to be resistant to deamination by hydrolysis under acidic conditions similar to those found in the digestive system but able to release gemcitabine 925 upon action by carboxylesterase. 


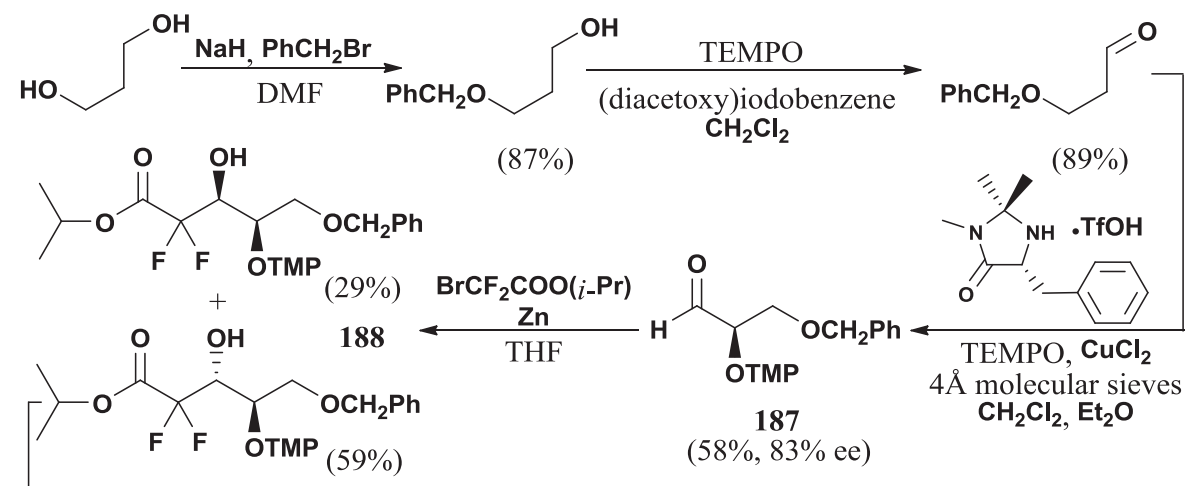

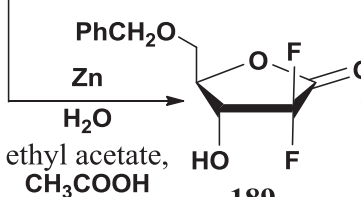

$\mathrm{CH}_{3} \mathrm{COOH}$
189 $(85 \%)$

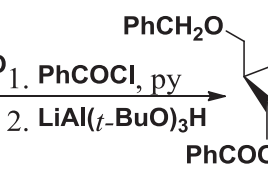

PhCOO

$(76 \%)$

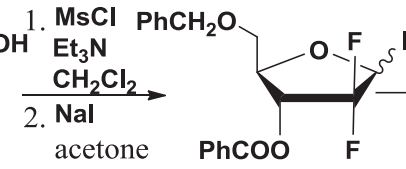

190 $(86 \%)$

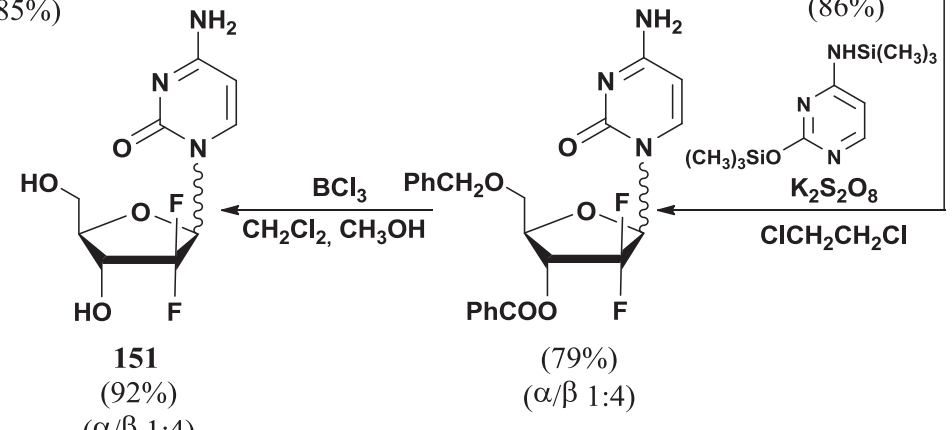

$(\alpha / \beta$ 1:4)

\section{Scheme 101}

$\mathrm{N}^{4}$-Benzoyl derivative 195 was prepared as depicted as shown in Scheme 104 and included into oligonucleotides aimed to preferentially kill cancerous cells over non-cancerous cells. ${ }^{208}$ Some oligonucleotides containing gemcitabine derivatives were shown to be more effective in killing cancerous cells at equivalent dosages of gemcitabine itself.

As in the case of capecitabine ${ }^{156}$ the hypoxic conditions of tumor cells can selectively activate a prodrug, mediating the fragmentation of a masked cytotoxic compound into the active cytotoxic agent; the masked cytotoxic agent can be $\mathrm{N}^{4}$-carbamate $196{ }^{156}$ (Scheme 105) or a $5^{\prime}$-ester with lipoic acid derivative $197^{209}$ (Scheme 106) that plays the role of the redox-modulating agent.

935 In a 2013 article the conjugation of gemcitabine with coumarin derivative $\mathbf{1 9 8}$ and biotin derivative 199 was described: ${ }^{210}$ the molecule contains the cleavable disulfide group of biotin, a molecule taken up preferentially by cancer cells, and a fluorescent moiety to enable real-time monitoring of the drug delivery. The synthesis of conjugate 200 and the proposed mechanism of action under physiological conditions, involving GSH, the most abundant thiol in the cells, are depicted in Scheme 107. 
<smiles>[R2]CCC(=O)Nc1ccn(C)c(=O)n1</smiles>

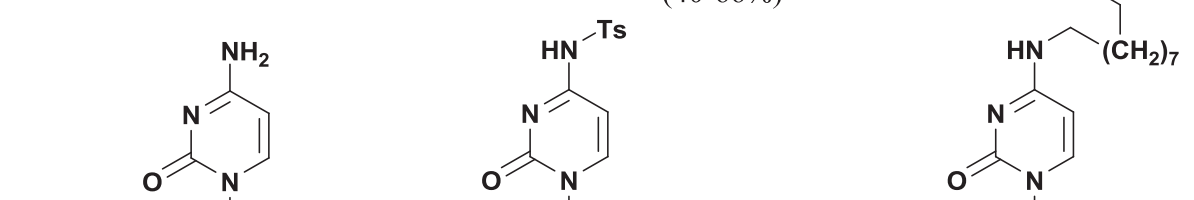

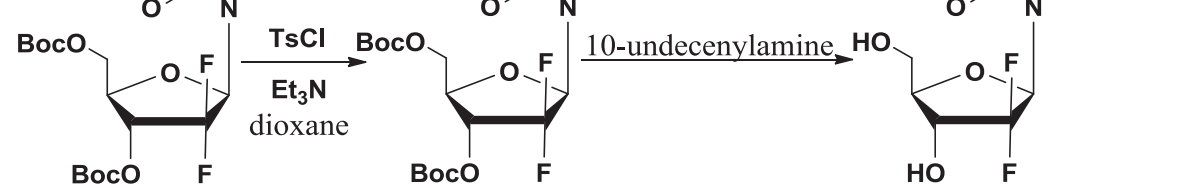

193

$(45 \%)$

$192 \mathrm{a}$

$(36 \%)$

11-amino-1-undecanol, $\mathrm{Et}_{3} \mathrm{~N}$, dioxane

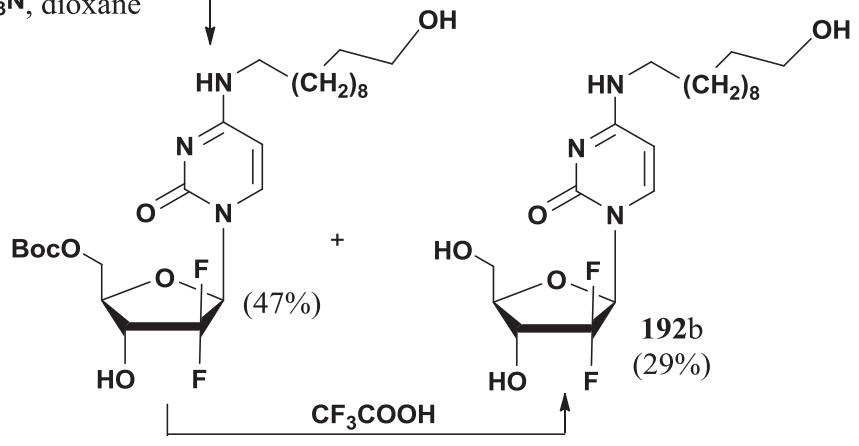

Scheme 102

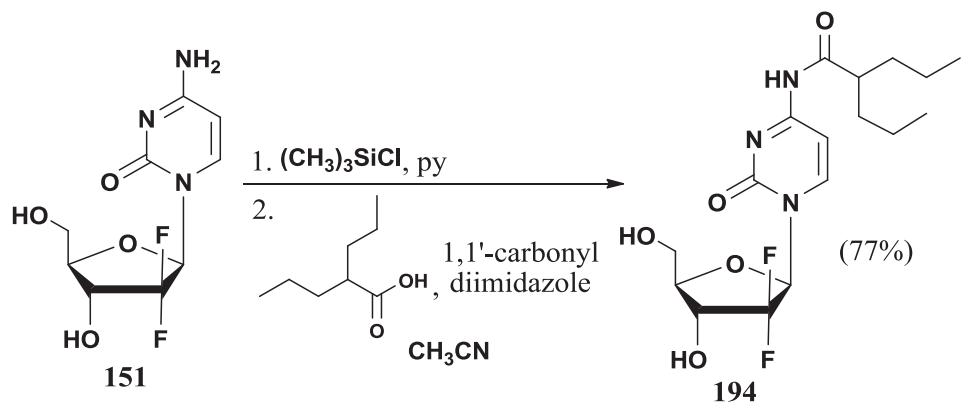

Scheme 103 


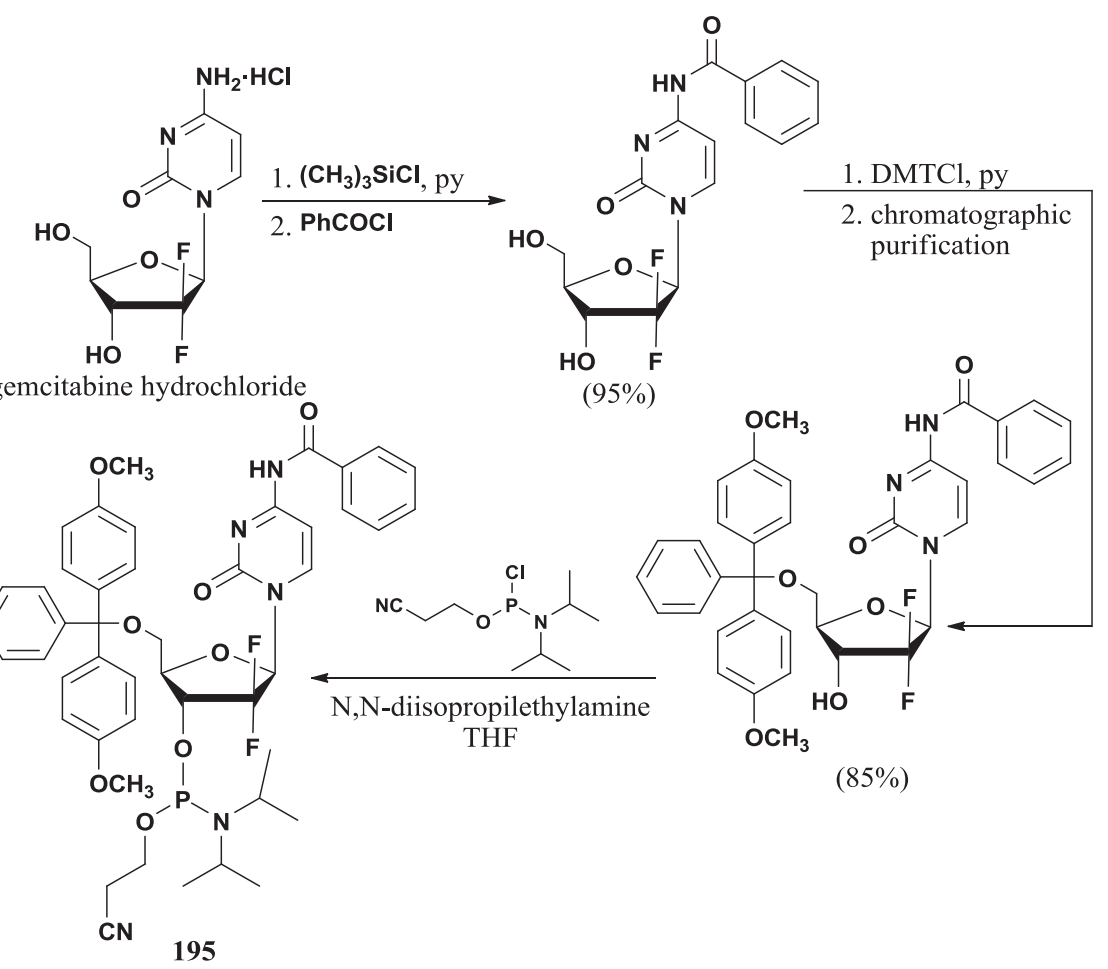

DMTCl = 4,4'-dimethoxytrityl chloride

\section{Scheme 104}

Besides conjugation with polymeric materials, ${ }^{211,212}$ the preparation of $\mathrm{N}^{4}$-derivatives with lipoaminoacid residues, suitable for penetration through biological membranes and barriers, was also reported. ${ }^{213}$ Lipoaminoacids are aminoacids bearing an alkyl chain in the 2-position. They impart to the molecule to which they are conjugated amphiphilic properties. Lipoaminoacid derivatives 201, prepared in $69 \%$ yield from gemcitabine hydrochloride (Scheme 108), in vitro results were encouraging of the study of the loading of these derivatives in liposomes and in other lipid based drug carriers.

Controlled drug delivery from chiral molecules is the aim of a study about the possibility of incorporating gemcitabine into the enantiomers of bis(diamido)-bridged basket 950 resorcin[4]arene 202, ${ }^{214}$ in the gaseous phase (Scheme 109). The diastereomeric complexes among the macrocycle, gemcitabine and a chiral amine behave as supramolecular devices which, depending on the configuration of macrocycle and amine, can or cannot release the nucleoside. Complexation phenomena were investigated ${ }^{215}$ by NMR methods and molecular modeling, allowing the identification of two different interaction sites of the guest in the resorcin[4]arene host. Different behaviors of resorcin[4]arene complexes with $2^{\prime}$-deoxycytidine, its $2^{\prime}$-epimer cytarabine and gemcitabine were observed. According to the authors, the assessment of the factors regulating the formations of these complexes offers the possibility to modulate the drug/receptor interactions, through the electronic properties of $2^{\prime}$-substituents on the nucleoside furanose ring.

960 The bioorthogonal approach, already described in the case of floxuridine, ${ }^{105}$ was also applied by the same authors to the preparation of gemcitabine prodrugs. ${ }^{216}$ Between the two masking possibilities, $5^{\prime}$-O-carbonate or $\mathrm{N}^{4}$-carbamate, the latter was chosen due to its higher 


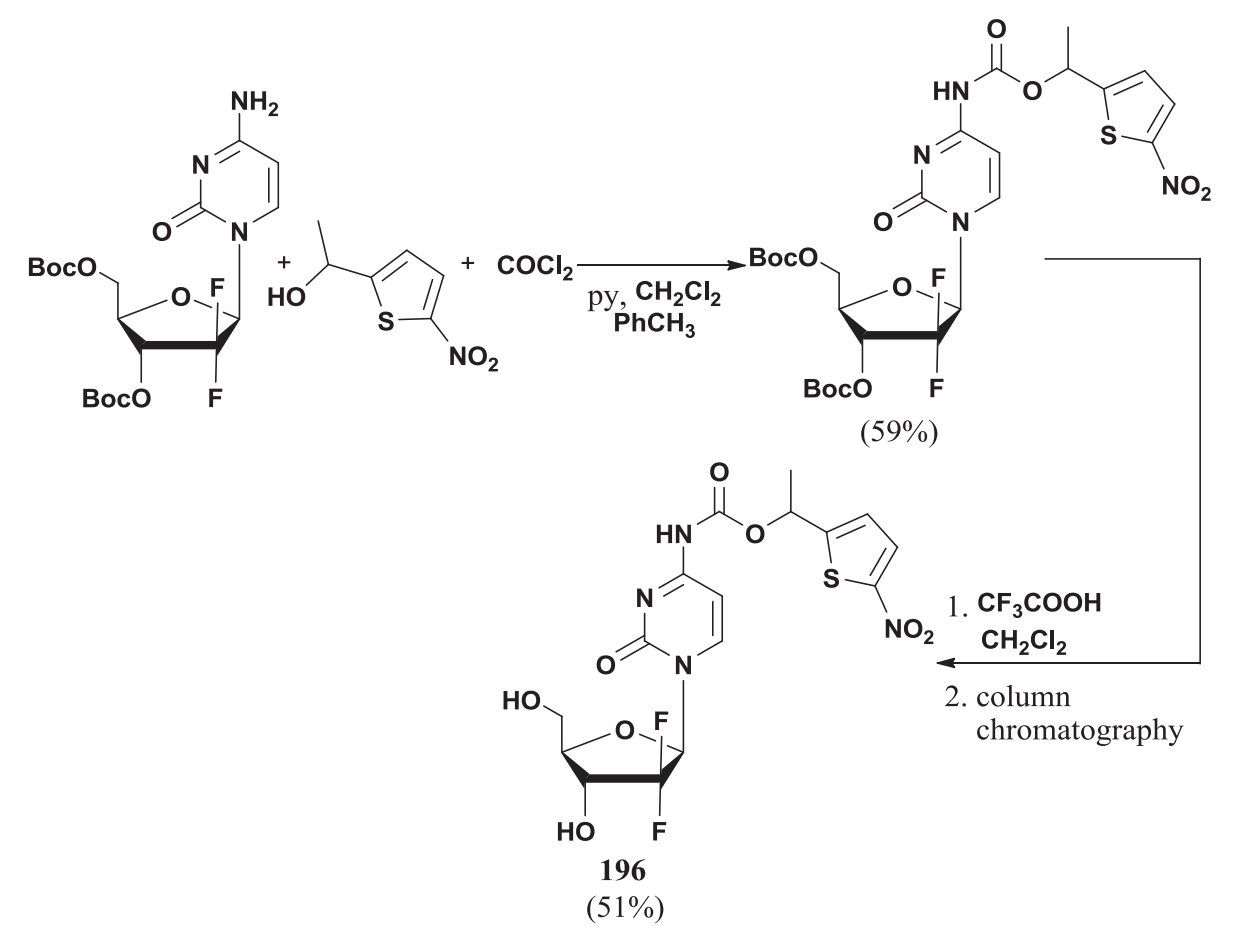

Scheme 105

stability to enzymatic metabolism. Starting from gemcitabine 151, propargyloxycarbonyl derivative 203 was prepared (Scheme 110), and treated with a $\mathrm{Pd}^{0}$-functionalized resin under 965 biocompatible conditions (buffer $\mathrm{pH} 7.4,37^{\circ} \mathrm{C}$ ), in order to remove the carbamate, and, then, placed in cell culture. In both cases the formation of free gemcitabine was monitored. DNA damage observed in pancreatic cancer cell cultures treated with $\mathrm{N}^{4}$-functionalized gemcitabine and $\mathrm{Pd}^{0}$-resin confirmed the bioorthogonal generation of free gemcitabine 151 .

\section{Related Non-Clinical Pyrimidine Nucleosides Fluorinated at the Sugar Moiety}

$9702^{\prime}, 2^{\prime}$-Difluorinated azacytidine 204 and $2^{\prime}, 2^{\prime}$-difluorodeoxyribose-trifluorothymidine 205 were recently ${ }^{169}$ prepared starting from suitably protected 1-bromo-2', $2^{\prime}$-difluorosugar, compound 206, in turn prepared as depicted in Scheme 111 and silylated (see Scheme 88) in order to obtain new fluoronucleosides.

Compound 204 is noteworthy for the presence of a nitrogen atom at the 5-position, 975 instead of a carbon, in addition to other modifications. Future studies will establish the clinical usefulness of these modifications.

In $2015^{217}$ two 2'-fluorotricyclo-DNA nucleosides 207 and 208 were synthesized. The introduction of fluorine on methylglycoside 209 was achieved through the electrophilic addition of Selectfluor to the 1,2-double bond of $\mathbf{2 1 0}$ and an approximately equimo980 lar mixture of 2-ribo $\mathbf{2 1 1}$ and 2-arabino $\mathbf{2 1 2}$ fluoro sugars was obtained as established by ${ }^{1} \mathrm{H}$ NMR NOE studies (Scheme 112). 


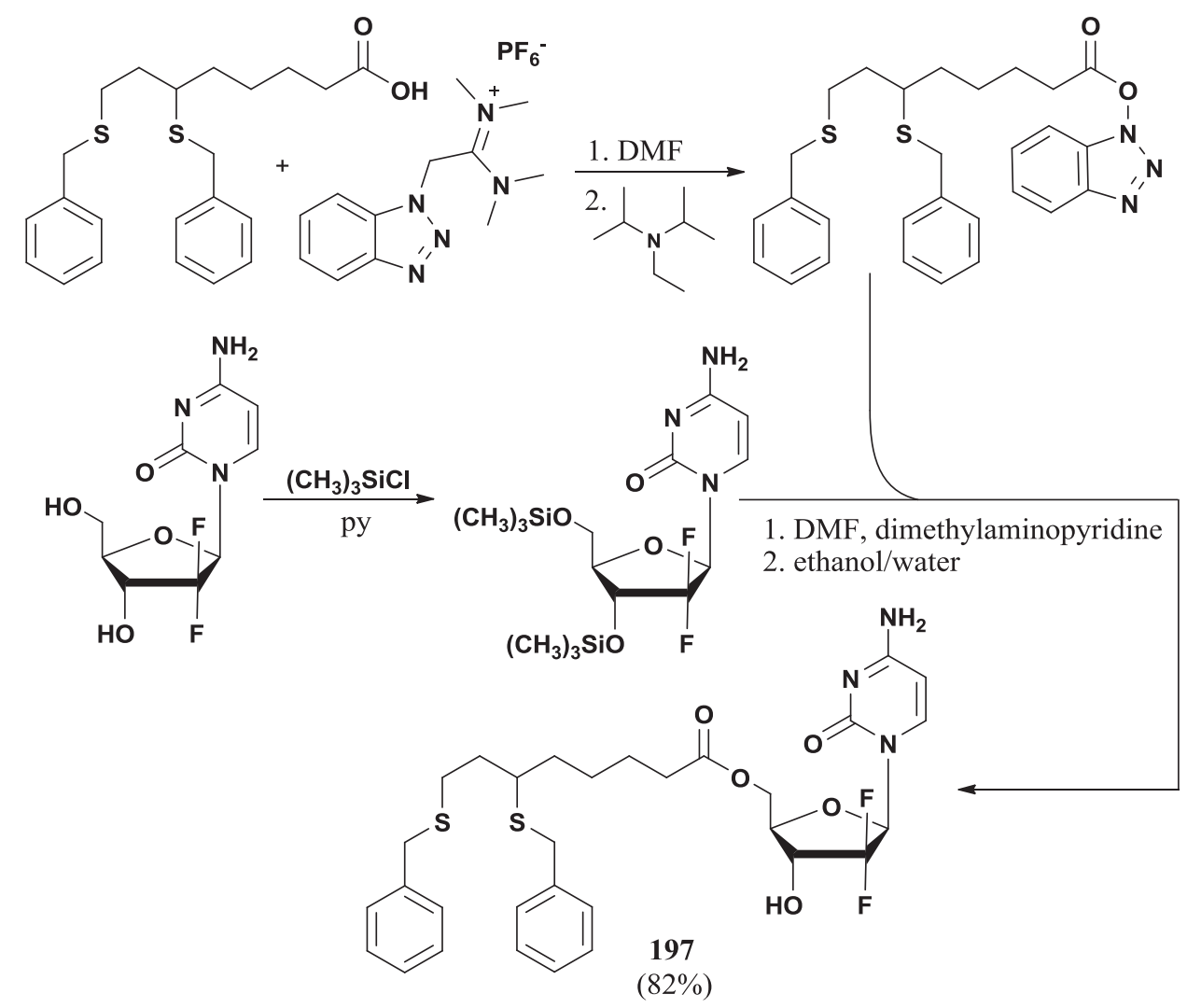

Scheme 106

The highly selective $\mathrm{N}$-glycosilation of 2-ribosugar 211, obtained after column chromatography, afforded thymine $2^{\prime}$-fluoro nucleoside 207 showing a 1:12 $\alpha / \beta$ anomeric ratio (Scheme 113).

985 The same intermediate $\mathbf{2 1 3}$ was converted into nucleoside $\mathbf{2 0 8}$ bearing the 5-methylcitosine as nucleobase according to Scheme 114.

Compounds 207 and 208 represent two novel fluorinated nucleoside analogues which in the future will be incorporated into oligonucleotide backbone structures.

\section{Radiolabeled Fluoropyrimidine Nucleosides as PET Tracers}

990 Radiolabeled antitumor agents may provide useful information about their metabolism and pharmacokinetics, in vivo, using functional imaging modalities such as Positron Emission Tomography (PET). Indeed, due to its good spatial resolution, PET allows workers to map the distribution of the radiotracers and their biological targets; moreover, depending on the selected molecular structure, PET is a powerful tool to accurately measure metabolic factors

995 and/or biochemical and physiological parameters. In the last decades, PET has found its major applications in oncology, where the preparation of molecules labeled with positron emitting radionuclides, and their subsequent use with human subjects provides useful diagnostic information. It even allows clinicians to directly affect therapeutic strategies. Based on the detection of high energy gamma photons generated by the annihilation of the posi1000 tron-electron pairs, PET is a highly sensitive technique, and radiolabeled tracers in nano to 


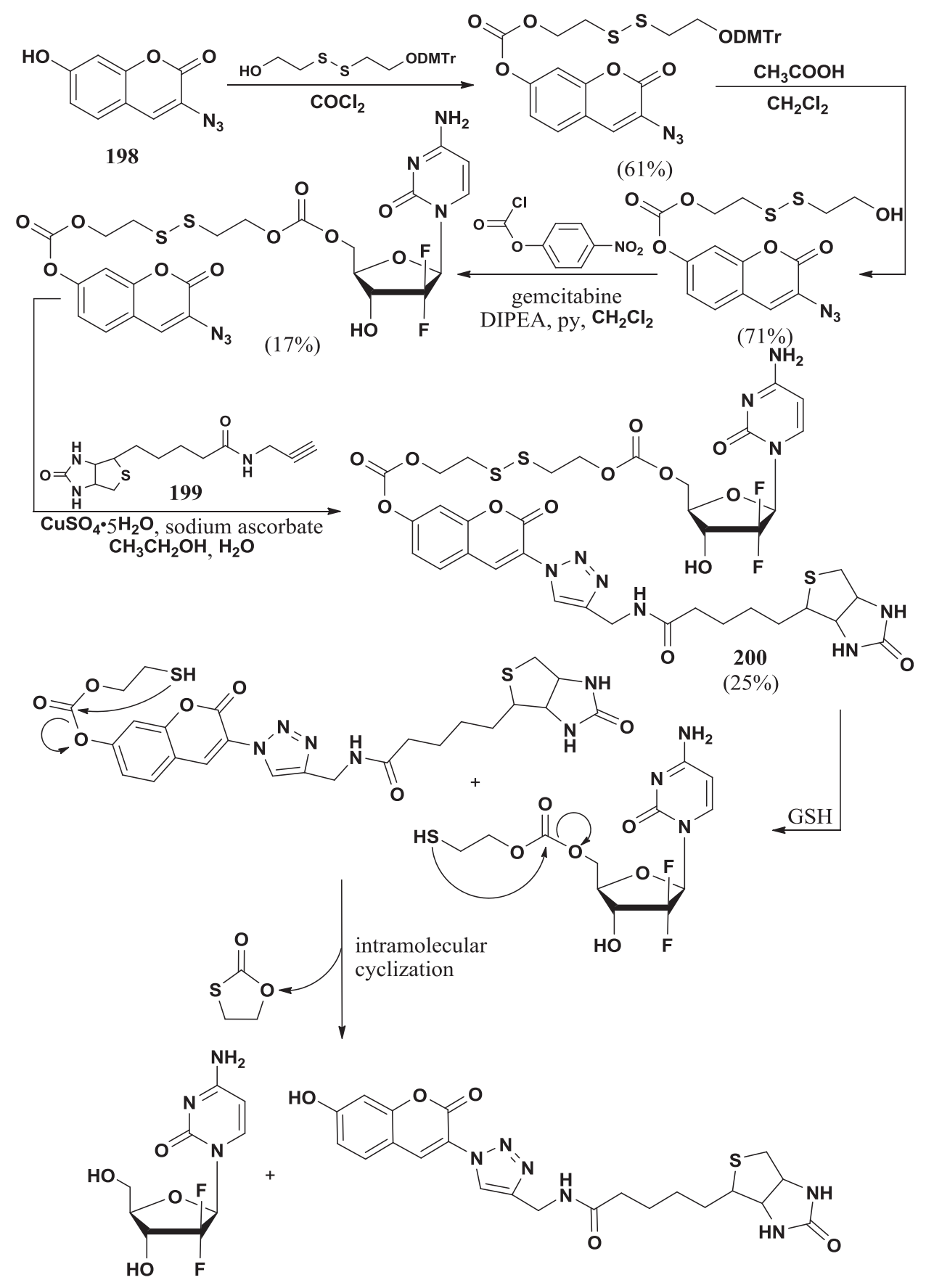

DMTr $=$ dimethoxytrityl

\section{Scheme 107}

picomolar concentrations (non-pharmacological concentrations) may be used, thus minimizing their potential toxicity. The most useful PET radionuclides are the short half-life ${ }^{11} \mathrm{C}\left(\mathrm{t}_{1 / 2}\right.$ $=20.4 \mathrm{~min})$ and ${ }^{18} \mathrm{~F}\left(\mathrm{t}_{1 / 2}=109.6 \mathrm{~min}\right)$. The first nucleoside based PET tracer was $\left[{ }^{11} \mathrm{C}\right]-$ 


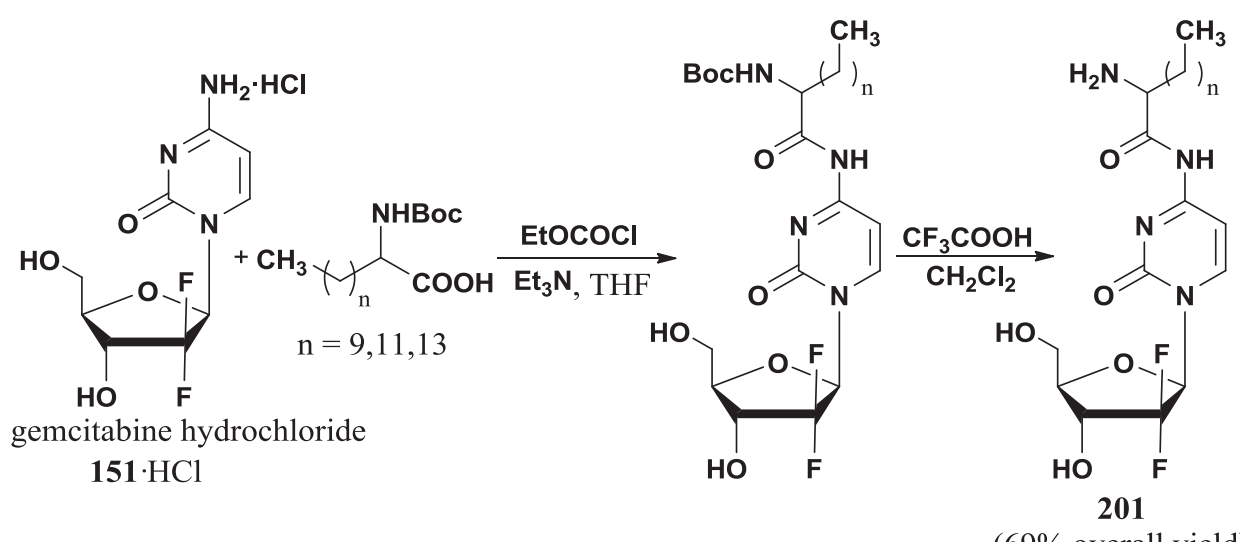

(69\% overall yield)

\section{Scheme 108}

thymidine ${ }^{218}$, and later $\left[{ }^{11} \mathrm{C}\right]-5-\mathrm{FU}$ was synthesized ${ }^{219}$, with the aim to monitor the levels of 1005 5-FU following therapeutic treatments. Starting from the $\beta$-(N-Benzoylamino)- $\alpha$-fluoroacrylamide 214, prepared from sodium ethyl-2-fluoro-3-hydroxyacrylate $\mathbf{2 1 5}$, as depicted in Scheme 115, the introduction of ${ }^{11} \mathrm{C}$ was achieved using $\left[{ }^{11} \mathrm{C}\right]$-phosgene, prepared by the same authors in 2002. ${ }^{220}$ Acrylamide with the suitable double bond E-stereochemistry 216 was obtained by the irradiation of the Z-isomer 217. The radiochemical yield was about $25 \%$.

$1010 \quad{ }^{11} \mathrm{C}$ was initially selected as the preferred radionuclide because it replace a ${ }^{12} \mathrm{C}$ in the molecular structure, thus not altering the biological behavior of the radiolabeled probe, compared with its "cold" counterpart. On the contrary, its very short half-life may be a

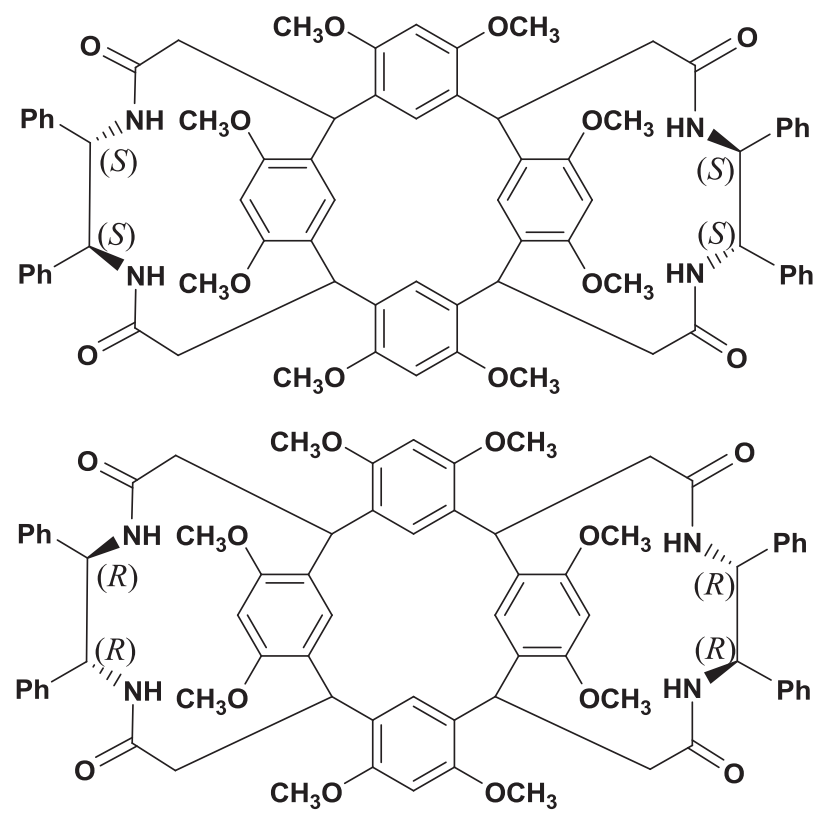

resorcin[4]arene macrocycle enantiomers

202

Scheme 109 


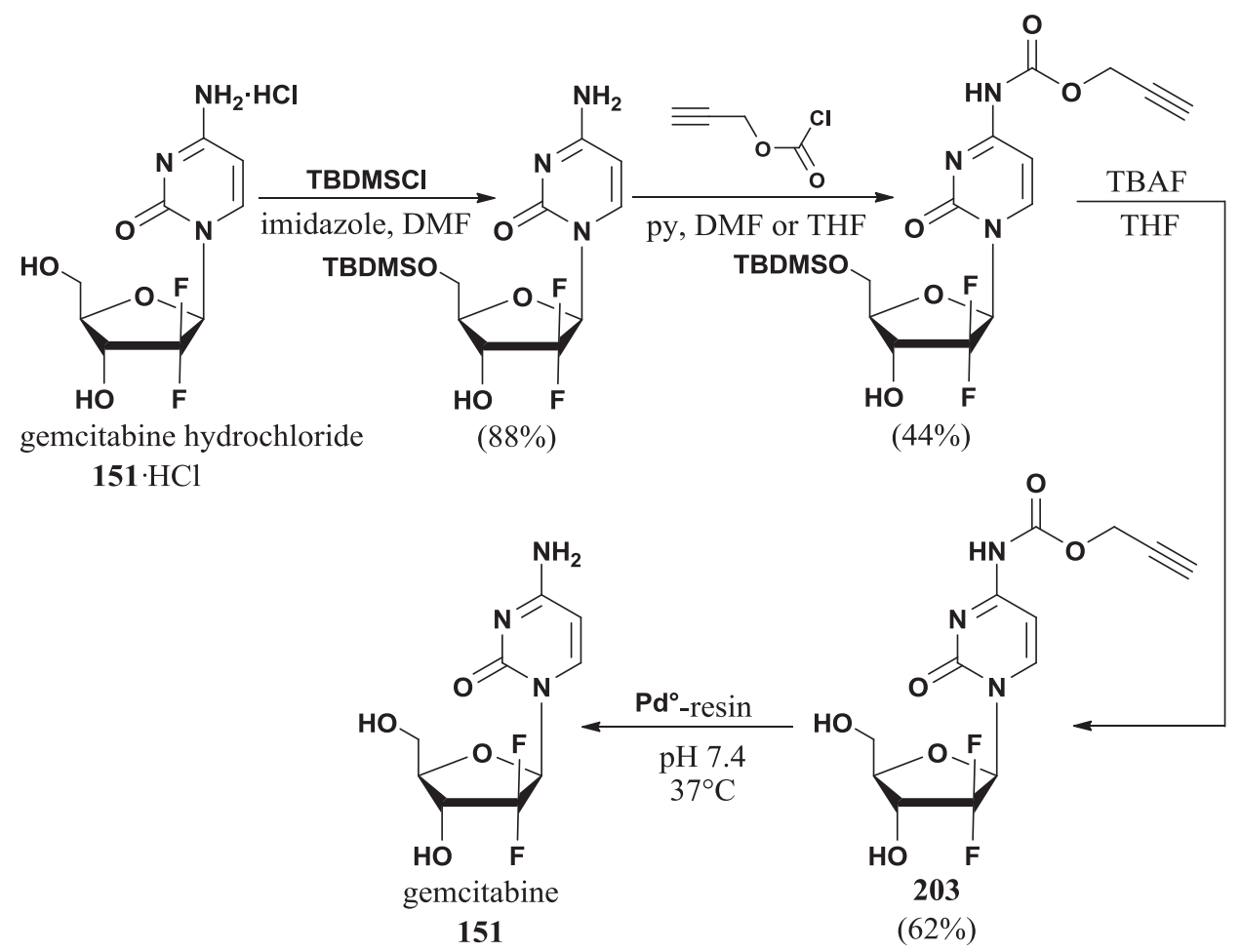

Scheme 110

serious drawback, especially in case of slow kinetics, in vivo. For these reasons, attention was then focused on the preparation of F-18 labeled radiotracers. F-18 has a considerably

1015 longer half-life, which is compatible with the biological half-life of slow kinetics molecules, and at the same time allows for longer radiosynthetic pathways. Furthermore, F-18 is produced efficiently and with high yield, and higher starting activity may also help to improve the radiopharmaceutical's availability, Finally, the $110 \mathrm{~min}$ half-life of F-18 allows for the radiotracer distribution to other PET centers not equipped with a cyclotron,

1020 thus improving availability and reducing general preparation costs. For instance, the $\left[{ }^{11} \mathrm{C}\right]$-based tracers were later superseded by $\left[{ }^{18} \mathrm{~F}\right]$-FLT ( $3^{\prime}$-deoxy- $3^{\prime}$-fluorothymidine), ${ }^{221}$ which is still one of the most frequently used PET radiotracers in the field of oncology.

$\left[{ }^{18} \mathrm{~F}\right]$-capecitabine218 ${ }^{222,}{ }^{223}$ was synthesized, as an enzyme based imaging agent, to enable non- invasive monitoring of tumor enzymes (thymidine phosphorylase and uridine phos-

1025 phorylase) (see Scheme 1) and tumor response to capecitabine therapy, using PET technique.

A $2004^{222}$ paper reported the synthesis of $\left[{ }^{18} \mathrm{~F}\right]$-capecitabine 218 through the nucleophilic substitution of the 5-nitro group of $2^{\prime}, 3^{\prime}$-di-O-acetyl-5'-deoxy-5-nitro- $\mathrm{N}^{4}$-(pentyloxycarbonyl)cytidine 219 by reaction with $\mathrm{K}^{18} \mathrm{~F}$ (prepared in a RDS-112 cyclotron) in the presence of a bicyclic kryptand, Kryptofix 2.2.2 (Scheme 116). The nitro-precursor

1030 was prepared from 5-deoxy-1,2,3-tri-O-acetyl-D-ribose $\mathbf{1 0 5}$ (obtained from D-ribose) and 5-nitrocytosine $\mathbf{2 2 0}$ in $18 \%$ overall yield.

A different approach was described by a Korean team ${ }^{223}$ using as substrate $\mathrm{N}^{4}$-(pentyloxycarbonyl)-cytidine 221, which introduced ${ }^{18} \mathrm{~F}$ by direct electrophilic fluorination with $\left[{ }^{18} \mathrm{~F}\right]-\mathrm{F}_{2}$ generated in a MC-50 cyclotron. The radiochemical yield and radiochemi1035 cal purity were $5-15 \%$ and $>95 \%$, respectively (Scheme 117). 


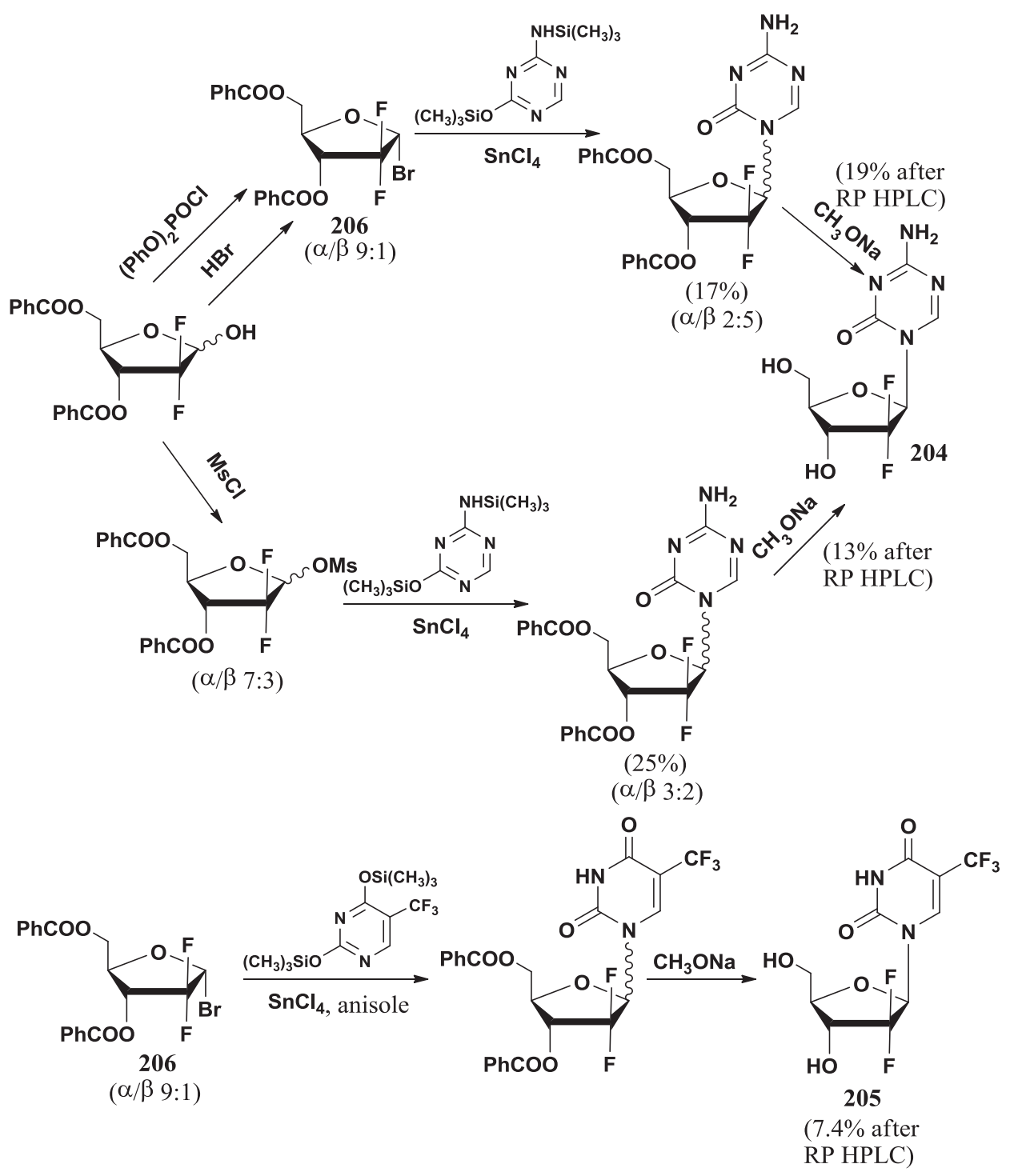

Scheme 111

An attempt to prepare a $\left[{ }^{18} \mathrm{~F}\right]$-labeled gemcitabine derivative, ${ }^{206}$ failed at the early steps of the synthesis since the addition of unlabeled HF (70\% in pyridine) to $\mathrm{N}^{4}-(10$ undecenoyl)-2',2'-difluorocytidine led to a mixture of 10-, 9- and 8-fluorinated isomers.

A very interesting enzyme-catalyzed formation of $\mathrm{C}-\mathrm{F}$, suitable also to produce 1040 labeled fluoronucleosides was proposed by O'Hagan and coworker in 2003. ${ }^{224-228}$ They used the enzyme fluorinase, crude or partially purified, extracted from Streptomyces cattleya. The enzyme is capable to catalyze the synthesis of fluoro compounds, particularly fluoronucleosides, in the presence of a fluorine donor (lithium, potassium or sodium fluoride) or hydrogen fluoride and of the substrate. (Scheme 118).

1045 The substrate was S-adenosyl-L-methionine (SAM) 222 that, by action of fluorinase, underwent a nucleophilic substitution (L-methionine 223 as leaving group) leading to $5^{\prime}$ - 


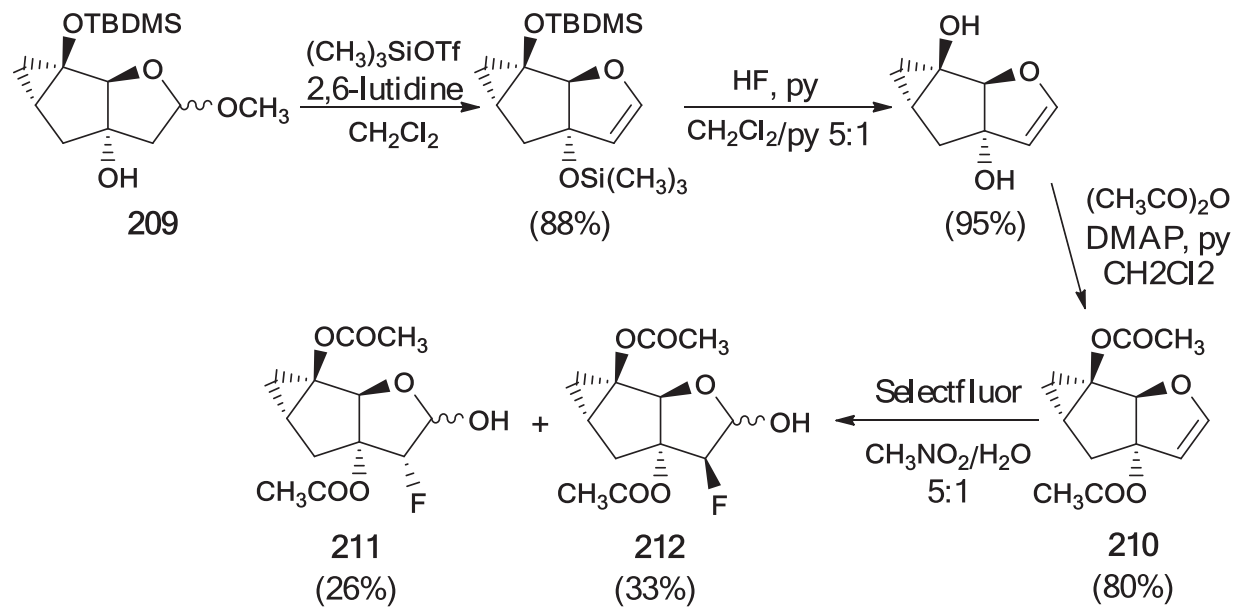

Scheme 112

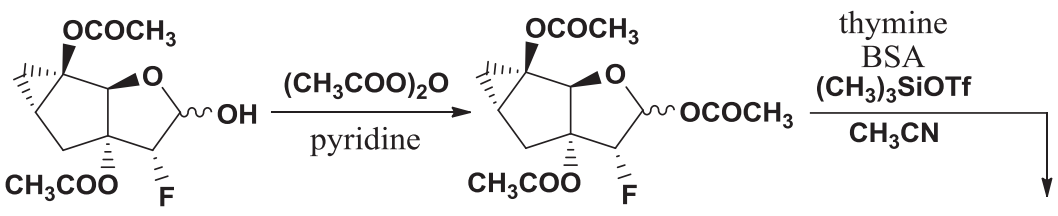

211

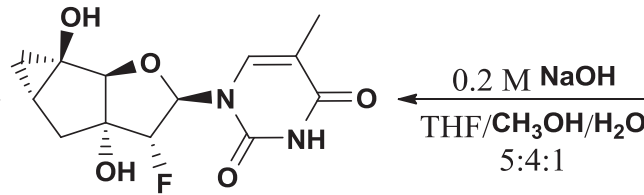

$(94 \%)$<smiles>CO[C@@H]1CC[C@]2(OC(C)=O)[C@@H](F)[C@H](n3cc(C)c(=O)[nH]c3=O)O[C@H]12</smiles>

213

(66\% from 211)

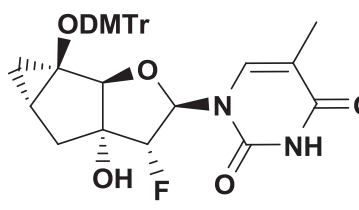

$(97 \%)$

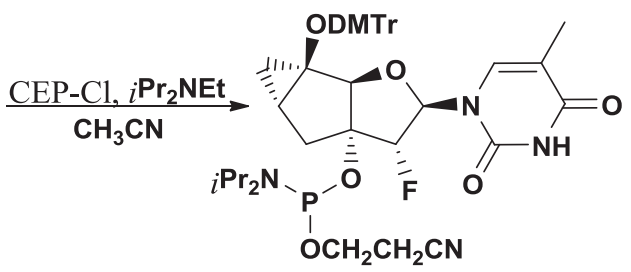

207

$(66 \%)$

$\mathrm{CEP}-\mathrm{Cl}=\operatorname{chloro}(2$-cyanoethoxy $)($ diisopropylamino $)$ phosphine DMTr-Cl = 4,4'-dimethoxytrityl chloride

Scheme 113 


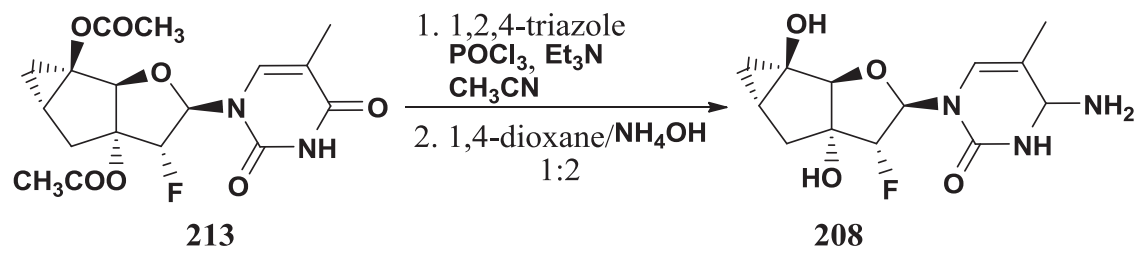

Scheme 114

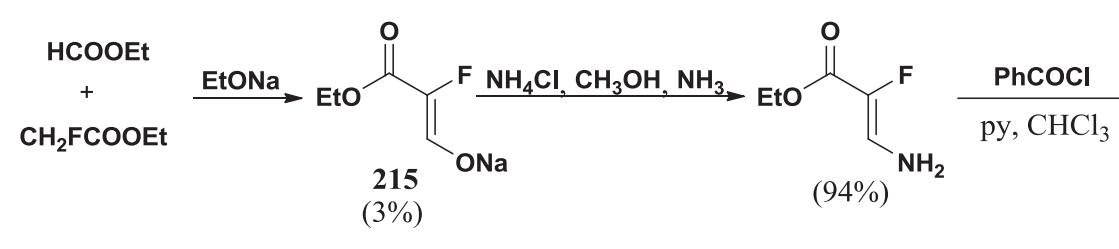

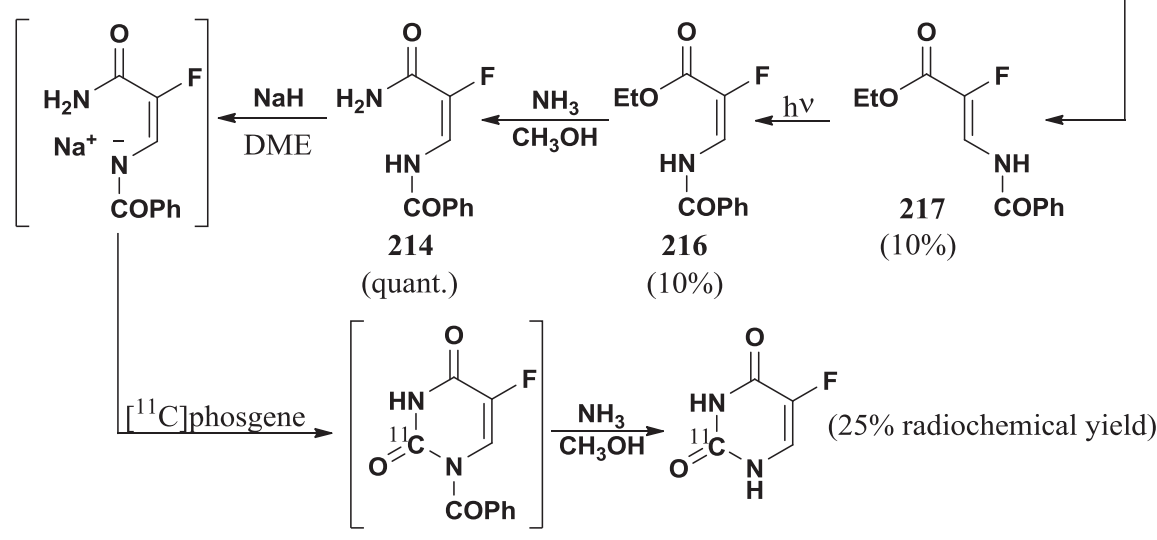

Scheme 115

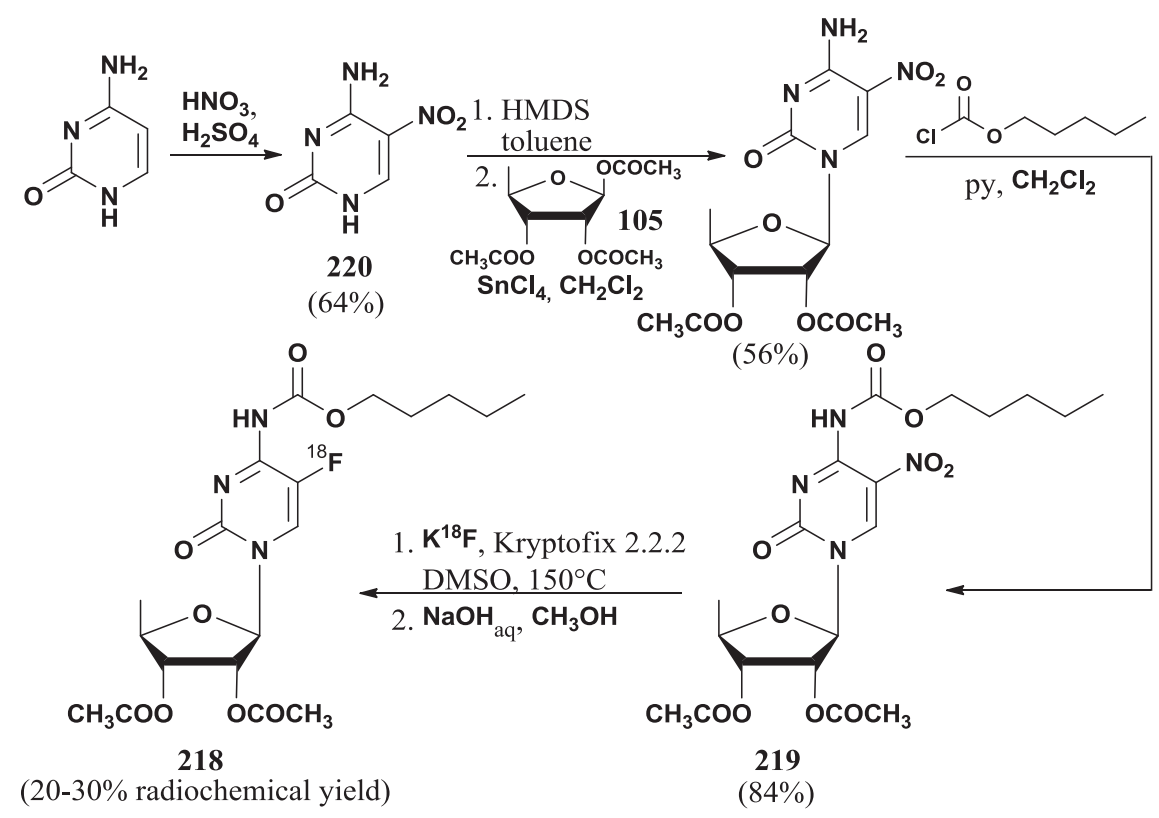

Scheme 116 


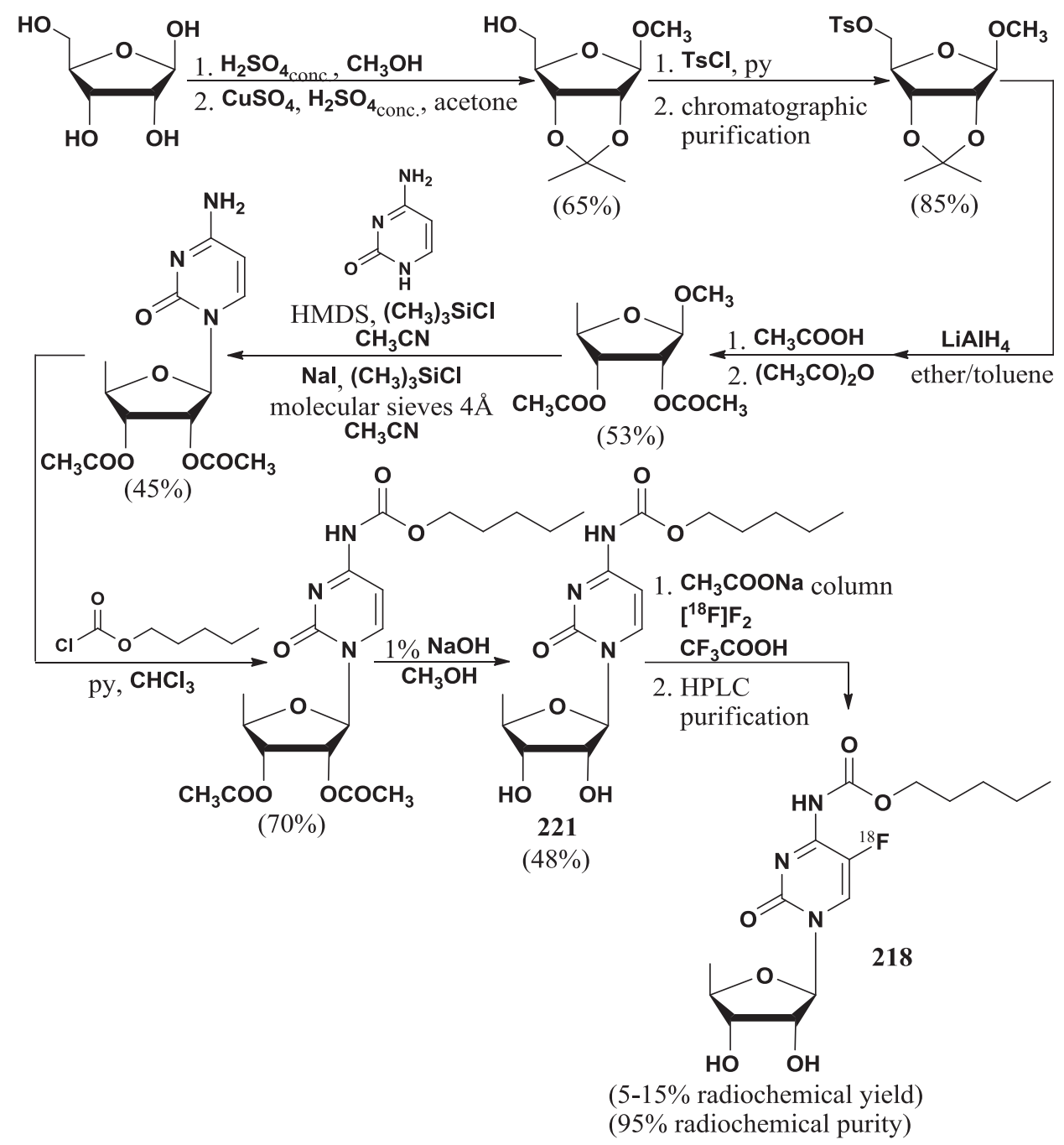

Scheme 117

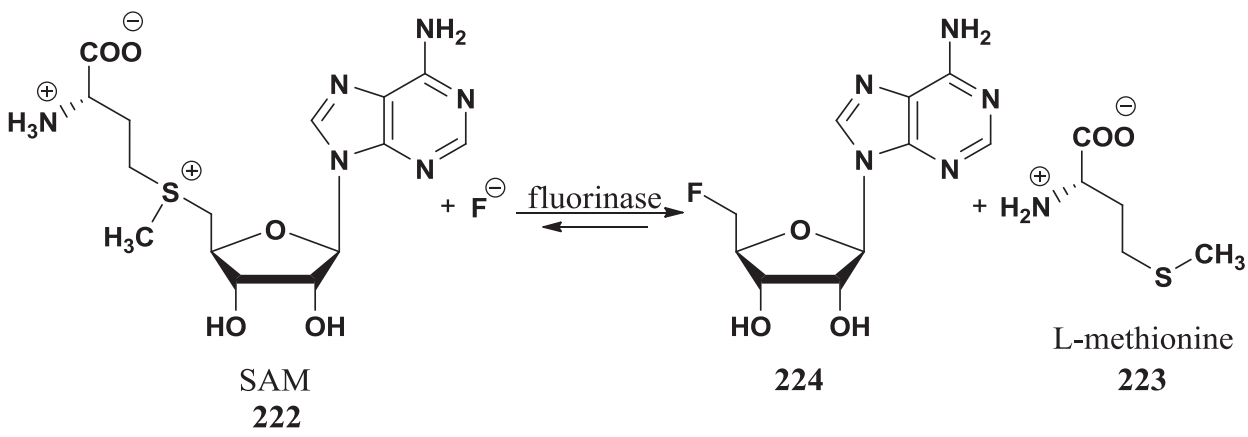

Scheme 118 
fluoro- $5^{\prime}$-deoxyadenosine 224; the method was also applied to the synthesis of $\left[{ }^{18} \mathrm{~F}\right]-5^{\prime}$ fluoro- $5^{\prime}$-deoxyadenosine. ${ }^{227}$ Hydrolysis of the N-glycosidic bond by means of nucleoside hydrolase from Trypanosoma vivax afforded 5-deoxy-5-[ $\left.{ }^{18} \mathrm{~F}\right]$-ribose. ${ }^{221}$ Starting

1050 from $\left[{ }^{18} \mathrm{~F}\right]-5^{\prime}$-fluoro- $5^{\prime}$-deoxyadenosine by means of an enzyme-catalyzed transglycosylation $\left[{ }^{18} \mathrm{~F}\right]-5^{\prime}$-fluoro- $5^{\prime}$-deoxy-5-fluorouracil was also obtained. ${ }^{227}$ This and other examples recently reviewed ${ }^{229}$ are promising of a wider application of the method, at the present limited to the fluorination of the $5^{\prime}$-position. More recently an enzyme with the same activity was isolated from the marine derived bacterium Streptomyces 1055 xinghaiensis. $^{230}$

\section{Conclusion}

Fluorinated nucleosides represent an important category of nucleoside analogues endowed with antitumor and/or antiviral activity. This review focused on antitumor pyrimidine nucleosides bearing fluorine on the nucleobase or on the glycone.

1060 5-FU 1 is more than 50 years old but it is still used, in combination with other anticancer drugs (for example, avastatatin and oxaliplatin), for the treatment of metastatic colorectal cancer. A more recent therapeutic indication of 5-FU $\mathbf{1}$ is the topical use (cream or solution) for the treatment of skin cancers and Bowen's disease. Capecitabine (Xeloda) 63 is the most frequently used therapeutic fluoropyrimidine nucleoside, alone or in com-

1065 bination with other drugs and, like other relevant fluoropyrimidines nucleosides analogues, can be regarded as a 5-FU prodrug. Gemcitabine (Gemzar) 151 belongs to the group of nucleosides fluorinated on the glycone moiety and it is among the ten leading brands in the global cancer market.

Considering the impressive number of fluorinated pyrimidine nucleosides, a choice

1070 of scope was mandatory, and we decided to select clinically well-established compounds, and their derivatives designed to improve the pharmacological properties of the parent compounds. This choice excluded, for example, nucleoside analogues characterized by the presence of a heteroatom $(\mathrm{N}, \mathrm{S}, \mathrm{Se})$, different from oxygen in the 5 -atoms ring ${ }^{173}$ or the carbocyclic analogues, ${ }^{172,231}$ which are no less interesting than the discussed com-

1075 pounds. Despite the numerous compounds that have received marketing authorization, the demand for antitumor oral fluoro pyrimidine nucleosides is still of concern; the design and the synthesis of more selective molecules remains a target of pharmaceutical research. Such research may develop the possibility of patient-tailored therapy based on individualized combinations of the described molecules. We hope that the synthetic meth-

1080 ods described in this review, suitably adapted, could be a valuable aid in the development of new nucleoside analogues.

\section{Acknowledgments}

We thank Dr. Paola Rota of the Department of Scienze Biomediche, Chirurgiche e Odontoiatriche for technical assistance.

\section{References}

1. T. Ishikawa, M. Utoh, N. Sawada, M. Nishida, Y. Fukase, F. Sekiguchi and H. Ishitsuka, Biochem. Pharmacol., 55, 1091 (1998). 
2. A. Yokoyama, Y. Nakai, S. Yoneda, Y. Kurita and H. Niitani, Anti-cancer Drugs, 8, 574 (1997).

1090 3. R. J. Rutman, A. Cantarow and K. E. Paschkis, Cancer Res., 14, 119 (1954).

4. C. Heidelberger, N. K. Chaudhuri, P. Danneberg, D. Mooren, L. Griesbach, R. Duschinsky, R. J. Schnitzer, E. Pleven and J. Scheiner, Nature, 179, 663 (1957).

5. M. Malet-Martino, P. Jolimaitre and R. Martino, Curr. Med. Chem. Anti-cancer Agents, 2, 267 (2002).

1095 6. M. G. Rose, M. P. Farrell and J. C. Schmitz, Clin. Colorectal Cancer, 1, 220 (2002).

7. D. Papamichael, Stem. Cells, 18, 166 (2000).

8. C. Aschele, A. Sobrero, M. A. Faderan and J. R. Bertino, Cancer Res., 52, 1855 (1992).

9. A. F. Sobrero, C. Aschele, A. P. Guglielmi, A. M. Mori, G. G. Melioli, R. Rosso and J. R. Bertino, J. Natl. Cancer Inst., 85, 1937 (1993).

1100 10. A. F. Sobrero, C. Aschele and J. R. Bertino, J. Clin. Oncol., 15, 368 (1997).

11. R. Duschinsky, E. Pleven and C. Heidelberger, J. Am. Chem. Soc., 79, 4559 (1957).

12. C. Heidelberger and R. Duschinsky, US 2802005, 1957; Chem. Abstr., 52, 11450 (1958).

13. M. J. Robins and S. R. Naik, J. Am. Chem. Soc., 93, 5277 (1971).

14. D. H. Barton, R. H. Hesse, H. T. Toh and M. M. Pechet, J. Org. Chem., 37, 329 (1972).

1105 15. M. J. Robins, M. MacCoss, S. R. Naik and G. Ramani, J. Am. Chem. Soc., 98, 7381 (1976).

16. D. Cech, H. Meinert, G. Etzold and P. Langen, J. Prakt. Chem., 315, 149 (1973).

17. R. Anderson and P. D. Schuman, US 3954759, 1976; Chem. Abstr., 85, 46744 (1976).

18. S. S. Yemul, H. B. Kagan and R. Setton, Tetrahedron Lett., 21, 277 (1980).

19. S. Misaki, S. Ishii, N. Suzuki, M. Wakabayashi and T. Sowa, US 4122251, 1978; Chem. $1110 \quad$ Abstr., 88, $121236(1978)$.

20. A. Yamazaki, H. Morisawa, Y. Oda and K. Uchida, US 4186266, 1980; Chem. Abstr., 90, 121648 (1979).

21. O. Miyashita, K. Matsumura, H. Shimadzu and N. Hashimoto, Chem. Pharm. Bull., 29, 3181 (1981).

1115 22. O. Miyashita, K. Matsumura, H. Shimazu and N. Hashimoto, US 4329460, 1982; Chem. Abstr., 88, 105397 (1978).

23. R. J. De Pasquale and P. D. Schuman, US 4299961, 1981; Chem. Abstr., 95, 187297 (1981).

24. B. Baasner and E. Klauke, J. Fluorine Chem., 45, 417 (1989).

25. R. E. Banks, D. S. Field and R. N. Haszeldine, J. Chem. Soc., C, 1280 (1970).

1120 26. A. Haas and D. Kortmann, Chem. Ber., 114, 1176 (1981).

27. T. Umemoto and E. Ogura, US 4631342, 1986; Chem. Abstr., 104, 34082 (1986).

28. M. Diksic, S. Farrokhzad and L. D. Colebrook, Can. J. Chem., 64, 424 (1986).

29. G. W. M. Visser, S. Boele, B. W. Van Halteren, G. H. J. N. Knops, J. D. M. Herscheid, G. A. Brinkman and A. Hoekstra, J. Org. Chem., 51, 1466 (1986). 
1125 30. G. W. M. Visser, R. E. Herder, F. J. J. Dekanter and J. D. M. Herscheid, J. Chem. Soc. Perkin Trans. I, 1203 (1988).

31. G. W. M. Visser, R. Wedzinga, R. P. Klok and J. D. M. Herscheid, J. Chem. Soc. Perkin Trans. II, 231 (1994).

32. G. S. Lal, W. Pastore and R. Pesaresi, J. Org. Chem., 60, 7340 (1995).

1130 33. W. K. Chung, J. H. Chung and K. A. Watanabe, J. Heterocycl. Chem., 20, 457 (1983).

34. T. Fuchikami, A. Yamanouchi and Y. Suzuki, Chem. Lett., 1573 (1984).

35. G. Q. Shi, Q. Wang and M. Schlosser, Tetrahedron, 52, 4403 (1996).

36. D. S. Hitchcock, A. A. Fedorov, E. V. Fedorov, S. C. Almo and F. M. Raushel, Biochemistry, 53, 7426 (2014).

1135 37. M. Kawase, K. Samejima, M. Okada, K. Ochi and I. Matsunaga, Chem. Pharm. Bull., 33, 2395 (1985).

38. F. M. Menger and M. J. Rourk, J. Org. Chem., 62, 9083 (1997).

39. T. W. B. Cai, X. P. Tang, J. Nagorski, P. G. Brauschweiger and P. G. Wang, Bioorgan. Med. Chem., 11, 4971 (2003).

1140 40. J. E. Saavedra, T. R. Billiar, D. L. Williams, Y. M. Kim, S. C. Watkins and L. K. Keefer, J. Med. Chem., 40, 1947 (1997).

41. T. Kametani, K. Kigasawa, M. Hiiragi, K. Wakisaka, S. Haga, Y. Nagamatsu, H. Sugi, K. Fukawa, O. Irino, T. Yamamoto, N. Nishimura, A. Taguchi, T. Okada and M. Nakayama, J. Med. Chem., 23, 1324 (1980).

1145 42. A. Buur and H. Bundgaard, J. Pharm. Sci., 75, 522 (1986).

43. R. M. Phelan, M. Ostermeier and C. A. Townsend, Bioorg. Med. Chem. Lett., 19, 1261 (2009).

44. T. Kametani, K. Kigasawa, M. Hiiragi, K. Wakisaka, K. Nakazato, K. Ichikawa, K. Fukawa, O. Irino, N. Nishimura and T. Okada, J. Med. Chem., 25, 1219 (1982).

45. R. A. Zhuk, A. S. Ludzisha, Y. G. Shpaer, M. Y. Lidak, A. A. Zidermane and D. V. Meirena, 1150 Chem. Heterocycl. Compd., 21, 1159 (1985).

46. Z. S. Zhang, Q. B. Zhang, J. Wang, X. L. Shi, J. J. Zhang and H. F. Song, Carbohyd. Polym., 79, 628 (2010).

47. M. K. Kilevitsa, Yu. A. Maurin'sh, R. A. Paégle, E. Liepin'sh, A. A. Zidermane and M. Yu. Lidak, Khim. Geterotsikl. Soedin., 11, 1532 (1981); Chem. Abstr., 96, 85922 (1982).

1155 48. Yu. A. Maurin' sh, R. A. Paégle, K. V. Khagi, D. V. Meirena, B. Z. Simkhovich and M. Yu. Lidak, Pharm. Chem. J., 22, 466 (1988).

49. T. Kuroda, K. Hisamura, I. Matsukuma, H. Nishikawa and N. Nakamizo, Bull. Chem. Soc. Jpn., 62, 674 (1989).

50. S. Nishimoto, H. Hatta, H. Ueshima and T. Kagiya, J. Med. Chem., 35, 2711 (1992).

1160 51. M. Mori, H. Hatta and S. Nishimoto, J. Org. Chem., 65, 4641 (2000).

52. S. S. Agasti, A. Chompoosor, C. C. You, P. Ghosh, C. K. Kim and V. M. Rotello, J. Am. Chem. Soc., 131, 5728 (2009).

53. K. Fujimoto, Y. K. Takematsu, A. Shigeno, M. Furusawa and T. Sakamoto, Bioorg. Med. Chem. Lett., 24, 3736 (2014). 
1165 54. J. S. de Bono and C. J. Twelves, Invest. New Drugs, 19, 41 (2001).

55. J. G. Kuhn, Ann. Pharmacother., 35, 217 (2001).

56. P. M. G. Hoff, Semin. Oncol., 30, 88 (2003).

57. T. Watanabe, Breast Cancer, 20, 302 (2013).

58. S. Hillers, R. A. Zhuk, M. Lidaks and A. Zidermane, GB 1168391, 1969; Chem. Abstr., 72 , $1170 \quad 43715(1970)$.

59. S. Hillers, M. Lidaks, R. A. Zhuk, A. Berzina, K. Pets, I. N. Getsova and E. I. Bruk, Chem. Heterocycl. Compds., 5, 283 (1969).

60. C. G. Kruse, F. L. Jonkers, V. Dert and A. Van der Gen, Recl. Trav. Chim. Pays-Bas, 98, 371 (1979).

1175 61. S. Ozaki, Y. Watanabe, T. Hoshiko, T. Nagase, T. Ogasawara, H. Furukawa, A. Uemura, K. Ishikawa, H. Mori, A. Hoshi, M. Iigo and R. Tokuzen, Chem. Pharm. Bull., 34, 150 (1986).

62. M. Yasumoto, A. Moriyama, N. Unemi, S. Hashimoto and T. Suzue, J. Med. Chem., 20, 1592 (1977).

63. S. Hillers, R. A. Zhuk, A. Berzina, L. Serina and A. Lazdins, DE 2357847, 1974; Chem. Abstr., 81, 120680 (1974).

64. J. Yamashita, M. Yasumoto and S. Hashimoto, Chem. Pharm. Bull., 31, 3872 (1983).

65. C. H. Lee, J. Y. Kim, W. J. Kim and Y. H. Kim, Heterocycles, 31, 211 (1990).

66. Y. Hoshide, Y. Hashimoto, H. Ogawa and S. Tasaka, FR 2355841, 1977; Chem. Abstr., 88, 121667 (1978).

1185 67. A. Kojima, Y. Jinno, S. Ike, T. Yokoyama and M. Odate, US 4256885, 1977; Chem. Abstr., 88, 136653 (1978).

68. K. Sakurai, S. Aoyagi, H. Toyofuku, M. Ohki, T. Yoshizawa and T. Kuroda, Chem. Pharm. Bull., 26, 3565 (1978).

69. I. Minami, Y. Yoshioka and H. Nomura, DE 2657709, 1977; Chem. Abstr., 87, 135396 (1977).

1190 70. K. Ishibashi, S. Ishiguro and R. Komaki, US 4159378, 1979; Chem. Abstr., 91, 20334 (1979).

71. T. Nakamura, Y. Hashimoto, Y. Hoshide, K. Suzuki and Y. Yoshida, US 4121037, 1978; Chem. Abstr., 88, 152656 (1978).

72. U. Michael, Z. Sasson and E. Schoenberger, US 4174446, 1979; Chem. Abstr., 89, 24357 (1978).

1195 73. H. Nomura, Y. Yoshioka and I. Minami, Chem. Pharm. Bull., 27, 899 (1979).

74. P. D. Schuman and R. Anderson, US 4024143, 1977; Chem. Abstr., 87, 135401 (1977).

75. T. Kametani, K. Kigasawa, M. Hiiragi, K. Wakisaka, O. Kusama, H. Sugi and K. Kawasaki, Heterocycles, 6, 529 (1977).

76. J. Kiss, US 4169201, 1979; Chem. Abstr., 88, 105398 (1978).

1200 77. T. Iwasaki, T. Nishitani, H. Horikawa and I. Inoue, Tetrahedron Lett., 22, 1029 (1981).

78. M. Matsui and T. Ogawa, US 4324895, 1982; Chem. Abstr., 87, 102600 (1977).

79. R. A. Earl and L. B. Townsend, J. Heterocycl. Chem., 9, 1141 (1972). 
80. W. Y. Lin, D. W. Peng, B. Wang, L. Long, C. Guo and J. Yuan, Eur. J. Org. Chem., 793 (2008).

1205 81. S. Mocellin, P. Pilati, M. Lise and D. Nitti, J. Clin. Oncol., 25, 5649 (2007).

82. M. Hoffer, R. Duschinsky, J. J. Fox and N. Yung, J. Am. Chem. Soc., 81, 4112 (1959).

83. M. Hoffer, US 2949451, 1960; Chem. Abstr., 55, 2812 (1961).

84. GB 878060, 1961; Chem. Abstr., 57, 56538 (1962).

85. A. Holy and D. Cech, Collect. Czech. Chem. Commun., 39, 3157 (1974).

1210 86. J. Brokes, H. Hrebabecky and J. Beranek, Collect. Czech. Chem. Commun., 44, 439 (1979).

87. R. Marumoto and M. Honjo, Chem. Pharm. Bull., 22, 128 (1974).

88. S. Ozaki, T. Katakami and M. Saneyoshi, Bull. Chem. Soc. Jpn., 50, 2197 (1977).

89. B. Schwarz, D. Cech, A. Holy and J. Skoda, Collect. Czech. Chem. Commun., 45, 3217 (1980).

90. H. Aoyama, Bull. Chem. Soc. Jpn., 60, 2073 (1987).

1215 91. A. Uemura, K. Nozaki, J. Yamashita and M. Yasumoto, Tetrahedron Lett., 30, 3819 (1989).

92. M. Taverna-Porro, L. A. Bouvier, C. A. Pereira, J. M. Montserrat and A. M. Iribarren, Tetrahedron Lett., 49, 2642 (2008).

93. I. Serra, T. Bavaro, D. A. Cecchini, S. Daly, A. M. Albertini, M. Terreni and D. Ubiali, J. Mol. Catal. B-Enzym., 95, 16 (2013).

1220 94. A. Hatano, M. Kurosu, S. Yonaha, M. Okada and S. Uehara, Org. Biomol. Chem., 11, 6900 (2013).

95. I. Votruba, A. Holy, H. Dvorakova, J. Gunter, D. Hockova, H. Hrebabecky, T. Cihlar and M. Masojidkova, Collect. Czech. Chem. Commun., 59, 2303 (1994).

96. C. N. Britos, V. A. Cappa, C. W. Rivero, J. E. Sambeth, M. E. Lozano and J. A. Trelles, J. 1225 Mol. Catal. B-Enzym., 79, 49 (2012).

97. V. A. Cappa, C. W. Rivero, C. N. Britos, L. M. Martinez, M. E. Lozano and J. A. Trelles, Process. Biochem., 49, 1169 (2014).

98. T. Kawaguchi, Y. Suzuki, Y. Nakahara, N. Nambu and T. Nagai, Chem. Pharm. Bull., 33, 301 (1985).

1230 99. Z. Zhang, H. Hatta, K. Tanabe and S. Nishimoto, Pharm. Res., 22, 381 (2005).

100. Y. Ge, X. Wu, D. Zhang and L. Hu, Bioorg. Med. Chem. Lett., 19, 941 (2009).

101. K. Yoshida, US 0111852 2010; Chem. Abstr., 149, 77397 (2008).

102. Y. Kinoshita, M. Sugimoto and T. Ishiguro, EP 2275135, 2009; Chem. Abstr., 151, 423612 (2009).

1235 103. Y. M. Wei, Y. F. Ya, D. H. Pei and B. Gong, Bioorg. Med. Chem. Lett., 8, 2419 (1998).

104. J. V. Voorde, S. Liekens, C. McGuigan, P. G. S. Murziani, M. Slusarczyk and J. Balzarini, Biochem. Pharmacol., 82, 441 (2011).

105. A. Usier-Brosceta and J. Weiss, PCT Int. Appl. WO 202994, 2014; Chem. Abstr., 162, 122992 (2014).

1240 106. R. D'Sousa and J. Kiss, US 4340729, 1982; Chem. Abstr., 95, 62602 (1981). 
107. J. Kiss, R. D’Souza, J. A. Van Koeveringe and W. Arnold, Helv. Chim. Acta, 65, 1522 (1982).

108. G. Bertolini and M. Frigerio, PCT Int. Appl. WO 040184, 2005; Chem. Abstr., 142, 411592 (2005).

109. H. Hrebabecky and J. Beranek, Nucleic Acids Res., 5, 1029 (1978).

1245 110. A. F. Cook, M. J. Holman, M. J. Kramer and P. W. Trown, J. Med. Chem., 22, 1330 (1979).

111. G. Cotticelli, G. De Meglio, S. Monciardini and G. Ordanini, US 0128467, 2002; Chem. Abstr., 130, 38646 (1998).

112. T. Bavaro, S. Rocchietti, D. Ubiali, M. Filice, M. Terreni and M. Pregnolato, Eur. J. Org. Chem., 1967 (2009).

1250 113. A. Hoshi and J. Castaner, Drugs Future, 21, 358 (1996).

114. G. Pentheroudakis and C. Twelves, Clin. Colorectal Cancer, 2, 16 (2002).

115. J. J. Hwang and J. L. Marshall, Expert Opin. Pharmacother., 3, 733 (2002).

116. C. M. Walko and C. Lindley, Clin. Ther., 27, 23 (2005).

117. C. Serdjebi, G. Milano and J. Ciccolini, Expert Opin. Drug Metab. Toxicol., 11, 665 (2015).

1255 118. A. Bronckaers, F. Gago, J. Balzarini and S. Liekens, Med. Res. Rev., 29, 903 (2009).

119. H. W. M. van Laarhoven and C. J. A. Punt, Eur. J. Gastroen. Hepat., 16, 283 (2004).

120. J. K. McGavin and K. L. Goa, Drugs, 61, 2309 (2001).

121. B. R. Hirsch and S. Y. Zafar, Cancer. Manag. Res., 3, 79 (2011).

122. J. Quidde, D. Arnold and A. Stein, Clin. Med. Insights Oncol., 6, 363 (2012).

1260 123. F. Y. Lee, R. Borzilleri, C. R. Fairchild, A. Kamath, R. Smykla, R. Kramer and G. Vite, Cancer Chemother. Pharmacol., 63, 157 (2008).

124. S. Bhushan and C. M. Walko, Ann. Pharmacother., 42, 1252 (2008).

125. P. Pronzato, Drugs, 68, 139 (2008).

126. J. Bonneterre and N. Penel, Expert Opin. Pharmacother., 9, 2901 (2008).

1265 127. C. G. Murphy and A. D. Seidman, Clin. Breast Cancer, 9, S58 (2009).

128. R. J. Herr, "Capecitabine (Xeloda): an oral chemotherapy agent" in Modern Drug Synthesis, p. 57, J. J. Li and D. S. Johnson (Eds.), John Wiley \& Sons, Inc, Hoboken, New Jersey, 2010.

129. H. M. Kissman and B. R. Baker, J. Am. Chem. Soc., 79, 5534 (1957).

130. G. Wang, R. C. Tam, E. Gunic, J. Du, J. Bard and B. Pai, J. Med. Chem., 43, 2566 (2000).

1270 131. J. Lee, G. S. Park, W. K. Yang, J. H. Kim, C. H. Park, Y.-H. An, C.-J. Choi, Y.-K. Chang and G. S. Lee, PCT Int. Appl. WO 105593, 2008; Chem. Abstr., 149, 308065 (2008).

132. P. Sairam, R. Puranik, B. S. Rao, P. V. Swamy and S. Chandra, Carbohydr. Res., 338, 303 (2003).

133. S. Mohanty, R. Bera, M. B. Murlidhar, T. N. Rao, K. K. Nerurkar, D. Mitra and B. P. R. Rao, IN 2010/CH/02474, 2013; Chem. Abstr., 158, 475020 (2013).

134. N. Shimma, I. Umeda, M. Arasaki, C. Murasaki, K. Masubuchi, Y. Kohchi, M. Miwa, M. Ura, N. Sawada, H. Tahara, I. Kuruma, I. Horii and H. Ishitsuka, Bioorg. Med. Chem., 8, 1697 (2000). 
135. C. R. Roberts and J.-W. Wong, PCT Int. Appl. WO 063786, 2005; Chem. Abstr., 143, 60196 $1280 \quad$ (2005).

136. G. J. B. Ettema, US 0300399, 2008; Chem. Abstr., 149, 576806 (2008).

137. R. V. Palle, A. M. Marathe, S. Aluru, R. Bochha, R. Kadaboina, S. M. Nariyam and A. Patni, PCT Int. Appl. WO 131062, 2008; Chem. Abstr., 149, 471763 (2008).

138. J. Lee, G.-S. Park, W. K. Yang, J. H. Kim, C. H. Park, Y.-H. An, Y. J. Lee, Y.-K. Chang and 1285 G. S. Lee, PCT Int. Appl. WO 066892, 2009; Chem. Abstr., 151, 8871 (2009).

139. J. Bautista Rodriguez, E. Ravaschino and E. Elhalem, PCT Int. Appl. WO 071726, 2009; Chem. Abstr., 151, 57090 (2009).

140. M. N. R. Arasaki, H. Ishitsuka, I. Kuruma, M. Miwa, C. Murasaki, N. Shimma and I. I. H. Umeda, US 5472949, 1995; Chem. Abstr., 122, 240352 (1995).

1290 141. H. R. Brinkman, P. Kalaritis and J. F. Morrissey, US 5476932, 1995; Chem. Abstr., 124, 233026 (1996).

142. P. L. MacDonald, P. Rossetto and M. Gallina, PCT Int. Appl. WO 088989, 2009; Chem. Abstr., 151, 173777 (2009).

143. K.-C. Lin and C. Chien, US 0184451, 2013; Chem. Abstr., 159, 197129 (2013).

1295 144. V. G. Gore, L. N. Patkar, R. Bhalerao, M. G. Hublikar and K. S. Pokharkar, PCT Int. Appl. WO 104540, 2011; Chem. Abstr., 155, 352803 (2011).

145. V. G. Gore, L. Patkar, A. Bagul and M. Edake, PCT Int. Appl. WO 067588, 2011; Chem. Abstr., 155, 12285 (2011).

146. B. Shen and T. F. Jamison, Org. Lett., 14, 3348 (2012).

1300 147. M. R. Dhananjeyan, J. Liu, C. Bykowski, J. A. Trendel, J. G. Sarver, H. Ando and P. W. Erhardt, J. Chromatogr. A, 1138, 101 (2007).

148. R. Kadaboina, S. M. Nariyam, V. Murki, R. R. Vinjamuri, S. Benda, S. K. Komati and N. Gunda, PCT Int. Appl. WO 065586, 2010; Chem. Abstr., 153, 11944 (2010).

149. T.-C. Hu and H.-T. Huang, PCT Int. Appl. WO 010967, 2011; Chem. Abstr., 154, 158730 1305 (2011).

150. S. Rocchietti, M. Terreni and M. Pregnolato, PCT Int. Appl. WO 057894, 2003; Chem. Abstr., 139, 116337 (2003).

151. M. Pregnolato, M. Terreni, D. Ubiali and T. Bavaro, PCT Int. Appl. WO 107771, 2008; Chem. Abstr., 149, 332574 (2008).

1310 152. T. Bavaro, D. Ubiali, S. Brocca, S. Rocchietti, I. Nieto, M. Pregnolato, M. Lotti and M. Terreni, Biocatal. Biotransform., 28, 108 (2010).

153. S. Ciceri, P. Ciuffreda, P. Grisenti and P. Ferraboschi, Tetrahedron Lett., 56, 5909 (2015).

154. M. Pascual Gilabert, V. M. Deroncele Thomas and R. Montilla Arevalo, EP 2883959, 2015; Chem. Abstr., 163, 103800 (2015).

1315 155. X. Jia, X. Liu, J. Wang, M. Wang, H. Guo and M. Liu, Chem. Res. Chin. Univ., 31, 78 (2015).

156. P. D. Davis, M. A. Naylor, P. Thomson, S. A. Everett, M. R. L. Stratford and P. Wardman, PCT Int. Appl. WO 032921, 2006; Chem. Abstr., 144, 350926 (2006).

157. V. Jhansi Rani, A. Raghavendra, P. Kishore, Y. Nanda Kumar, K. Hema Kumar and K. Jagadeeswarareddy, Eur. J. Med. Chem., 54, 690 (2012). 
1320 158. S. Nakai, K. Sasai and T. Ezawa, Chem. Pharm. Bull., 40, 2568 (1992).

159. T. Kamiya, M. Ishiduka and H. Nakajima, US 5453497, 1995; Chem. Abstr., 122, 188034 (1995).

160. M. Kurono, T. Chiba and S. Fujii, US 4124765, 1978; Chem. Abstr., 84, 17405 (1976).

161. J. Yamashita, I. Yamawaki, S. Ueda, M. Yasumoto, N. Unemi and S. Hashimoto, Chem. 1325 Pharm. Bull., 30, 4258 (1982).

162. S. Ozaki, Y. Watanabe, T. Hoshiko, T. Nagase, T. Ogasawara, H. Furukawa, A. Uemura, K. Ishikawa, H. Mori, A. Hoshi, M. Iigo and R. Tokuzen, Chem. Pharm. Bull., 34, 150 (1986).

163. S. Fujii, US 4864021, 1989; Chem. Abstr., 105, 97331 (1986).

164. M. Hirohashi, M. Kido, Y. Yamamoto, Y. Kojima, K. Jitsukawa and S. Fujii, Chem. Pharm. 1330 Bull., 41, 1498 (1993).

165. R. A. Persichetti and J. F. Liu, PCT Int. Appl. WO 109274, 2011; Chem. Abstr., 155, 423410 (2011).

166. S. Ozaki, Y. Ike, H. Mizuno, K. Ishikawa and H. Mori, Bull. Chem. Soc. Jpn., 50, 2406 (1977).

1335 167. C. Heidelberger, D. G. Parsons and D. C. Remy, J. Med. Chem., 7, 1 (1964).

168. A. Zaniboni, P. Bertocchi, S. Barni and F. Petrelli, Clin. Colorectal Cancer (2016) DOI: $10.1016 /$ j.clcc. 2016.06 .003

169. R. Daifuku and D. S. Sergueev, PCT Int. Appl. WO 057828, 2016; Chem. Abstr., 164, 492751 (2016).

1340 170. K. W. Pankiewicz, Carbohydr. Res., 327, 87 (2000).

171. W.-D. Meng and F.-L. Qing, Curr. Top. Med. Chem., 6, 1499 (2006).

172. P. Liu, A. Sharon and C. K. Chu, J. Fluor. Chem., 129, 743 (2008).

173. X. L. Qiu, X. H. Xu and F. L. Qing, Tetrahedron, 66, 789 (2010).

174. V. E. Marquez, C. K. H. Tseng, H. Mitsuya, S. Aoki, J. A. Kelley, H. Ford, J. S. Roth, S. Broder, D. G. Johns and J. S. Driscoll, J. Med. Chem., 33, 978 (1990).

175. G. M. Blackburn, D. A. England and F. Kolkmann, J. Chem. Soc., Chem. Commun., 930 (1981).

176. J.-L. Paparin, E. Badaroux, C. Pierra and C. B. Dousson, WO 081297, 2015; Chem. Abstr., 163, 66114 (2015).

1350 177. K. Fauster, M. Hartl, T. Santner, M. Aigner, C. Kreutz, K. Bister, E. Ennifar and R. Micura, ACS Chem. Biol., 7, 581 (2012).

178. J. Salon, J. Sheng, J. Gan and Z. Huang, J. Org. Chem., 75, 637 (2010).

179. J. L. Clark, L. Hollecker, J. C. Mason, L. J. Stuyver, P. M. Tharnish, S. Lostia, T. R. McBrayer, R. F. Schinazi, K. A. Watanabe, M. J. Otto, P. A. Furman, W. J. Stec, S. E. Patterson and K. W. Pankiewicz, J. Med. Chem., 48, 5504 (2005).

180. A. B. Eldrup, M. Prhavc, J. Brooks, B. Bhat, T. P. Prakash, Q. Song, S. Bera, N. Bhat, P. Dande, P. D. Cook, C. F. Bennett, S. S. Carroll, R. G. Ball, M. Bosserman, C. Burlein, L. F. Colwell, J. F. Fay, O. A. Flores, K. Getty, R. L. LaFemina, J. Leone, M. MacCoss, D. R. McMasters, J. E. Tomassini, D. Von Langen, B. Wolanski and D. B. Olsen, J. Med. Chem., $1360 \quad 47,5284(2004)$. 
181. K. Brown, M. Dixey, A. Weymouth-Wilson and B. Linclau, Carbohydr. Res., 387, 59 (2014).

182. L. W. Hertel, J. S. Kroin, J. W. Misner and J. M. Tustin, J. Org. Chem., 53, 2406 (1988).

183. T. S. Chou, P. C. Heath, L. E. Patterson, L. M. Poteet, R. E. Lakin and A. H. Hunt, Synthesis, 565 (1992).

1365 184. R. B. Polturi, S. H. Venkata and R. Betini, PCT Int. Appl. WO 095430, 2005; Chem. Abstr., 143, 367533 (2005).

185. R. B. Potluri, H. Venkata Subramanian, R. Betini and S. Gunturu, PCT Int. Appl. WO 095359, 2006; Chem. Abstr., 145, 315226 (2006).

186. B. Parthasaradhi Reddy, K. Rathnakar Reddy, R. Raji Reddy, D. Muralidhara Reddy and I. Srinivas Reddy, PCT Int. Appl. WO 015257, 2007; Chem. Abstr., 146, 229557 (2007).

187. M.-S. Kim, Y.-J. Kim, J.-H. Choi, H.-G. Lim and D.-W. Cha, PCT Int. Appl. WO 069838, 2007; Chem. Abstr., 147, 95870 (2007).

188. Y. Xu, H. Yang and W. Hou, US 0179314, 2010; Chem. Abstr., 148, 168918 (2008).

189. V. R. A. Palle, S. M. Nariyam, V. Murki, A. A. Waghmare and V. N. Mundhada, PCT Int. 1375 Appl. WO 117760, 2007; Chem. Abstr., 147, 449039 (2007).

190. G. C. Maikap, D. Bhatt and B. K. Panda, PCT Int. Appl. WO 092808, 2006; Chem. Abstr., 145, 293299 (2006).

191. A. Ujagare, D. A. Kochrekar and M. C. Uzagare, PCT Int. Appl. WO 049294, 2007; Chem. Abstr., 146, 468552 (2007).

1380 192. S.-J. Park, C.-R. Oh and Y.-D. Kim, PCT Int. Appl. WO 117955, 2008; Chem. Abstr., 149, 378977 (2008).

193. B. Vishnukant, P. Purohit, K. Paparao and V. Veereshappa, PCT Int. Appl. WO 026222, 2008; Chem. Abstr., 148, 331958 (2008).

194. X. R. Jiang, J. F. Li, R. X. Zhang, Y. Zhu and J. S. Shen, Org. Process Res. Dev., 12, 888 1385 (2008).

195. L. Zelikovitch, O. Friedman, T. Fizitzky and J. Manascu, US 0262215, 2008; Chem. Abstr., 149, 471761 (2008).

196. A. Varalli, P. Anesa, M. Argese and G. Guazzi, US 0105887, 2010; Chem. Abstr., 152, 493457 (2010).

1390 197. C.-Y. Chu, W.-D. Lee, W. Li and C. K. Hwang, US 0124797, 2009; Chem. Abstr., 150, 473105 (2009).

198. C. Chien, P.-S. Chien and C.-K. Hwang, US 0259106, 2012; Chem. Abstr., 157, 520692 (2012).

199. Y. K. Chang, J. Lee, G. S. Park, M. Lee, C. H. Park, H. K. Kim, G. Lee, B. Y. Lee, J. Y. Baek 1395 and K. S. Kim, Tetrahedron, 66, 5687 (2010).

200. J. Lee, G. S. Park, M. Lee, H.-J. Bang, J. C. Lee, C. K. Kim, C.-J. Choi, H. K. Kim, H. C. Lee, Y.-K. Chang and G. S. Lee, US 0249818, 2007; Chem. Abstr., 145, 124819 (2006).

201. C. Gong, US 0003963, 2006; Chem. Abstr., 144, 51839 (2006).

202. D. P. Kjell, US 5633367, 1997; Chem. Abstr., 125, 329284 (1996).

1400 203. Y. Cen and A. A. Sauve, Nucleosides Nucleotides Nucleic Acids, 29, 113 (2010). 
204. M. Peifer, R. Berger, V. W. Shurtleff, J. C. Conrad and D. W. MacMillan, J. Am. Chem. Soc., 136, 5900 (2014).

205. H. Zhong, A. Lv, R. Kalidindi, S. Lin and X. Su, PCT Int. Appl. WO 112473, 2007; Chem. Abstr., 147, 427652 (2007).

1405 206. J. Pulido, A. J. Sobczak, J. Balzarini and S. F. Wnuk, J. Med. Chem., 57, 191 (2014).

207. D. M. Bender and D. M. Remick, PCT Int. Appl. WO 065525, 2006; Chem. Abstr., 145, 76625 (2006).

208. S. C. Srivastava, S. K. Bajpai and K.-H. Sit, US 0159375, 2005; Chem. Abstr., 143, 133642 (2005).

1410 209. R. G. L. Shorr, R. J. Rodriguez and L. Boteju, PCT Int. Appl. WO 143593, 2011; Chem. Abstr., 155, 649030 (2011).

210. S. Maiti, N. Park, J. H. Han, H. M. Jeon, J. H. Lee, S. Bhuniya, C. Kang and J. S. Kim, J. Am. Chem. Soc., 135, 4567 (2013).

211. A. J. Martinez, A. Pendri, R. B. Greenwald and Y. H. Choe, US 6395266, 2002; Chem. Abstr., 1415 136, 401913 (2002).

212. J. M. Harris, K. Yoon, M. D. Bentley, Z. Fang and T. Viegas, US 0273074, 2015; Chem. Abstr., 151, 174043 (2009).

213. R. Pignatello, L. Vicari, V. Pistara, T. Musumeci, M. Gulisano and G. Puglisi, Drug. Develop. Res., 71, 294 (2010).

1420 214. B. Botta, C. Fraschetti, I. D’Acquarica, F. Sacco, J. Mattay, M. C. Letzel and M. Speranza, Org. Biomol. Chem., 9, 1717 (2011).

215. I. D’Acquarica, A. Calcaterra, F. Sacco, F. Balzano, F. Aiello, A. Tafi, N. Pesci, G. UccelloBarretta and B. Botta, Chirality, 25, 840 (2013).

216. J. T. Weiss, J. C. Dawson, C. Fraser, W. Rybski, C. Torres-Sanchez, M. Bradley, E. E. Patton, 1425 N. O. Carragher and A. Unciti-Broceta, J. Med. Chem., 57, 5395 (2014).

217. A. Istrate, M. Medvecky and C. J. Leumann, Org. Lett., 17, 1950 (2015).

218. J. L. Eiseman, C. Brown-Proctor, P. E. Kinahan, J. M. Collins, L. W. Anderson, E. Joseph, D. R. Hamburger, S. S. Pan, C. A. Mathis, M. J. Egorin and R. W. Klecker, Clin. Cancer Res., 10, 6669 (2004).

1430 219. K. Seki, K. Nishijima, K. Sanoki, Y. Kuge, M. Takahashi, H. Akizawa, N. Tamaki, L. I. Wiebe and K. Ohkura, Heterocycles, 77, 1307 (2009).

220. K. I. Nishijima, Y. Kuge, K. Seki, K. Ohkura, N. Motoki, K. Nagatsu, A. Tanaka, E. Tsukamoto and N. Tamaki, Nucl. Med. Biol., 29, 345 (2002).

221. A. F. Shields, J. Nucl. Med., 44, 1432 (2003).

1435 222. X. Fei, J.-Q. Wang, K. D. Miller, G. W. Sledge, G. D. Hutchins and Q.-H. Zheng, Nucl. Med. Biol., 31, 1033 (2004).

223. B. S. Moon, A. Y. Shim, K. C. Lee, H. J. Lee, B. S. Lee, G. I. An, S. D. Yang, D. Y. Chi, C. W. Choi, S. M. Lim and K. S. Chun, Bull. Korean Chem. Soc., 26, 1865 (2005).

224. D. O'Hagan and C. Schaffrath, PCT Int. Appl. WO 020945, 2003; Chem. Abstr., 138, 237025 (2003). 
225. L. Martarello, C. Schaffrath, H. Deng, A. D. Gee, A. Lockhart and D. O'Hagan, J. Label. Compd. Radiopharm., 46, 1181 (2003).

226. D. O'Hagan, J. Naismith, C. Schaffrath, C. Dong, J. B. Spencer and F. Huang, PCT Int. Appl. WO 078914, 2004; 141, 256535 (2004).

1445 227. M. Winkler, J. Domarkas, L. F. Schweiger and D. O’Hagan, Angew. Chem. Int. Ed., 47, 10141 (2008).

228. M. Onega, J. Domarkas, H. Deng, L. F. Schweiger, T. A. Smith, A. E. Welch, C. Plisson, A. D. Gee and D. O'Hagan, Chem. Commun., 46, 139 (2010).

229. D. O'Hagan and H. Deng, Chem. Rev., 115, 634 (2015).

1450 230. L. Ma, Y. F. Li, L. P. Meng, H. Deng, Y. Y. Li, Q. Zhang and A. P. Diao, RSC Adv., 6, 27047 (2016).

231. H. Wojtowicz-Rajchel, J. Fluorine Chem., 143, 11 (2012). 